Rubens Augusto Amaro Junior

\title{
Simulação Computacional do \\ Comportamento Elástico de Materiais pelo Método de Partículas Moving Particle Semi-implicit (MPS)
}

Dissertação apresentada à Escola Politécnica da Universidade de São Paulo para obtenção do Título de Mestre em Engenharia. 


\section{Rubens Augusto Amaro Junior}

\section{Simulação Computacional do Comportamento Elástico de Materiais pelo Método de Partículas Moving Particle Semi-implicit (MPS)}

Dissertação apresentada à Escola Politécnica da Universidade de São Paulo para obtenção do Título de Mestre em Engenharia.

Área de concentração:

Engenharia de Construção Civil e Urbana

Orientador:

Prof. Dr. Cheng Liang Yee 
Este exemplar foi revisado e corrigido em relação à versão original, sob responsabilidade única do autor e com a anuência de seu orientador.

São Paulo, de outubro de 2013.

Assinatura do autor

Assinatura do orientador

FICHA CATALOGRÁFICA

Amaro Junior, Rubens Augusto

Simulação computacional do comportamento elástico de materiais pelo método de partículas Moving Particle SemiImplicit (MPS) / R.A. Amaro Junior. -- versão corr. -- São Paulo, 2013.

$93 \mathrm{p}$.

Dissertação (Mestrado) - Escola Politécnica da Universidade de São Paulo. Departamento de Engenharia de Construção Civil.

1.Interação fluido-estrutura 2.Dinâmica dos sólidos 3.Méto dos numéricos I.Universidade de São Paulo. Escola Politécnica. Departamento de Engenharia de Construção Civil Il.t. 
A meus pais, Heloisa Helena da Cunha e Rubens Augusto Amaro. 


\section{Agradecimentos}

Ao meu orientador Prof. Dr. Cheng Liang Yee pela grandiosa atenção e paciência durante nossas numerosas conversas ao longo desse trabalho.

Aos colegas de pesquisa do grupo MPS do Tanque de Provas Numérico, em especial aos colegas Marcio Michiharu Tsukamoto, Fabio Kenji Motezuki, Cezar Augusto Bellezi, Eric Henrique Favero e Celso de Almeida Saad, pelas inúmeras contribuições e apoio em nossas discussões.

A Coordenação de Aperfeiçoamento Pessoal de Nível Superior (CAPES) pela bolsa de mestrado concedida e a Petrobras S.A. pelo suporte financeiro no desenvolvimento do simulador de hidrodinâmica não linear baseado no método MPS.

Aos funcionários da secretaria de pós-graduação pela atenção dispensada em todos os momentos que foram solicitados.

Aos funcionários do Tanque de Provas Numérico (TPN / USP), que permitiram ótimas condições de trabalho. 


\section{Resumo}

Neste trabalho um método de partículas para simular a dinâmica de sólidos elásticos e interação fluido estrutura é implementado. O método é baseado no Moving Particle Semi-implicit (MPS), originalmente desenvolvido para escoamentos incompressíveis com superfície livre. A estratégia principal do MPS é substituir os operadores diferenciais das equações governantes por operadores diferenciais discretos em uma distribuição de nós irregulares, derivados de um modelo de interação entre partículas. Inicialmente são apresentados os detalhes da formulação do método e modelos constitutivos utilizados. Uma condição simplificada de fragmentação é proposta, assim como um algoritmo de detecção de contato, permitindo a fragmentação entre vários sólidos. No caso da interação fluido-estrutura, as partículas de superfície do sólido são tratadas como partículas de fluido e as pressões destas partículas são calculadas pela resolução da equação de Poisson para a pressão, tal como as partículas de fluido. Desta forma, o acoplamento entre sólido e fluido é realizado utilizando o deslocamento e velocidade do sólido elástico, como condições de contorno do fluido, e a pressão na interface, obtida pela resolução do movimento do fluido, é aplicada ao movimento do sólido elástico. São apresentados e detalhados os algoritmos de sólido elástico, fragmentação, colisão e acoplamento fluido-estrutura. Validações qualitativas e quantitativas do método são realizadas para casos estáticos e dinâmicos sujeitos a diferentes condições de contorno, comparando os resultados numéricos obtidos pelo MPS, outros métodos numéricos, soluções analíticas e medições experimentais presentes na literatura. 


\section{Abstract}

In this work a particle method to simulate the dynamics of elastic solids and fluid-structure interaction is implemented. It is based on the Moving Particle Semi-implicit Method (MPS), which was originally developed for incompressible flows with free surface. The main strategy of the MPS is to replace the differential operators of the governing equations by discrete differential operators on irregular nodes, which are derived from a model of interaction between particles. Initially details of the method and constitutive equations are shown. A simplified condition of fragmentation and collision between solids are proposed to allow the investigation of fragmentation amount multiple solids. In case of fluid-structure interaction, the solid's surface particles are treated as a fluid particle and the pressures of the surface particles are computed by solving Poisson equation for the pressure, just as the fluid particles. Therefore, the coupling between solid and fluid is done by using the displacement and velocity of elastic solid as the boundary conditions of the fluid, and the pressure at the interface, which is obtained when solving the fluid motion, is used to calculate the motion of the elastic solid. The algorithms for elastic solid, fragmentation, collision and fluid-structure interaction are presented and detailed. The qualitative and quantitative validations of the method are carried out herein considering static and dynamic cases subjected to different boundary conditions by comparing the numerical results from MPS with other numerical, analytical and experimental results available in the literature. 


\section{Sumário}

\section{Lista de Figuras}

Lista de Tabelas

Lista de Abreviaturas

\section{Lista de Símbolos}

1 Introdução 1

1.1 Objetivos do Trabalho . . . . . . . . . . . . . . . . 2

1.2 Organização do Trabalho . . . . . . . . . . . . . . . . . . . . . . 3

2 Revisão Bibliográfica 4

2.1 Métodos numéricos . . . . . . . . . . . . . . . . . . . 4

2.2 Interação fluido-estrutura . . . . . . . . . . . . . . . . . . . . 7

2.3 Método MPS . . . . . . . . . . . . . . . . . . . 8

3 Método de Partículas MPS 20

3.1 Equações Constitutivas . . . . . . . . . . . . . . . . . . . . . 20

3.2 Equações Governantes . . . . . . . . . . . . . . . . . . . . . . . . 21

3.3 Método MPS . . . . . . . . . . . . . . . . . . . . 22

3.3.1 Função Peso . . . . . . . . . . . . . . . . . . . . . . . 23

3.3.2 Densidade do Número de Partículas . . . . . . . . . . . . . . . . . . 23

3.3.3 Gradiente . . . . . . . . . . . . . . . . . . 23

3.3.4 Correção do Gradiente . . . . . . . . . . . . . . . . . . 24 


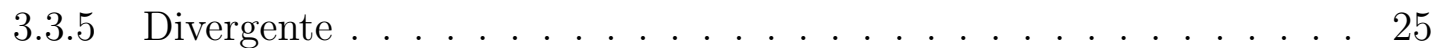

3.3 .6 Laplaceano . . . . . . . . . . . . . . . . . . . . . 26

3.3.7 Rotacional ...................... 26

3.3.8 Interação entre partículas . . . . . . . . . . . . . . . 26

3.4 Velocidades e posições . . . . . . . . . . . . . . . . . . . 30

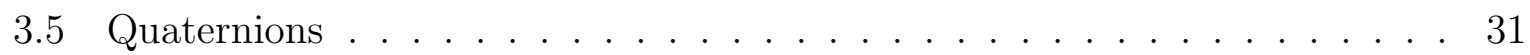

3.6 Fragmentação . . . . . . . . . . . . . . . . . . . . . . . . . . 32

3.7 Interação fluido-estrutura . . . . . . . . . . . . . . . . . . . . . 32

4 Implementação Numérica 35

4.1 Algoritmo sólido elástico . . . . . . . . . . . . . . . . . . . . . . 35

4.2 Algoritmo de fragmentação e detecção de contato . . . . . . . . . . . . . . 38

4.3 Algoritmo interação fluido-estrutura . . . . . . . . . . . . . . . . . . . . 41

4.4 Condição CFL . . . . . . . . . . . . . . . . . . . . . . . 42

5 Resultados $\quad 43$

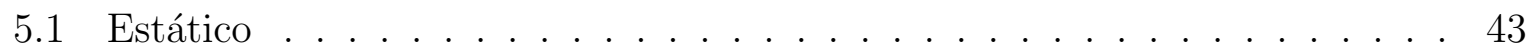

5.2 Dinâmico . . . . . . . . . . . . . . . . . . . . 47

5.3 Colisão . . . . . . . . . . . . . . . . . . . . . . . . . 51

5.4 Fragmentação . . . . . . . . . . . . . . . . . . . . . . . 54

5.5 Interação fluido-estrutura . . . . . . . . . . . . . . . . . . . 57

5.5 .1 Coluna d'água em placa elástica . . . . . . . . . . . . 57

5.5.2 Placa elástica submetida a pressão de uma coluna d'água . . . . . . 65

5.5.3 Placa elástica submetida a sloshing . . . . . . . . . . . . . 73

6 Considerações Finais $\quad 80$

Referências $\quad 82$ 


\section{Anexo A - Método MPS para fluido}

A.1 Equações governantes de fluidos . . . . . . . . . . . . . . . . . . . . . . 91

A.2 Algoritmo para o escoamento incompressível . . . . . . . . . . . . . . . 91 


\section{Lista de Figuras}

3.1 Modelo de partículas para sólidos no MPS. . . . . . . . . . . . . . . . . 22

3.2 Variáveis no ponto médio entre $i$ e $j \ldots \ldots \ldots$. . . . . . . . . 24

3.3 Modelo MPS para sólidos elásticos (SONG; KOSHIZUKA; OKA, 2003). . . . . 28

3.4 Interação entre partículas de fluido, superfície e sólidas. . . . . . . . . . . . 33

4.1 Fluxograma do algoritmo MPS para sólidos elásticos. . . . . . . . . . . . . 36

4.2 Partículas de superfície (vermelho) e particulas internas (laranja) durante a fragmentação. . . . . . . . . . . . . . . . . . . . . . . . . . 39

4.3 Subciclagem para simulação de interação fluido-estrutura. . . . . . . . . . . . 41

5.1 Caso estático de barra tridimensional. . . . . . . . . . . . . . . . . . 44

5.2 Função gravidade. . . . . . . . . . . . . . . . . . . . . . . . 44

5.3 Deslocamento transversal $u_{x}(x, y, z) \ldots \ldots \ldots \ldots \ldots$

5.4 Deslocamento longitudinal $u_{z}(x, y, z) \ldots \ldots \ldots \ldots$

5.5 Viga bi-engastada. . . . . . . . . . . . . . . . . 47

5.6 Linha elástica da viga. . . . . . . . . . . . . . . . . . . . . . . . . . . 48

5.7 Amplitude do primeiro modo de vibração. . . . . . . . . . . . . . . . . . . 49

5.8 Condições inciais do caso de colisão. . . . . . . . . . . . . . . . . . . . 51

5.9 Colisão entre os sólidos elásticos de $0.05 s$ até $0.15 s . \ldots . . .52$

5.10 Colisão entre os sólidos elásticos de $0.20 s$ até $0.30 s . \quad \ldots \ldots$. . . . . 53

5.11 Condições iniciais do caso de fragmentação. . . . . . . . . . . . . . . . . . 54

5.12 Esquerda: sem detecção de contato, Direita: com detecção de contato. . . . 55

5.13 Esquerda: sem detecção de contato, Direita: com detecção de contato. . . . 56

5.14 Condições iniciais da coluna d'água em placa elástica. . . . . . . . . . . . . 58 
5.15 Deslocamento horizontal do topo da placa elástica para $d p=3.00 \mathrm{~mm}$. . $\quad 59$

5.16 Deslocamento horizontal do topo da placa elástica para $d p=1.50 \mathrm{~mm}$. . $\quad 59$

5.17 Deslocamento horizontal do topo da placa elástica para $d p=0.50 \mathrm{~mm}$. . 60

5.18 Deslocamento horizontal do topo da placa elástica para $d p=3.00 \mathrm{~mm}$, $d p=1.50 \mathrm{~mm}$ e $d p=0.50 \mathrm{~mm} . \ldots \ldots \ldots$. . . . . . . . . 60

5.19 Comparação entre os métodos SPH (RAFIEE; THIAGARAJAN, 2009), PFEM (IDELSOHN et al., 2008b) e MPS com $d p=3.00 \mathrm{~mm}(0.14 \mathrm{~s}, 0.16 \mathrm{~s}, 0.26 \mathrm{~s}$, $0.34 \mathrm{~s}, 0.42 \mathrm{~s}, 0.62 \mathrm{~s}, 0.80 \mathrm{~s}, 1.48 \mathrm{~s}) \ldots \ldots \ldots \ldots \ldots$

5.20 Comparação entre os métodos SPH (RAFIEE; THIAGARAJAN, 2009), PFEM (IDELSOHN et al., 2008b) e MPS com $d p=1.50 \mathrm{~mm}(0.14 \mathrm{~s}, 0.16 \mathrm{~s}, 0.26 \mathrm{~s}$, $0.34 \mathrm{~s}, 0.42 \mathrm{~s}, 0.62 \mathrm{~s}, 0.80 \mathrm{~s}, 1.48 \mathrm{~s}) \ldots \ldots \ldots \ldots \ldots$

5.21 Comparação entre os métodos SPH (RAFIEE; THIAGARAJAN, 2009), PFEM (IDELSOHN et al., 2008b) e MPS com $d p=0.50 \mathrm{~mm}(0.14 \mathrm{~s}, 0.16 \mathrm{~s}, 0.26 \mathrm{~s}$, $0.34 \mathrm{~s}, 0.42 \mathrm{~s}, 0.62 \mathrm{~s}, 0.80 \mathrm{~s}, 1.48 \mathrm{~s}) \ldots \ldots \ldots \ldots \ldots$

5.22 Condições iniciais da placa elástica submetida a pressão. . . . . . . . . . 65

5.23 Deslocamento horizontal experimental da extremidade inferior da placa elástica, valores do método SPH-FEM (YANG; JONES; MCCUE, 2012) e valores obtidos pelo MPS para $d p=1.00 \mathrm{~mm}, d p=0.50 \mathrm{~mm}$ e $d p=0.25 \mathrm{~mm} .66$

5.24 Deslocamento vertical experimental da extremidade inferior da placa elástica, valores do método SPH-FEM (YANG; JONES; MCCUE, 2012) e valores obtidos pelo MPS para $d p=1.00 \mathrm{~mm}, d p=0.50 \mathrm{~mm}$ e $d p=0.25 \mathrm{~mm} \ldots$. . .

5.25 Valores experimentais da altura da coluna d'água e valores obtidos pelo MPS para $d p=1.00 \mathrm{~mm}, d p=0.50 \mathrm{~mm}$ e $d p=0.25 \mathrm{~mm} . \ldots . . .$.

5.26 Comparação entre o experimento e a simulação com o MPS para $d p=$ $1.0 \mathrm{~mm}(0.04 \mathrm{~s}, 0.08 \mathrm{~s}, 0.12 \mathrm{~s}, 0.16 \mathrm{~s}, 0.20 \mathrm{~s}, 0.24 \mathrm{~s}, 0.28 \mathrm{~s}, 0.32 \mathrm{~s}, 0.36 \mathrm{~s}$, $0.40 \mathrm{~s})$.

5.27 Comparação entre o experimento e a simulação com o MPS para $d p=$ $0.5 \mathrm{~mm}(0.04 \mathrm{~s}, 0.08 \mathrm{~s}, 0.12 \mathrm{~s}, 0.16 \mathrm{~s}, 0.20 \mathrm{~s}, 0.24 \mathrm{~s}, 0.28 \mathrm{~s}, 0.32 \mathrm{~s}, 0.36 \mathrm{~s}$, $0.40 \mathrm{~s})$ 
5.28 Comparação entre o experimento e a simulação com o MPS para $d p=$ $0.25 \mathrm{~mm}(0.04 \mathrm{~s}, 0.08 \mathrm{~s}, 0.12 \mathrm{~s}, 0.16 \mathrm{~s}, 0.20 \mathrm{~s}, 0.24 \mathrm{~s}, 0.28 \mathrm{~s}, 0.32 \mathrm{~s}, 0.36 \mathrm{~s}$,

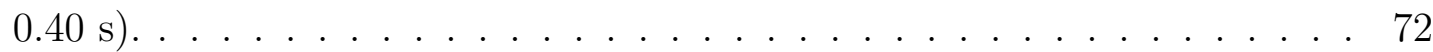

5.29 Referencial local. . . . . . . . . . . . . . . . . . . 73

5.30 Condições iniciais do caso raso de sloshing. . . . . . . . . . . . . . . . . . . 74

5.31 Deslocamento horizontal experimental da ponta da placa elástica e valores obtidos pelo MPS para $d p=1.00 \mathrm{~mm}, d p=0.80 \mathrm{~mm}$ e $d p=0.50 \mathrm{~mm} . \quad$. $\quad 75$

5.32 Comparação entre o experimento e a simulação com o MPS para $d p=1.00$, 0.80 e $0.50 \mathrm{~mm}(0.90 \mathrm{~s}, 1.20 \mathrm{~s}, 1.67 \mathrm{~s}, 2.07 \mathrm{~s}, 2.47 \mathrm{~s}, 2.87 \mathrm{~s}, 3.33 \mathrm{~s}, 3.76 \mathrm{~s}) \ldots 76$

5.33 Condições iniciais do caso fundo de sloshing. . . . . . . . . . . . . . . . . 77

5.34 Deslocamento horizontal experimental da ponta da placa elástica e valores obtidos pelo MPS para $d p=1.00 \mathrm{~mm}, d p=0.80 \mathrm{~mm}$ e $d p=0.50 \mathrm{~mm} . \quad$. 78

5.35 Comparação entre o experimento e a simulação com o MPS para $d p=1.00$, 0.80 e $0.50 \mathrm{~mm}(1.10 \mathrm{~s}, 1.34 \mathrm{~s}, 1.74 \mathrm{~s}, 1.98 \mathrm{~s}, 2.30 \mathrm{~s}, 2.54 \mathrm{~s}, 2.94 \mathrm{~s}, 3.18 \mathrm{~s}) \ldots 79$

A.1 Fluxograma do algoritmo MPS para fluido. . . . . . . . . . . . . . . . . 93 


\section{Lista de Tabelas}

5.1 Discrepância MPS x Analítico. . . . . . . . . . . . . . . . 46

5.2 Resultados do primeiro modo de vibração. . . . . . . . . . . . . . . . . . . 49

5.3 Discrepância. . . . . . . . . . . . . . . . . . . . 50

5.4 Propriedades. . . . . . . . . . . . . . . . . . . . . . . 51

5.5 Propriedades. . . . . . . . . . . . . . . . . . 54

5.6 Parâmetros de simulação. . . . . . . . . . . . . . . . . . . 57

5.7 Parâmetros de simulação. . . . . . . . . . . . . . . . . . 65

5.8 Parâmetros de simulação. . . . . . . . . . . . . . . . . . . . . . . . 74

5.9 Erro MPS x Experimental. . . . . . . . . . . . . . . . 75

5.10 Parâmetros de simulação. . . . . . . . . . . . . . . . . . . . 77

5.11 Erro MPS x Experimental. . . . . . . . . . . . . . . . . . . 78 


\title{
Lista de Abreviaturas
}

\author{
ALE Arbitrary Lagrangian-Eulerian \\ CMPS Corrected Moving Particle Semi-implicit \\ CPU Central Processing Unit \\ DEM Discrete Element Method \\ EDP Equação Diferencial Parcial \\ FPSO Floating Production Storage and Offloading
}

FSI Fluid-Structure Interaction

GPU Graphics Processing Unit

ISPH Incompressible Smoothed Particle Hydrodynamics

MDF Método das Diferenças Finitas

MEC Método dos Elementos de Contorno

MEF Método dos Elementos Finitos

MLS Moving Least Square

MPS Moving Particle Semi-implicit

MVF Método dos Volumes Finitos

PAF Particle and Force

PFEM Particle Finite Element Method

RCM Random Collocation Method

SPH Smoothed Particle Hydrodynamics

SPS Sub-Particle Scale 
WCSPH Weakly Compressible Smoothed Particle Hydrodynamics 


\section{Lista de Símbolos}

\begin{tabular}{|c|c|}
\hline$\sigma$ & tensor de tensão \\
\hline$\varepsilon$ & tensor de deformação \\
\hline$C$ & propriedades do material \\
\hline$\mu$ & constante de Lamé \\
\hline$\lambda$ & constante de Lamé \\
\hline$E$ & módulo de Young \\
\hline$\nu$ & coeficiente de Poisson \\
\hline$\delta_{\alpha \beta}$ & delta de Kronecker \\
\hline$f_{e x t}$ & vetor forças externas \\
\hline$b$ & vetor forças de volume \\
\hline$t$ & vetor tensão \\
\hline$\rho$ & densidade \\
\hline$v$ & vetor velocidade \\
\hline$S$ & superfície \\
\hline$V$ & volume \\
\hline$n$ & vetor unitário normal à superfície $\mathrm{S}$ \\
\hline$L$ & vetor momento angular \\
\hline$I$ & momento de inércia \\
\hline$\omega$ & vetor velocidade angular \\
\hline$M$ & vetor momento \\
\hline$r_{e}$ & raio de interação \\
\hline$l_{o}$ & distância inicial entre partículas \\
\hline $\boldsymbol{r}_{i j}$ & vetor distância entre as partículas $i$ e $j$ \\
\hline$w$ & função peso \\
\hline$n$ & número de densidade de partículas \\
\hline$d$ & número de dimensões \\
\hline$\phi$ & quantidade genérica \\
\hline $\boldsymbol{s}_{i j}$ & versor perpendicular ao vetor $\boldsymbol{r}_{i j}$ \\
\hline$R_{i j}$ & matriz de rotação \\
\hline$\theta$ & angulo de rotação \\
\hline
\end{tabular}




$\begin{array}{ll}\boldsymbol{u}_{i j} & \text { vetor deslocamento } \\ \boldsymbol{\varepsilon}_{i j} & \text { vetor deformação } \\ \boldsymbol{\sigma}_{i j} & \text { vetor tensão } \\ p_{i} & \text { pressão interna na partícula } i \\ \boldsymbol{F}_{i j} & \text { força ocasionada pelo cisalhamento entre as partículas } i \text { e } j \\ \boldsymbol{M}_{i j} & \text { momento gerado pela força } \boldsymbol{F}_{i j} \\ \boldsymbol{q} & \text { quaternion } \\ \boldsymbol{\eta}_{i j} & \text { vetor unitário de rotação }\end{array}$




\section{Introdução}

Nos últimos 50 anos, a simulação numérica têm permitido a análise dos mais diversos problemas físicos em diversas áreas da ciência e engenharia. Os métodos numéricos mais comuns são: método das diferenças finitas (MDF), método dos elementos finitos (MEF), método dos volumes finitos (MVF) e método dos elementos de contorno (MEC). No entanto, métodos com malha enfrentam várias restrições quando os problemas envolvem grande deformação ou fronteiras móveis, como superfície livre, fragmentação, junção ou interação entre vários corpos. Desta forma, técnicas de rastreamento de fronteira e reconstrução de malha são necessários, aumentando a complexidade computacional. Contornando as dificuldades enfrentadas por métodos com malha e devido sua implementação relativamente fácil e flexibilidade, métodos sem malha têm atraído muita atenção recentemente. Uma importante classe de métodos sem malha são os métodos de partículas, onde cada partícula move-se pela ação de seu peso próprio e forças internas/externas, calculadas pelas interações com partículas vizinhas (IDELSOHN; OÑATE, 2006).

Este trabalho apresenta a fundamentação teórica da mecânica dos sólidos utilizada no desenvolvimento e implementação do método de partículas Moving Particle Semiimplicit (MPS) para simulação e análise envolvendo sólidos elásticos. O método MPS foi desenvolvido originalmente para escoamentos incompressíveis com a presença de superfície livre (KOSHIZUKA; TAMAKO; OKA, 1995; KOSHIZUKA; OKA, 1996), mas na última década, foi estendido para a análise de estruturas elásticas e elastoplásticas (CHIKAZAWA; KOSHIZUKA; OKA, 2001; SONG; KOSHIZUKA; OKA, 2003). O método MPS é baseado na descrição lagrangeana, onde todas as propriedades estudadas referem-se a pontos móveis no espaço. Todas as estruturas envolvidas na simulação são discretizadas como partículas, não necessitando de malha para os cálculos. Por ser um método sem malha, o MPS é muito eficaz para a simulação hidrodinâmica envolvendo superfícies livres, fragmentação e fusão, e problemas envolvendo grandes deformações, corpos de geometria complexa e fronteiras móveis. No caso de sólidos, o método permite contornar as restrições impostas por métodos com malha e realizar com facilidade análises envolvendo grandes deformações 
ou fragmentação. A equação constitutiva para sólidos elásticos caracterizada pela densidade do material, módulo de Young e coeficiente de Poisson é substituída por equações algébricas derivadas da aplicação de um modelo de interação entre partículas. Disso, resulta, essencialmente, um sistema de partículas conectadas entre si por molas normais e tangenciais, onde os movimentos de translação e rotação de cada partícula são calculados através da integração numérica da equação de movimento discretizada pelo método.

Tendo em vista que a dinâmica de corpos elásticos e de sistemas hidroelásticos têm aplicações importantes em diversas áreas da engenharia, como por exemplo: desenvolvimento de absorvedores de energia; prevenção de falhas em tubulações; movimento de fluidos dentro de tanques flexíveis; projeto, desenvolvimento e segurança de estruturas flutuantes muito grandes (Very Large Floating Structures); estudo de proteção natural costeira; interação de ondas e geleiras; área de engenharia biomédica, no estudo de interação entre sangue e tecidos flexíveis, entre outros; um simulador baseado no método MPS foi implementado neste trabalho para o estudo da dinâmica de sólidos envolvendo colisões e fragmentação e o acoplamento da análise hidrodinâmica e estrutural para investigar problemas envolvendo modelos hidroelásticos. No caso de análise $3 \mathrm{D}$, em vez de Ângulos de Euler, os ângulos são determinados pela álgebra dos quatérnions de Hamilton, evitando erros de singularidades. Um algoritmo de fragmentação e detecção de colisão é proposto para permitir a investigação de fragmentação entre vários sólidos. No modelo simplificado, a ocorrência de fragmentação é detectada quando a deformação entre as partículas é maior do que uma deformação crítica. No caso da interação fluido-estrutura, as partículas de superfície do sólido são tratadas como partículas de fluido e as pressões destas partículas são calculadas pela resolução da equação de Poisson para a pressão, tal como as partículas de fluido. Desta forma, o acoplamento fraco entre sólido e fluido é realizado utilizando o deslocamento e velocidade do sólido elástico, como condições de contorno do fluido, e a pressão na interface, obtida pela resolução do movimento do fluido, aplicada ao movimento do sólido elástico.

\subsection{Objetivos do Trabalho}

Como uma primeira etapa para a modelagem da dinâmica e deformação de materiais elásticos o trabalho apresenta uma implementação do método MPS para simular a dinâmica de sólidos elásticos no espaço 2D e 3D, baseado nos estudos de Chikazawa, Koshizuka e Oka (2001), Song, Koshizuka e Oka (2003), Robortella, Cheng e Nishimoto (2009). Um algoritmo de fragmentação e detecção de colisão é proposto possibilitando a 
investigação de fragmentação entre vários sólidos. Por fim, o módulo de sólidos elásticos é integrado ao módulo de fluidos do simulador MPS, possibilitando a simulação de casos de interação fluido-estrutura. Desta forma, o trabalho visa disponibilizar uma ferramenta computacional para a investigação de problemas envolvendo dinâmica de sólidos elásticos com relação tensão x deformação linear e fenômenos de interação fluido-estrutura em diversas áreas da engenharia.

Especificamente, os principais objetivos são:

- Desenvolver a formulação e o algoritmo baseado no método MPS para análise numérica do comportamento de materiais elásticos.

- Implementar o módulo de análise de sólidos elásticos do simulador MPS em desenvolvimento no TPN/USP.

- Integrar o módulo de sólidos elásticos com o módulo de fluídos do simulador MPS.

- Validar os módulos implementados.

- Disponibilizar uma ferramenta computacional para estudo de modelos hidroelásticos.

\subsection{Organização do Trabalho}

Este trabalho está dividido em seis capítulos.

No $1^{\circ}$ capítulo são apresentados uma introdução sobre o trabalho e seus objetivos.

No $2^{\circ}$ capítulo é realizada uma revisão bibliográfica dos principais temas abordados no trabalho; métodos numéricos, interação fluido-estrutura e o método MPS.

O $3^{\circ}$ capítulo trata a teoria de sólidos elásticos inserida no método MPS e apresenta uma breve explanação sobre uma condição de fragmentação e o acoplamento fluidoestrutura adotado no trabalho.

No $4^{\mathrm{o}}$ capítulo são apresentados os algoritmos do método implementado e a condição adotada para a escolha do incremento de tempo.

No $5^{\circ}$ capítulo são apresentados os resultados obtidos com o MPS e sua comparação com resultados obtidos por outros métodos numéricos, soluções analíticas ou experimentos presentes na literatura.

No $6^{\circ}$ capítulo são discutidos os resultados das simulações realizadas e questões a serem investigadas em trabalhos futuros. 


\section{Revisão Bibliográfica}

Neste capítulo são apresentados alguns dos principais métodos numéricos utilizados em mecânica computacional, as principais abordagens e formulações utilizadas em problemas de interação fluido-estrutura e as diversas aplicações do método MPS.

\subsection{Métodos numéricos}

Em muitos problemas físicos tratados pela engenharia, em que tempo, eficiência e precisão são imprescindíveis, a simulação numérica tem apresentado um papel fundamental. Nos últimos 50 anos, houve um desenvolvimento significativo nessa área e a evolução na tecnologia computacional teve um papel crucial nesse progresso.

Para resolução numérica de equações diferenciais parciais (EDPs), associados ao modelo físico ou matemático, alguns métodos numéricos se destacam:

- Método das diferenças finitas (MDF);

- Método dos volumes finitos (MVF);

- Método dos elementos finitos (MEF);

- Método dos elementos de contorno (MEC);

- Métodos sem malha (Meshfree).

O método das diferenças finitas foi desenvolvido por A. Thom em 1920 (THOM; APELT, 1961) sob o título de "the method of squares" para resolver equações hidrodinâmicas nãolineares. A resolução de EDPs pelo MDF permite obter uma aproximação da solução num conjunto de pontos do domínio, ou seja, as EDPs são substituídas por equações de diferenças finitas. O MDF pode ser utilizado para resolver problemas de valor de contorno ou valor inicial, envolvendo equações diferenciais ordinárias ou parciais. A extensão da 
solução para outros pontos nem sempre é óbvia ou mesmo possível para sistemas com geometria irregular ou condições de contorno complexas, limitando a aplicação do método. Desenvolvimentos posteriores utilizando coordenadas generalizadas ampliaram de forma significativa o potencial do método.

O método dos volumes finitos é um método que tem sido amplamente utilizado em diversos campos da engenharia, tais como mecânica dos fluidos, transferência de calor e transferência de massa. No MVF o domínio é discretizado em volumes de controle e a equação de conservação é aplicada a cada volume. Através de uma função de interpolação, os valores das variáveis do nó central são utilizados para obtenção das variáveis dos vizinhos na superfície do volume de controle. Dessa forma, um sistema de equações é obtido para todo o domínio. Algumas das características mais importantes do MVF são semelhantes aos do método de elementos finitos, como a utilização em geometrias arbitrárias, usando malhas estruturados ou não estruturados e obtenção de sistemas robustos. Uma característica adicional é a conservação local dos fluxos numéricos, onde o fluxo numérico, a partir de uma célula discretizada, é conservado para os seus vizinhos. Essa última característica faz com que o MVF seja bastante atraente ao modelar problemas para os quais o fluxo é de extrema importância, como na mecânica dos fluidos, semi-condutores, transferência de calor e massa, entre outros (EYMARD; GALLOUËT; HERBIN, 2000).

Dentre os métodos apresentados, o método dos elementos finitos é o que mais se destaca, graças a sua vasta aplicabilidade nos diversos campos da ciência. O MEF surgiu em 1955, evoluindo da análise matricial de modelos reticulados (SORIANO, 2003). Os primeiros trabalhos tratando sobre o MEF foram de Argyris e Kelsey (1954) e Turner et al. (1956). No MEF, o domínio computacional é dividido em subdomínios ou elementos de dimensões finitas (elementos finitos) interligados por meio de pontos denominados nós. A formulação do MEF pode ser baseada no modelo dos deslocamentos, modelos de equilíbrio, ou em métodos híbridos e mistos (ZIENKIEWICZ; TAYLOR, 2000). De todos esses métodos, aquele que apresenta uma maior simplicidade e, consequentemente, uma maior versatilidade é o modelo dos deslocamentos. No modelo dos deslocamentos, o campo de deslocamentos é representado em função dos deslocamentos nodais e a interação de componentes de tensão entre elementos adjacentes é substituída pela interação de forças nodais entre elementos. Dessa maneira, o equilíbrio infinitesimal que se considera no modelo matemático de meio contínuo é substituído pelo equilíbrio de cada elemento finito isoladamente, trocando-se as equações diferenciais de equilíbrio por equações algébricas de equilíbrio do elemento como um todo. Das equações algébricas obtidas para cada elemento, resulta um sistema de equações de equilíbrio da malha de elementos. Esse sistema, 
após a introdução de condições de vinculação ao meio exterior, permite a determinação da solução em termos de deslocamentos nodais (SORIANO, 2003). Atualmente, a literatura do MEF é vasta e de certa forma complexa, mas alguns trabalhos apresentam as principais evoluções do método ao longo do tempo, como o trabalho de Cook et al. (2002).

O método dos elementos de contorno transforma as EDPs em identidades integrais que são aplicadas sobre a superfície ou contorno do problema analisado. Essas integrais são resolvidas numericamente ao longo do contorno, que é dividido em pequenos segmentos nos problemas 2D ou painéis nos problemas 3D (elementos de contorno). Assim como nos outros métodos numéricos, desde que as condições de contorno sejam satisfeitas, um sistema de equações algébricas lineares é obtido, possibilitando uma solução aproximada para o problema (BECKER, 1992). O trabalho de Cheng e Cheng (2005) apresenta em detalhes o desenvolvimento do MEC.

Aproximadamente na década de 70, algumas áreas da mecânica computacional voltaram sua atenção para uma nova família de métodos, os métodos sem malha (meshfree). Os métodos sem malha aproximam as EDPs por um sistema de equações algébricas, discretizando o domínio por um conjunto de nós dispersos aleatoriamente, sem interligação topológica fixa entre eles. Por causa dessa característica peculiar, o método de aproximação da solução do problema é definido unicamente em função dos nós. Ainda num estágio de desenvolvimento, os métodos sem malha têm sido vistos como alternativa aos métodos tradicionais, os quais apresentam deficiência na resolução de problemas envolvendo: geometrias complexas, descontinuidades do domínio, grandes deformações, deformação localizada e necessidade de refinamento e remalhamento. Devido ao recente desenvolvimento dos métodos sem malha, poucas obras didáticas são encontradas, como por exemplo Liu (2003), Liu e Gu (2005).

Uma importante classe de métodos sem malha são os métodos de partículas, onde cada partícula move-se pela ação de seu peso próprio e forças internas/externas, calculadas pelas interações com partículas vizinhas (IDELSOHN; OÑATE, 2006). Exemplos de métodos de partículas utilizados em diferentes campos da ciência e engenharia são: Particle in Cell (PIC) (HARLOW, 1964), Discrete Element Method (DEM) (CUNDALL; STRACK, 1979), Smoothed Particle Hydrodynamics (SPH) (LUCY, 1977; GINGOLD; MONAGHAN, 1977), Material Point Method (MPM) (SULSKY; CHEN; SCHREYER, 1994), Particle Finite Element Method PFEM (IDELSOHN; OÑATE; DEL PIN, 2004) e o MPS. 


\subsection{Interação fluido-estrutura}

A medida que a área de mecânica computacional vai se desenvolvendo, fenômenos mais complexos vão sendo modelados e seus resultados analíticos ou ensaios experimentais são confrontados com simulações computacionais. Dentre esses fenômenos, a interação fluidoestrutura (FSI, do inglês Fluid-structure Interaction) tem ganhando crescente interesse pela sua importância em diversas áreas.

$\mathrm{Na}$ análise de problemas FSI, uma estratégia de acoplamento deve satisfazer a compatibilidade geométrica e as condições de equilíbrio na interface fluido-estrutura (ISHIHARA; YOSHIMURA, 2005). As principais abordagens adotadas para solução podem ser divididas:

- Monolítica: totalmente acoplado com interação fluido-estrutura na interface tratada de forma síncrona. Dependendo do modelo utilizado, as propriedades podem ser conservadas, garantindo estabilidade numérica (BRUMELEN; HULSHOFF; BORST, 2003).

- Particionado: equações de fluido e estrutura integradas no tempo de forma alternada, e condições de interface tratadas de forma assíncrona. Devido a diferenças entre passos de tempo para fluido e estrutura, as propriedades do sistema podem não ser conservadas, normalmente aumentando a energia do sistema, tornando o problema numericamente instável (PIPERNO; FARHAT; LARROUTUROU, 1995).

Para modelar problemas FSI, formulações Euleriana, Lagrangeana ou LagrangeanaEuleriana Arbitrária (ALE, do inglês Arbitrary Lagrangian-Eulerian) podem ser utilizadas.

Entre as formulações, a Euleriana é menos utilizada para problemas FSI devido a complexidade envolvida na formulação numérica da parte estrutural (PAIK, 2010). Liu e Walkington (2001) desenvolveram equações governantes do fluxo de fluido contendo partículas visco-hiperelásticas para a formulação Euleriana. No entanto, eles simplificaram códigos numéricos que normalmente calculam a deformação da malha Lagrangeana se movendo através de uma malha Euleriana. Dunne e Rannacher (2006) utilizaram uma técnica similar ao Level Set Method e malha adaptativa para resolver problemas FSI na formulação Euleriana. O trabalho apresentou resultados semelhantes aos da formulação ALE, para o caso de um cilindro com barra elástica submetidos ao fluxo de fluido.

Para os problemas FSI envolvendo superfície livre, a formulação Lagrangeana é bastante utilizada, destacando-se os métodos de partículas, como o SPH, MPS e PFEM. 
Idelsohn, Oñate e Del Pin (2004) utilizaram o PFEM para simular casos de sloshing, quebra de onda em praia, sólido flutuante submetido a uma onda, e sólido em queda livre em um recipiente com água. Casos de quebra de onda em uma barra elástica foram analisados por Idelsohn et al. (2008b) utilizando o PFEM e por Amanifard, Hessan e Rahbar (2011) utilizando o SPH. Antoci, Gallati e Sibilla (2007) analisaram o caso de uma placa elástica submetida a pressão de uma coluna d'água utilizando o SPH. Idelsohn et al. (2008a) simularam casos de sloshing, interagindo com vigas elásticas engastadas, colocadas em diferentes posições de um tanque.

A formulaçao Lagrangeana-Euleriana Arbitrária tem sido amplamente aplicada a casos envolvendo superfície livre, contorno móveis, grandes deformações e problemas de interface de contato (DONEA; GIULIANI; HALLEUX, 1982; KUHL; HULSHOFF; BORST, 2003; LO; YOUNG, 2004; SOULI; BENSON, 2010; SANCHES; CODA, 2010).

\subsection{Método MPS}

Apresentado inicialmente em Koshizuka, Tamako e Oka (1995) como um método de partículas para simulação de escoamentos incompressíveis viscosos com superfície livre, o "Moving Particle Semi-implicit Method" ou simplesmente MPS, que receberia este nome apenas no trabalho de Koshizuka e Oka (1996), mostrou um grande potencial para simular geometrias e fenômenos complexos como, por exemplo, a fragmentação de fluidos e quebra de ondas. O método introduziu novos operadores algébricos para determinar gradiente de pressão, difusão, incompressibilidade e condição de contorno sólido e de superfície livre. Termos da difusão artificial usados nos métodos Particle and Force (PAF) (DALY et al., 1965) e SPH não foram necessários. A incompressibilidade foi modelada com um algoritmo semelhante ao Marker-and-Cell (MAC) (HARLOW; WELCH, 1965), onde o cálculo foi dividido em uma parte explícita e outra implícita. O resultado da simulação de uma coluna de fluido presa em um dos lados de um tanque retangular sendo liberada e depois chocando-se com um obstáculo foi obtida com sucesso. Grandes deformações e fragmentações do fluido foram observados, havendo uma boa aderência de resultados numéricos e experimentais.

Em Koshizuka e Oka (1996), alguns valores de coeficiente de superfície livre e de raio de vizinhança foram testados, obtendo-se os valores que apresentavam os melhores resultados. A função peso e o modelo de incompressibilidade foram modificados, obtendose uma grande melhoria de estabilidade numérica e diminuição do tempo computacional. A simulação da coluna de fluido, apresentada em Koshizuka, Tamako e Oka (1995), foi 
repetida com as mudanças no código fonte e comparada com os experimentos de Martin e Moyce (1952), mostrando uma boa aderência de resultados, mesmo quando o fluido foi fragmentado devido ao choque.

No trabalho de Koshizuka, Nobe e Oka (1998) foi proposta uma otimização para o cálculo da vizinhança, consistindo em determinar, a cada passo de tempo, as partículas vizinhas dentro de uma região de raio $r_{e}$ e em intervalos pré definidos e determinar os candidatos a partículas vizinhas dentro de uma região de raio $r_{e}+h$. As partículas vizinhas eram procuradas apenas na lista de candidatos, diminuindo consideravelmente o número de partículas a serem checadas. Foi obtida uma redução de tempo de cálculo de ordem $N^{2.0}$ para $N^{1.5}$, onde $N$ representa o número de partículas. Foram apresentados resultados de ondas sendo geradas e quebradas na praia. As formas das ondas tiveram uma boa aderência com resultados analíticos. Porém, foi detectado um atrito artificial que os autores concluíram ser devido ao movimento desordenado das partículas.

Escoamentos multifásicos vêm sendo analisados com o MPS por diversos autores. Koshizuka, Ikeda e Oka (1999) realizaram a simulação numérica de jatos de água em um tanque de fusão utilizando o MPS, onde um modelo numérico foi desenvolvido para calcular ebulição da água em vapor, com a geração de partículas na interface água-vapor. Os autores analisaram dois modelos de ebulição, adotando duas geometrias diferentes e alterando as velocidades dos jatos de água e densidades dos fluidos envolvidos. Em Zhang et al. (2004), o MPS foi utilizado para estudar a instabilidade de Rayleigh-Taylor, entre óleo de silicone e água, desencadeada pela força de empuxo. Os resultados desse trabalho mostraram os estágios típicos da instabilidade concordando com a análise linear e as formas das bolhas e picos foram consistentes com as observações experimentais. Ichikawa e Labrosse (2010) apresentaram um algoritmo para resolver problemas tridimensionais multifásicos baseados no MPS, onde a curvatura média e o vetor normal da interface, necessários para o cálculo de tensão de superfície, foram estimados pelos operadores diferenciais do SPH e MPS. Os autores adotaram uma abordagem em duas fases, onde o vetor normal foi calculado pelo SPH, enquanto que a curvatura média e a função delta de superfície foram obtidos pelo MPS. O método foi aplicado a dois problemas: a oscilação livre de uma gota e a transição de uma gota caindo dentro de um anel de vórtice. Os resultados apresentaram consistência com a teoria e dados experimentais. Park e Jeun (2011) acoplaram a dinâmica do corpo rígido e o MPS para simulação de fluidos multifásicos isotérmicos, com as simulações apresentando boa estabilidade global relacionada com a incompressibilidade do fluido, principalmente para fluidos monofásicos. Um caso de dam break e um caso de interação combustível-refrigerante isotérmico, em que um jato de água 
é dirigido para dentro de um tanque de fluido mais denso, foram simulados e comparados com dados experimentais apresentando boa concordância. Tian et al. (2010) analisaram o colapso de bolhas, devido a condensação, com o MPS. A deformação, tempo de vida, variação de tamanho e outros parâmetros das bolhas foram obtidos pelas simulações e analisados, comparando-se os resultados com soluções analíticas e dados experimentais.

O fenômeno de sloshing, onde um fluido com superfície livre se move no interior de um tanque, tem sido investigado empregando-se o MPS. Sueyoshi (2009) simulou um caso de sloshing em um tanque com baffles, considerando os baffles como placas finas. As placas receberam uma atenção especial, permitindo que partículas de fluído em diferentes lados da placa não interagissem entre si e simulações para casos 2D e 3D foram realizadas. Em Kim et al. (2011), o acoplamento e interação entre os movimentos de um navio e o interior do tanque submetido ao sloshing foram investigados usando o MPS. As forças e momentos devido ao sloshing no tanque foram considerados no cálculo do movimento do navio, que, por sua vez, foi introduzido no sistema do método MPS como movimentos forçados. Para a verificação do acoplamento, a dinâmica de uma plataforma do tipo Floating Production Storage and Offloading (FPSO) com dois tanques parcialmente cheios foi simulada e comparada com resultados experimentais para várias razões de enchimento. Lee et al. (2011a) utilizaram o MPS para simular o problema de sloshing com flutuadores de superfície para reduzir as cargas de impacto. Pelas simulações realizadas, os autores concluíram que as cargas de impacto máximos podem ser reduzidas, pela escolha adequada da densidade do flutuador. Lee et al. (2011b) estudaram casos de dam break e sloshing com o MPS, analisando passo a passo o método. Os autores investigaram a flutuação dos valores de pressão, alterando os valores do coeficiente de colisão e coeficientes do termo fonte da equação de Poisson para a pressão. O perfil da superfície, campo de pressões e pressões de pico dos casos simulados foram comparados com resultados experimentais. Tsukamoto, Cheng e Nishimoto (2011) propuseram uma formulação analítica e uma abordagem numérica baseada no MPS para avaliar cargas hidrodinâmicas em um tanque retangular parcialmente cheio com um corpo ligado ao tanque por meio de molas. Casos simples de movimento do corpo flutuante foram utilizados para validar o método, comparando os resultados numéricos com soluções analíticas. A eficácia do dispositivo de deslocamento de supressão também foi investigado. Zhang e Wan (2012) simularam o fenômeno de sloshing 2D num tanque de gás natural liquefeito do tipo membrana, com base no MPS. Para superar as instabilidades do MPS, os autores adotaram uma função peso não-singular, termo fonte misto para a equação de Poisson para a pressão e um novo método de detecção de partículas de superfície. O tanque foi submetido a movimentos 
forçados e os efeitos do período de excitação e amplitude do fluido foram investigados. A pressão prevista na parede do tanque pelo MPS mostrou uma boa concordância com os dados experimentais e outros resultados numéricos.

Outro fenômeno envolvendo superfície livre e que vem sendo estudado com auxílio do MPS é o fenômeno de green water, onde as ondas e os movimentos do navio, em condições de mar severo, permitem o embarque de água no convés do navio. Shibata e Koshizuka (2007a) realizaram uma simulação tridimensional de green water no convés prevendo a pressão de impacto sobre o convés, com auxílio do MPS. Devido o problema ser de larga escala, envolvendo uma quantidade muito grande de partículas, os autores adotaram um algoritmo otimizado de busca de vizinhança de partículas, baseado na descrição prévia do domínio em grid. Com isso conseguiram diminuir o tempo proporcional de $N^{2.0}$ para $N^{1.0}$, onde $N$ representa o número de partículas. O movimento do fluido, a elevação da superfície, e a pressão de impacto sobre o convés foram comparadas entre um experimento bidimensional e a simulação realizada, apresentando uma boa concordância. Baseado nos resultados obtidos, os autores sugeriram que o MPS necessita de uma elevada discretização espacial para estimar a pressão de impacto de forma acurada. Em Shibata, Tanizawa e Koshizuka (2007b), o barco foi considerado como um corpo rígido livre, sujeito as forças da interação fluido-estrutura, e as condições de mar severo foram adotadas. Comparando os resultados do MPS com resultados experimentais, o movimento de heave (vertical) apresentou boa concordância, enquanto que o movimento de pitch (rotação no plano longitudinal ), para o intervalo de razões entre comprimento de onda e comprimento do barco entre 1.0 e 1.5, diferiu significativamente. Os autores destacaram a necessidade de uma melhor discretização espacial e otimização nas dimensões do tanque a fim de se evitar a reflexão de ondas Shibata, Koshizuka e Tanizawa (2009) realizaram uma análise numérica 3D de green water em um navio em movimento, usando o MPS. Foram simulados três casos com comprimentos de onda típicos e movimentos de translação e rotação forçados. O comportamento do fluido e a pressão de impacto sobre o convés foram comparados com os dados experimentais, apresentando boa concordância. Shibata et al. (2012) estudaram o fenômeno de green water em um navio 3D com o MPS, considerando cinco condições de ondas. Os movimentos do navio foram comparados com resultados experimentais e como resultado, o efeito não linear do green water foi simulado com sucesso através do MPS, embora diferenças quantitativas entre os resultados calculados e experimentais foram observados.

Alguns modelos de tensão superficial têm sido propostos e introduzidos no MPS, afim de se estudar interação fluido-fluido ou fluido-gás. Nomura et al. (2001) utilizaram o 
MPS para analisar a separação de gotas em sistemas liquido-liquido e gás-liquido. Um modelo para o cálculo da tensão superficial foi desenvolvido e verificado pela simulação de vibração de uma gota de etanol. Para diferentes números de Weber, os modos de rompimento e tempos de dissolução adimensionais obtidos nas simulações apresentaram boa concordância com os experimentos. Em Sun, Xi e Chen (2009b), a colisão binária de duas gotas de líquido idênticas foi simulada através do MPS, permitindo o estudo dos mecanismos de deformação e de transferência de massa na colisão. Um modelo modificado da tensão superficial foi implementado para estudar os processos de grande deformação. Fenômenos de colisão frontal e impacto excêntrico foram investigados, e um mapa do mecanismo foi estabelecido para distinguir, qualitativamente, diferentes regimes de impacto. As propriedades de transferência de massa foram obtidas pelos caminhos traçados pelas partículas. Os resultados mostraram concordância com experiências realizadas anteriormente.

Para estudo de turbulência, através da faixa de frequência dos vórtices das partículas de fluido, o modelo de turbulência Sub-particle Scale (SPS) foi incorporado no MPS em alguns trabalhos. Shao e Gotoh (2005) compararam os métodos MPS e SPH, incorporando o modelo de turbulência SPS. A robustez dos modelos foi validada através de dados experimentais de um caso de dam break. Uma série de ensaios numéricos foi realizada para investigar o modo de convergência dos modelos, em relação ao intervalo de tempo e espaçamento das partículas. Por último, a eficiência do modelo SPS incorporado foi demonstrada pelos padrões de turbulência simulados a partir de um caso de quebra de onda. Gotoh e Sakai (2006) revisaram o modelo de turbulência SPS incorporado ao MPS, simulando modelos sólido-líquido e líquido-gás de duas fases, apresentando o desempenho do MPS em um cálculo de quebra de onda.

Problemas envolvendo troca de calor também foram estudados com o MPS. Zhang et al. (2006a, 2006b) aplicaram o MPS em casos tridimensionais de fluidos sob a convecção de Rayleigh-Bénard. Os resultados mostraram os padrões de convecção típicos da convecção de Rayleigh-Bénard, também obtidos pelo métodos Eulerianos. Segundo os resultados apresentados, os autores sugeriram que o método MPS é aplicável para a simulação numérica de problemas tridimensionais convectivos de transferência de calor.

Além das simulações envolvendo fluído, o MPS foi adaptado para simulação de sólidos elásticos. O método adaptado para estruturas sólidas foi apresentado em Chikazawa, Koshizuka e Oka (2001). Adotando um sistema de partículas conectadas entre si por molas normais e tangenciais, os movimentos de translação e rotação de cada partícula foram calculados através da integração numérica da equação de movimento discretizada 
pelos operadores do MPS. Testes com viga engastada, placa tracionada e barra viscoplástica apresentaram resultados numéricos com boa aderência comparados aos resultados analíticos. Testes com deformação por fluência e fratura de placa com trinca tiveram bons resultados quando comparados com resultados experimentais. O método adaptado combinado com o método MPS para fluidos foi usado para análises de interação fluidoestrutura. Um teste de gota d'água caindo em uma barra engastada gerou uma simulação bem sucedida onde, no encontro da água com a viga, a água fragmentou-se juntamente com o deslocamento da barra engastada. Ondas geradas colidindo com uma parede foram simuladas e a distribuição de pressão dessa parede teve uma boa aderência com resultados analíticos. Song, Koshizuka e Oka (2003, 2004) adaptaram o MPS para simulação dinâmica de sólidos elásticos bidimensionais. A estabilidade numérica em função do incremento de tempo foi analisada, aplicando uma velocidade na extremidade livre de uma viga engastada. Os autores concluíram que a estabilidade numérica é governada pela condição de Courant (COURANT; FRIEDRICHS; LEWY, 1967), dependente da velocidade da onda elástica. Um exemplo de colisão entre dois anéis elásticos, envolvendo grande deformação, foi simulado apresentando conservação de energia do sistema. Outro exemplo envolvendo fragmentação foi simulado e comparado com um ensaio experimental, apresentando propriedades qualitativas similares. Koshizuka, Song e Oka (2004) estenderam o método MPS para simulação dinâmica de sólidos elásticos tridimensionais. Testes bidimensionais de vigas submetidas a deslocamento e velocidade impostos, apresentaram boa concordância com os resultados analíticos. A energia total do sistema foi obtida por três métodos de integração: Euler explícito, simpléctico de $1^{a}$ ordem e simpléctico de $2^{a}$ ordem. Para o método de Euler explícito notou-se que a energia total aumenta ao longo do tempo. Para o método simpléctico de $1^{a}$ ordem a energia total foi conservada apresentando pequenos erros. Para o método simpléctico de $2^{a}$ a energia total foi conservada com erros desprezíveis. Um material flexível retangular caindo em uma placa rígida foi simulado apresentando semelhanças qualitativas com um caso real. A colisão entre dois cubos elásticos com mesmas propriedades foi simulada e a energia total apresentada graficamente. Notou-se que a energia total dessa colisão aumenta ao longo do tempo. Os autores argumentaram que o erro se deve a não utilização do formalismo Hamiltoniano. Ogasawara, Kikuchi e Sakai (2010) analisaram a interação entre fluido e sólido elástico baseados no MPS. Um experimento consistindo em um tanque com um gerador de onda e uma barreira elástica foi ensaiado e a máxima deformação da barreira elástica foi comparada com o caso simulado com o MPS. Casos com diferentes módulos de Young para a barreira elástica, também foram simulados e os deslocamentos e distribuição de pressão analisados. Os resultados apresentaram boa concordância com os dados experimentais. 
Procurando uma melhor aproximação para casos distintos, alguns autores estudaram a influência da função peso no MPS. Ataie-Ashtiani e Farhadi (2006) analisaram 6 funções peso em um problema de dam break verificando a estabilidade e acurácia do MPS. Os autores concluíram que a função $B$-spline apresentou melhor estabilidade e performance para o caso simulado. Kakuda et al. (2010) apresentaram o MPS utilizando uma função peso logarítmica. Como exemplos numéricos, o fluxo orientado em uma cavidade e o fluxo em uma bomba circular, com rotor girando, foram simulados e comparados com dados experimentais e resultados numéricos. Sheu, Chiao e Huang (2011) propuseram novas funções peso para o MPS, visando a suavidade apresentada na função delta de Dirac. Os problemas de onda solitária e dam break foram investigados e os resultados foram comparados com dados de referência, apresentando boa compatibilidade visual. Kakuda et al. (2012b) propuseram uma função peso logarítmica e redução do raio de influência para a resolução da equação de Poisson para a pressão, visando reduzir a oscilação do campo de pressão no método MPS. Um caso de dam break foi simulado demonstrando a viabilidade e validade da presente abordagem.

Demonstrado o potencial do MPS para simular diversos fenômenos, alguns autores têm proposto modificações no MPS, como operadores de alta ordem, alteração da equação de Poisson para a pressão, novas condições de superfície livre, melhora na busca de vizinhança, entre outras. Gotoh et al. (2005) utilizaram o MPS para simular o processo de overtopping em um dique vertical. Os autores aplicaram uma condição de anti-reflexão de ondas e aperfeiçoaram o processo de busca de vizinha, reduzindo a carga computacional. Resultados experimentais e resultados obtidos pelo MPS mostraram concordância razoável. Khayyer e Gotoh (2008) propuseram uma nova versão do MPS, nomeada Corrected Moving Particle Semi-implicit (CMPS). Modificações e correções foram feitas para garantir a conservação do momento de um fluido viscoso incompressível. No trabalho foram realizados testes numéricos simples demonstrando excelente desempenho do método CMPS na conservação do momento linear e significativa melhora da conservação do momento angular. Comparações qualitativas e quantitativas, entre as simulações e dados experimentais, confirmaram a precisão do método. Um tensor da viscosidade relacionado com taxa de deformação do escoamento foi proposto para simular escoamentos com deformação não uniforme. Em Khayyer e Gotoh (2010), os métodos MPS, Incompressible Smoothed Particle Hydrodynamics (ISPH) e Weakly Compressible Smoothed Particle Hydrodynamics (WCSPH), em versões padrão e modificada, foram utilizados para simulações de dam break em uma base molhada. No trabalho, os métodos MPS e ISPH foram alterados com a utilização de termo fonte de alta ordem e o método WCSPH alterado pela 
reinicialização do campo de densidade tomando como base o método Moving Least Square (MLS). Os autores realizaram comparações diretas entre experimentos e simulações dos diferentes métodos, analisando os perfis de superfície livre e processos de mistura. Shakibaeinia e Jin (2010) substituíram o modelo de incompressibilidade do MPS original por um modelo fracamente incompressível e simularam casos envolvendo fluxo com fronteiras abertas e superfície livre. Um algoritmo foi desenvolvido, permitindo condições de entrada e saída do fluxo, juntamente uma estratégia de reciclagem das partículas. Os modelos e algoritmos propostos foram validados e aplicados em um problema de ressalto hidráulico. Os resultados mostraram a eficiência e precisão do modelo proposto. Em Shakibaeinia e Jin (2011) o modelo fracamento incompressível foi utilizado para simular um caso de dam break sobre uma base móvel, tratando-se de um problema de fluxo altamente erosivo e transiente. Um modelo multifásico, capaz de lidar com a descontinuidade da densidade e viscosidade em que a fase (sedimentos) sólida é tratada como um fluido não-newtoniano, foi introduzido. O modelo resultante foi primeiramente validado utilizando um modelo dam break de duas fases e então aplicado ao problema de dam break sobre uma base móvel com diferentes materiais e formas iniciais, comparando-se os resultados com dados de alguns trabalhos experimentais. Tanaka e Masunaga (2010) propuseram um método para estabilizar as simulações e suprimir a oscilação de pressão no MPS. Para suavizar a pressão tanto em termos de espaço e tempo, uma nova formulação do estado incompressível, baseado no divergente da velocidade, foi proposta. Um caso de dam break foi simulado, apresentando melhor estabilidade e distribuição espacial e a oscilação da pressão mais suave do que o método original. Além disso, partículas de superfície foram detectadas de forma mais precisa. Khayyer e Gotoh (2011) investigaram o desempenho e estabilidade do MPS na simulação de problemas hidrodinâmicos gerais, incluindo problemas caracterizados por tensões de expansão ou por mudanças nos estados de tensão. Foi mostrado que o MPS é propenso a tornar-se desestabilizado em presença de forças de atração entre partículas, semelhante à instabilidade de tensão no método SPH. Duas modificações foram propostas, alterando o termo fonte da equação de Poisson para a pressão e introdução de uma matriz corretiva para o modelo de gradiente de pressão. Essas duas novas modificações, juntamente com duas melhorias propostas anteriormente, são apresentadas para estabilizar e melhorar o desempenho do método de MPS. Kondo e Koshizuka (2011) também investigaram a estabilidade do MPS e propuseram uma nova formulação do termo fonte da equação de Poisson para a pressão. Os autores incluíram dois termos de compensação multiplicados por dois coeficientes. Com a nova formulação, distribuições mais suaves de pressão foram obtidas para casos de pressão hidrostática e problemas de dam break. Isshiki (2011) analisou os operadores do MPS, comparando as 
soluções para equações diferenciais com as soluções exatas, em domínios com nós irregulares e regulares. Além do MPS, o autor analisou o método Random Collocation Method (RCM), proposto por ele. Também foi discutido os aspectos matemáticos e numéricos do MPS. Khayyer e Gotoh (2012) propuseram um modelo de Laplaciano 3D de ordem superior para a melhoria e estabilização da pressão em cálculos 3D baseados no MPS. Um caso hidrostático e de dam break com obstáculo 3D foram simulados e comparados com dados experimentais. Os casos apresentaram boa concordância com dados experimentais, mas ainda tiveram a presença de flutuações de pressão sem origem física. Souto-Iglesias et al. (2013) investigaram a consistência do MPS em reproduzir os operadores diferenciais gradiente, divergente e Laplaciano e mostraram a relação entre os métodos MPS e SPH. O método MPS foi utilizado para resolver as equações de Navier-Stokes, adotando uma método de projeção (fractional step method), que revelou problemas de inconsistência ao resolver a equação de Poisson para a pressão. Um novo método corrigido do MPS incorporando integrais de contorno foi proposto. Casos 1D com condições de contorno de Dirichlet e Neumann-Dirichlet misto e um caso 2D de evolução de uma onda viscosa foram simulados apresentando melhoras nos resultados.

Métodos híbridos, que resulta do acoplamento dos métodos baseados em partículas e métodos baseados em malhas, têm sido propostos, buscando as vantagens das descrições Euleriana e Lagrangeana. Yoon, Koshizuka e Oka (1999) propuseram um método híbrido de partícula-malha para análise de fluidos incompressíveis. O esquema numérico consistia em uma fase Lagrangeana, baseada no método MPS, e uma fase Euleriana, onde foi desenvolvido um esquema convectivo. O método foi aplicado em problemas de sloshing, apresentando boa concordância com dados experimentais. Em Koshizuka e Oka (2000) o método híbrido foi apresentado com o nome de "Meshless Advection using Flowdirectional Local-grid" (MAFL) e utilizado na análise de crescimento periódico de bolhas afastando-se de paredes aquecidas, no processo de ebulição nucleada. Foram analisados a velocidade de crescimento da bolha e a transferência de calor, os quais apresentaram boa concordância com os dados experimentais. Heo, Koshizuka e Oka (2002) estudaram o crescimento de bolhas em uma liquido em ebulição, em situação transitória, usando o MPS-MAFL. Analisaram o processo de crescimento de bolha com raios iniciais diferentes e condição de sub-arrefecimento e fluxo de calor elevados. Em Premoze et al. (2003), os métodos MPS e MPS-MAFL foram utilizados para simular um caso de enchente em corredor subterrâneo, enchimento de uma caixa por três bocais e enchimento de uma caixa com fluidos de viscosidade e densidade diferentes. Concluíram que poderiam utilizar esquemas de interpolação melhores para aumentar a precisão dos resultados. Lee, 
Noguchi e Koshizuka (2007) analisaram a interação fluido-casca pelo método MPS acoplado ao MEF adotando a formulação particionada. Na interface foi adotado a condição Neumann-Dirichlet. Para o fluido utilizaram integração semi-implícita e para a casca integração explícita simplética, garantindo conservação de energia do sistema. O fenômeno de sloshing foi simulado com as paredes modeladas como placas elásticas e sólidos rígidos, comparando a resposta do tanque em função da frequência de ressonância. Em Sueyoshi, Kihara e Kashiwagi $(2007,2008)$ um novo método híbrido, decompondo o domínio foi introduzido, combinando o método MPS para a região superior, incluindo a superfície livre e um corpo flutuante, e o método dos elementos de contorno (MEC) para a região inferior. Cada método troca suas informações através de seu contorno correspondente, proporcionando condições de contorno necessárias para o outro método, a cada passo de tempo. No MPS, as velocidades das partículas de contorno são obtidas como o resultado de valores interpolados a partir da velocidades normais do contorno. Por outro lado, no MEC, o valor de potencial em cada nó é dado como o resultado da integração numérica da pressão no contorno das partículas em movimento. A validade do método foi verificada para o problema de geração de ondas através de comparação com os resultados calculados pelo método MEC totalmente não-linear.

Procurando uma melhor performance computacional através da utilização de placas gráficas (GPU - Graphics Processing Unit), alguns trabalhos têm implementado o MPS em GPU, analisando o ganho de velocidade em relação a utilização de processadores (CPU - Central Processing Unit). Em Hori et al. (2011), os autores investigaram os principais itens causadores de gargalos na simulação, como busca de vizinhança e resolução do sistema de equações de Poisson. A evolução da queda de uma gota elíptica e um caso de dam break foram simulados pelo método de MPS utilizando uma GPU, e a precisão e desempenho da GPU foram comparadas com os casos simulados apenas com CPU. Em Zhu et al. (2011), Kakuda et al. (2012a) também foi apresentado o MPS em GPU, analisando a busca de vizinhança e resolução do sistema de equações, comparando a performance da GPU e CPU. Taniguchi, Sato e Cheng (2012) implementaram o MPS totalmente explícito em CPU com vários núcleos, GPU e GPU's em paralelo. Um caso de dam break 3D foi simulado e a performance das três aplicações foram comparadas, demonstrando um grande ganho de velocidade para GPU's em paralelo quando simulado casos com grande número de partículas.

Além dos problemas citados acima, a flexibilidade e capacidade do MPS em modelar fenômenos complexos também encontra aplicações em outras áreas.

Na área médica o MPS foi utilizado por alguns autores em trabalhos com fluido ou 
órgãos modelados como corpos elásticos. Tsubota et al. (2006), Tsubota, Wada e Yamaguchi (2006), Nagayama e Honda 2012 (2012) utilizaram o MPS para a simulação de fluxo sanguíneo, analisando o movimento de glóbulos vermelhos deformáveis no fluxo de plasma sanguíneo. Os glóbulos e o plasma foram discretizados por partículas, sendo os glóbulos caracterizados por uma membrana elástica e o plasma como um fluido viscoso. As partículas de membrana foram representadas por conexões entre molas e o fluxo de plasma foi modelado como um escoamento incompressível. As simulações demonstraram a capacidade do método para expressar os fenômenos de fluxo sanguíneo observados experimentalmente. Semelhante aos trabalhos citados anteriormente, Ahmadian, Firoozbakhsh e Hasanian (2012) propuseram um algoritmo modificado do MPS para simular o movimento dos glóbulos vermelhos deformáveis através de microvasos, reduzindo o tempo de simulação. Por se tratar de um meio microscópico viscoso, o movimento das partículas é muito pequeno em relação ao tubo sanguíneo, possibilitando a atualização de variáveis dependentes das posições das partículas apenas em determinados instantes de tempo. Dessa forma, os autores reduziram o tempo de simulação, atualizando a matriz com operadores laplaciano e busca de vizinhança apenas em determinados instantes de tempo. Chhatkuli, Koshizuka e Uesaka (2009), Chhatkuli et al. (2009) aplicaram o MPS para simular a deformação do pulmão durante a respiração, auxiliando no desenvolvimento de uma nova terapia de radiação no câncer de pulmão, diminuindo efeitos colaterais e garantindo a eficiência do tratamento. O pulmão foi modelado como um sólido elástico, com as equações de movimento regidas pelos operadores do MPS. Resultados experimentais e numéricos foram comparados apresentando uma razoável concordância. Kamada et al. (2010) estudaram o processo de trombogênese considerando a agregação de plaquetas sob a influência da dinâmica dos fluidos. O MPS foi aplicado no escoamento do plasma e das plaquetas e um modelo de mola foi utilizado para modelar a adesão de plaquetas às paredes lesionadas e a agregação de plaquetas. No trabalho foi apresentado a capacidade do método de simular a formação e destruição de trombos.

Na área nuclear, Ikeda et al. (2001) apresentaram análises de simulações de fluidos com diferentes densidades. O modelo utilizado foi composto por um recipiente com metal derretido em seu interior e um jato de água vindo de cima do recipiente que se mistura com o metal derretido. Foram feitas simulações bidimensionais e tridimensionais que foram comparadas com resultados reais medindo a quantidade de água que penetrou no metal líquido. No caso bidimensional, a água penetrou menos que em experimentos reais enquanto que no caso tridimensional teve uma boa aderência de resultados. Xie, Koshizuka e Oka (2005) simularam um caso 3D da incidência de uma gota sobre uma 
película de líquido, utilizando o MPS. Foram analisados o efeito de esguicho sobre os processos de deposição e reentrada de gotas de fluxo anular-névoa.

Na área industrial, Sun, Xi e Chen (2009a) simularam o processo de mistura de dois líquidos viscosos através do MPS. Os autores investigaram a velocidade de mistura, a viscosidade do líquido e o número, posição, período e velocidade de rotação das hastes de agitação. Através do rastreamento dos movimentos das partículas líquidas, a área de fluxo e mecanismos de mistura foram analisados, possibilitando a otimização do processo de mistura. Hirasawa et al. (2010) investigaram o efeito da geometria da ferramenta sobre o fluxo de plástico e mistura de material durante a fricção de solda a ponto, utilizando o MPS. Diferentes geometrias foram simuladas e, correlacionando os resultados com os ensaios experimentais, os modelos foram utilizados para prever o fluxo de material para trabalhos envolvendo solda a ponto.

Para investigar problemas em encostas, Nakaza, Iribe e Rouf (2010) simularam correntes de tsunami em torno de estruturas móveis e fixas usando o MPS. Um canal aberto com quatro conjuntos diferentes de estruturas foi analisado e os resultados indicaram que o fluxo em torno da estrutura em movimento é mais rápido do que em torno da estrutura fixa. O fluxo se mostrou mais complexo para os casos com estruturas adicionais. 


\section{Método de Partículas MPS}

Neste capítulo é apresentado uma breve descrição das equações constitutivas e governantes para sólidos elásticos, a formulação do método MPS é detalhada e são apresentadas a condição de fragmentação e interação fluido estrutura.

\subsection{Equações Constitutivas}

Para especificarmos o comportamento mecânico de diversos materiais de engenharia, é necessário um conjunto de equações denominadas equações constitutivas. As equações constitutivas mecânicas relacionam as tensões com alguma medida do movimento do corpo, normalmente a deformação ou a taxa de deformação.

Para a maioria dos sólidos, as deformações são proporcionais às forças aplicadas, desde que a carga não exceda um determinado valor (limite elástico). Os componentes do tensor de tensão $\boldsymbol{\sigma}$ em qualquer ponto no corpo são uma função linear dos componentes do tensor de deformação $\boldsymbol{\varepsilon}$. Essa afirmação é conhecida como Lei de Hooke Generalizada, e pode ser definida como

$$
\left[\begin{array}{c}
\sigma_{x x} \\
\sigma_{y y} \\
\sigma_{z z} \\
\tau_{x y} \\
\tau_{y z} \\
\tau_{z x}
\end{array}\right]=\left[\begin{array}{cccccc}
C_{11} & C_{12} & \cdot & \cdot & \cdot & C_{16} \\
C_{21} & \cdot & \cdot & \cdot & \cdot & \cdot \\
\cdot & \cdot & \cdot & \cdot & \cdot & \cdot \\
\cdot & \cdot & \cdot & \cdot & \cdot & \cdot \\
\cdot & \cdot & \cdot & \cdot & \cdot & \cdot \\
C_{61} & . & . & \cdot & \cdot & C_{66}
\end{array}\right]\left[\begin{array}{c}
\varepsilon_{x x} \\
\varepsilon_{y y} \\
\varepsilon_{z z} \\
2 \varepsilon_{x y} \\
2 \varepsilon_{y z} \\
2 \varepsilon_{z x}
\end{array}\right]
$$

onde os coeficientes $C_{i j}$ são propriedades do material.

Considerando um material homogêneo e isotrópico, a matriz de coeficientes $C_{i j}$ pode ser apresentada em função das constantes de Lamé $\mu$ e $\lambda$, 


$$
\begin{gathered}
{\left[\begin{array}{c}
\sigma_{x x} \\
\sigma_{y y} \\
\sigma_{z z} \\
\tau_{x y} \\
\tau_{y z} \\
\tau_{z x}
\end{array}\right]=\left[\begin{array}{cccccc}
\lambda+2 \mu & \lambda & \lambda & 0 & 0 & 0 \\
\lambda & \lambda+2 \mu & \lambda & 0 & 0 & 0 \\
\lambda & \lambda & \lambda+2 \mu & 0 & 0 & 0 \\
0 & 0 & 0 & 2 \mu & 0 & 0 \\
0 & 0 & 0 & 0 & 2 \mu & 0 \\
0 & 0 & 0 & 0 & 0 & 2 \mu
\end{array}\right]\left[\begin{array}{c}
\varepsilon_{x x} \\
\varepsilon_{y y} \\
\varepsilon_{z z} \\
\varepsilon_{x y} \\
\varepsilon_{y z} \\
\varepsilon_{z x}
\end{array}\right]} \\
\quad \mu=\frac{E}{2(1+\nu)} \\
\lambda=\frac{E \nu}{(1+\nu)(1-2 \nu)}
\end{gathered}
$$

onde $E$ é o módulo de Young e $\nu$ o coeficiente de Poisson.

A relação tensão-deformação, Eq. (3.2), pode ser simplificada pela seguinte equação

$$
\boldsymbol{\sigma}=2 \mu \boldsymbol{\varepsilon}+\lambda \operatorname{tr}(\boldsymbol{\varepsilon}) \boldsymbol{I}
$$

onde $\operatorname{tr}(\varepsilon)$ é o traço do tensor deformação $\varepsilon$ e $\boldsymbol{I}$ é o tensor identidade.

\subsection{Equações Governantes}

As equações de equilíbrio de um corpo podem ser obtidas pela soma da integral das forças atuantes nos pontos materiais do corpo. Dessa forma, a condição de equilíbrio dinâmico pode ser obtido por

$$
\boldsymbol{f}_{e x t}=\int_{V} \boldsymbol{b} d V+\int_{S} \boldsymbol{t} d S=\int_{V} \rho \frac{D \boldsymbol{v}}{D t} d V
$$

onde $\boldsymbol{f}_{\text {ext }}$ é o vetor forças externas, $\boldsymbol{b}$ é o vetor forças de volume, $\boldsymbol{t}$ é o vetor tensão e $\rho, \boldsymbol{v}, S$ e $V$ a densidade, vetor velocidade, superfície e volume do sólido, respectivamente.

Aplicando-se o Teorema do Divergente para a integral de superfície, obtém-se

$$
\begin{gathered}
\int_{S} \boldsymbol{t} d S=\int_{S} \boldsymbol{\sigma} \boldsymbol{n} d S=\int_{V} \nabla \cdot \boldsymbol{\sigma} \\
\int_{V}\left(\nabla \cdot \boldsymbol{\sigma}+\boldsymbol{b}-\rho \frac{D \boldsymbol{v}}{D t}\right) d V=0
\end{gathered}
$$


onde $\boldsymbol{n}$ é o vetor unitário normal à superfície S.

Como a Eq. (3.8) pode ser aplicada a qualquer parte do sólido, a integral deve ser nula em todo volume $V$, ou seja,

$$
\rho \frac{D \boldsymbol{v}}{D t}=\nabla \cdot \boldsymbol{\sigma}+\boldsymbol{b}
$$

Introduzindo a Eq. (3.5) na Eq. (3.9), têm-se a seguinte equação de movimento de translação para o sólido deformável

$$
\rho \frac{D \boldsymbol{v}}{D t}=\nabla \cdot(2 \mu \varepsilon+\lambda \operatorname{tr}(\boldsymbol{\varepsilon}) \boldsymbol{I})+\boldsymbol{b}
$$

\subsection{Método MPS}

No método MPS, todos os termos das equações governantes, de sólidos ou fluidos, representados por operadores diferenciais (divergente, gradiente, laplaceano e rotacional) são substituídos por operadores algébricos, derivados de um modelo de interações entre partículas.

A Figura 3.1 esquematiza um modelo plano de interação entre partículas. A partícula $i$ possui um raio de interação $r_{e}$ que estabelece quais partículas $j$ devem ser consideradas no cálculo das suas grandezas físicas. O vetor distância entre partículas é representado por $\boldsymbol{r}_{\boldsymbol{i}, \boldsymbol{j}}$ e o parâmetro $l_{o}$ é a distância entre as partículas adjacentes no instante inicial.

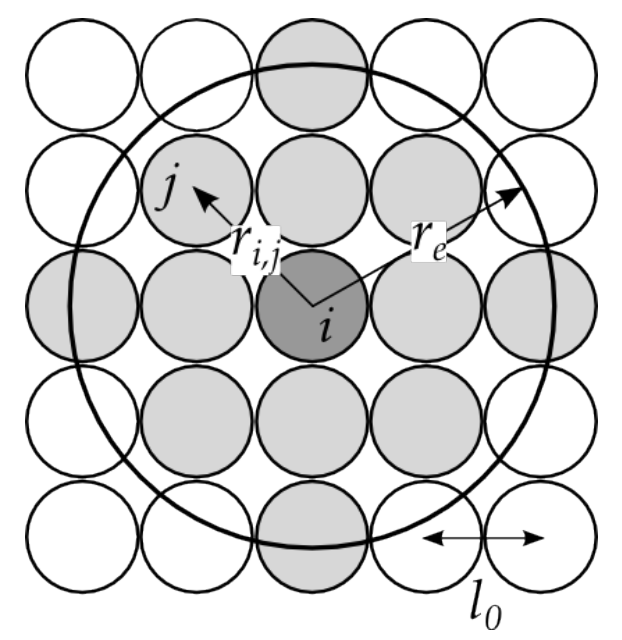

Figura 3.1: Modelo de partículas para sólidos no MPS.

As subseções seguintes apresentam termos e aproximações utilizados no MPS. 


\subsubsection{Função Peso}

A função peso $w\left(\left|\boldsymbol{r}_{i, j}\right|\right)$, definida na Eq. (3.11), determina o quanto cada partícula vizinha, situada em torno da partícula $i$, influencia no comportamento da partícula central $i$.

$$
\begin{gathered}
w\left(\left|\boldsymbol{r}_{i, j}\right|\right)=\left\{\begin{array}{cc}
\frac{r_{e}}{\left|\boldsymbol{r}_{i, j}\right|}-1, & \left|\boldsymbol{r}_{i, j}\right| \leq r_{e} \\
0, & \left|\boldsymbol{r}_{i, j}\right|>r_{e}
\end{array}\right. \\
\left|\boldsymbol{r}_{i, j}\right|=\left|\boldsymbol{r}_{j}-\boldsymbol{r}_{i}\right|
\end{gathered}
$$

onde $\boldsymbol{r}_{i}$ e $\boldsymbol{r}_{j}$ são os vetores posição das partículas $i$ e $j$.

\subsubsection{Densidade do Número de Partículas}

Outro parâmetro importante utilizado no método é a densidade do número de partículas $n_{i}$, definido na Eq. (3.13). Ele é a soma das contribuições das partículas vizinhas $j$ da partícula $i$.

$$
n_{i}=\sum_{j \neq i} w\left(\left|\boldsymbol{r}_{i, j}\right|\right)
$$

\subsubsection{Gradiente}

Dada uma função escalar $\phi$, o vetor gradiente na direção entre duas partículas $i$ e $j$, possuindo quantidades escalares genéricas $\phi_{i}$ e $\phi_{j}$, é aproximado por $\frac{\left(\phi_{j}-\phi_{i}\right)\left(\boldsymbol{r}_{j}-\boldsymbol{r}_{i}\right)}{\left|\boldsymbol{r}_{j}-\boldsymbol{r}_{i}\right|^{2}}$. O vetor gradiente na posição da partícula $i$ é obtido pela média ponderada da contribuição de cada vetor gradiente entre partículas $i$ e $j$ (KOSHIZUKA; OKA, 1996)

$$
\langle\nabla \phi\rangle_{i}=\frac{d}{n_{i}^{0}} \sum_{j \neq i} \frac{\left(\phi_{j}-\phi_{i}\right)}{\left|\boldsymbol{r}_{j}-\boldsymbol{r}_{i}\right|^{2}}\left(\boldsymbol{r}_{j}-\boldsymbol{r}_{i}\right) w\left(\left|\boldsymbol{r}_{i, j}\right|\right)
$$

onde $d$ é o número de dimensões ( $d=2$ para casos bidimensionais e $d=3$ para casos tridimensionais) e $n_{i}^{0}$ a densidade do número de partículas no instante inicial.

Neste trabalho, utilizaremos o subscrito $j^{\prime}$ para indicar grandezas avaliadas na posição média entre as partículas $i$ e $j$. Por exemplo, se a função $\phi$ for calculada na posição média entre duas partículas $i$ e $j$, teremos valores e posições médias $\phi_{j^{\prime}}$ e $\boldsymbol{r}_{j^{\prime}}=\frac{\boldsymbol{r}_{i}+\boldsymbol{r}_{j}}{2}$, respectivamente, Figura 3.2. Substituindo essas variáveis na Eq. (3.14), têm-se a seguinte 
equação do gradiente para a posição correspondente a partícula $i$

$$
\langle\nabla \phi\rangle_{i}=\frac{2 d}{n_{i}^{0}} \sum_{j \neq i} \frac{\phi_{j^{\prime}}\left(\boldsymbol{r}_{j}-\boldsymbol{r}_{i}\right)}{\left|\boldsymbol{r}_{j}-\boldsymbol{r}_{i}\right|^{2}} w\left(\left|\boldsymbol{r}_{i, j}\right|\right)
$$

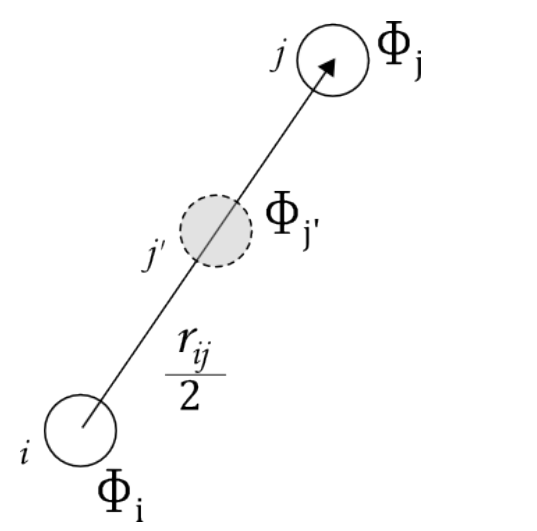

Figura 3.2: Variáveis no ponto médio entre $i$ e $j$.

\subsubsection{Correção do Gradiente}

Adotando a técnica de correção, proposta inicialmente para o método SPH, (BONET; LOK, 1999), o operador gradiente pode ser melhorado, pela multiplicação do gradiente original por uma matriz de correção $A$, Eq. (3.22).

Através da expansão da série de Taylor, o seguinte equacionamento pode ser escrito, desconsiderando os termos de $2^{a}$ ordem.

$$
\begin{aligned}
& \phi_{j}=\phi_{i}+\left.\nabla \phi\right|_{i, j} \cdot\left(\boldsymbol{r}_{j}-\boldsymbol{r}_{i}\right) \\
& \left.\nabla \phi\right|_{i, j} \cdot\left(\boldsymbol{r}_{j}-\boldsymbol{r}_{i}\right)=\phi_{j}-\phi_{i}
\end{aligned}
$$

Dividindo pelo módulo da distância e multiplicando pelo versor $\boldsymbol{r}_{i, j}$

$$
\left[\left.\nabla \phi\right|_{i, j} \cdot \frac{\left(\boldsymbol{r}_{j}-\boldsymbol{r}_{i}\right)}{\left|\boldsymbol{r}_{j}-\boldsymbol{r}_{i}\right|}\right] \frac{\left(\boldsymbol{r}_{j}-\boldsymbol{r}_{i}\right)}{\left|\boldsymbol{r}_{j}-\boldsymbol{r}_{i}\right|}=\frac{\phi_{j}-\phi_{i}}{\left|\boldsymbol{r}_{j}-\boldsymbol{r}_{i}\right|} \frac{\left(\boldsymbol{r}_{j}-\boldsymbol{r}_{i}\right)}{\left|\boldsymbol{r}_{j}-\boldsymbol{r}_{i}\right|}
$$

Reagrupando os termos do lado esquerdo, a Eq. (3.18) fica

$$
\left.\left[\frac{\left(\boldsymbol{r}_{j}-\boldsymbol{r}_{i}\right)}{\left|\boldsymbol{r}_{j}-\boldsymbol{r}_{i}\right|} \otimes \frac{\left(\boldsymbol{r}_{j}-\boldsymbol{r}_{i}\right)}{\left|\boldsymbol{r}_{j}-\boldsymbol{r}_{i}\right|}\right] \nabla \phi\right|_{i, j}=\frac{\phi_{j}-\phi_{i}}{\left|\boldsymbol{r}_{j}-\boldsymbol{r}_{i}\right|} \frac{\left(\boldsymbol{r}_{j}-\boldsymbol{r}_{i}\right)}{\left|\boldsymbol{r}_{j}-\boldsymbol{r}_{i}\right|}
$$


onde $\otimes$ representa o produto tensorial.

Adotando a ideia utilizada no MPS, de média ponderada da contribuição entre partículas $i$ e $j$, podemos reescrever a Eq. (3.19) como

$$
\left.\left[\frac{1}{n_{i}^{0}} \sum_{j \neq i} \frac{\left(\boldsymbol{r}_{j}-\boldsymbol{r}_{i}\right)}{\left|\boldsymbol{r}_{j}-\boldsymbol{r}_{i}\right|} \otimes \frac{\left(\boldsymbol{r}_{j}-\boldsymbol{r}_{i}\right)}{\left|\boldsymbol{r}_{j}-\boldsymbol{r}_{i}\right|} w\left(\left|\boldsymbol{r}_{i, j}\right|\right)\right] \nabla \phi\right|_{i, j}=\frac{1}{n_{i}^{0}} \sum_{j \neq i} \frac{\phi_{j}-\phi_{i}}{\left|\boldsymbol{r}_{j}-\boldsymbol{r}_{i}\right|} \frac{\left(\boldsymbol{r}_{j}-\boldsymbol{r}_{i}\right)}{\left|\boldsymbol{r}_{j}-\boldsymbol{r}_{i}\right|} w\left(\left|\boldsymbol{r}_{i, j}\right|\right)
$$

e o gradiente corrigido fica expresso por

$$
\begin{aligned}
& \left.\nabla \phi\right|_{i, j}=A\left[\frac{1}{n_{i}^{0}} \sum_{j \neq i} \frac{\phi_{j}-\phi_{i}}{\left|\boldsymbol{r}_{j}-\boldsymbol{r}_{i}\right|} \frac{\left(\boldsymbol{r}_{j}-\boldsymbol{r}_{i}\right)}{\left|\boldsymbol{r}_{j}-\boldsymbol{r}_{i}\right|} w\left(\left|\boldsymbol{r}_{i, j}\right|\right)\right] \\
& A=\left[\frac{1}{n_{i}^{0}} \sum_{j \neq i} \frac{\left(\boldsymbol{r}_{j}-\boldsymbol{r}_{i}\right)}{\left|\boldsymbol{r}_{j}-\boldsymbol{r}_{i}\right|} \otimes \frac{\left(\boldsymbol{r}_{j}-\boldsymbol{r}_{i}\right)}{\left|\boldsymbol{r}_{j}-\boldsymbol{r}_{i}\right|} w\left(\left|\boldsymbol{r}_{i, j}\right|\right)\right]^{-1}
\end{aligned}
$$

Multiplicado pela matriz A, o gradiente original que tinha um erro de ordem 0 , apresenta um erro de ordem 1 na forma corrigida. Dessa forma, para campos escalares $\phi$ lineares, o gradiente corrigido fornece resultados mais precisos.

\subsubsection{Divergente}

De maneira semelhante ao vetor gradiente, o divergente entre duas partículas $i$ e $j$ possuindo quantidades vetoriais genéricas $\boldsymbol{\phi}_{i}$ e $\boldsymbol{\phi}_{j}$ é definido por $\frac{\left(\phi_{j}-\boldsymbol{\phi}_{\boldsymbol{i}}\right) \cdot\left(\boldsymbol{r}_{j}-\boldsymbol{r}_{i}\right)}{\left|\boldsymbol{r}_{j}-\boldsymbol{r}_{i}\right|^{2}}$. O divergente entre a partícula $i$ e sua vizinhança fica (KOSHIZUKA; OKA, 1996)

$$
\langle\nabla \cdot \phi\rangle_{i}=\frac{d}{n_{i}^{0}} \sum_{j \neq i} \frac{\left(\phi_{j}-\phi_{i}\right) \cdot\left(\boldsymbol{r}_{j}-\boldsymbol{r}_{i}\right)}{\left|\boldsymbol{r}_{j}-\boldsymbol{r}_{i}\right|^{2}} w\left(\left|\boldsymbol{r}_{i, j}\right|\right)
$$

Semelhante a modificação realizada no gradiente, se a quantidade vetorial $\phi$ for calculada na posição média entre duas partículas $i$ e $j$, teremos valores e posições médias $\phi_{j^{\prime}}$ e $\boldsymbol{r}_{j^{\prime}}=\frac{\boldsymbol{r}_{i}+\boldsymbol{r}_{j}}{2}$, respectivamente, Figura 3.2. Substituindo essas variáveis na Eq. (3.23), tem-se a seguinte equação do divergente para a partícula $i$

$$
\langle\nabla \cdot \boldsymbol{\phi}\rangle_{i}=\frac{2 d}{n_{i}^{0}} \sum_{j \neq i} \frac{\phi_{j^{\prime}} \cdot\left(\boldsymbol{r}_{j}-\boldsymbol{r}_{i}\right)}{\left|\boldsymbol{r}_{j}-\boldsymbol{r}_{i}\right|^{2}} w\left(\left|\boldsymbol{r}_{i, j}\right|\right)
$$




\subsubsection{Laplaceano}

O laplaceano pode ser obtido como o divergente do gradiente

$$
\left\langle\nabla^{2} \phi\right\rangle_{i}=\langle\nabla \cdot \nabla \phi\rangle_{i}
$$

Combinando os operadores divergente e gradiente do MPS, o laplaceano fica

$$
\left\langle\nabla^{2} \phi\right\rangle_{i}=\frac{2 d}{n_{i}^{0}} \sum_{j \neq i} \frac{\phi_{j}-\phi_{i}}{\left|\boldsymbol{r}_{j}-\boldsymbol{r}_{i}\right|^{2}} w\left(\left|\boldsymbol{r}_{i, j}\right|\right)
$$

\subsubsection{Rotacional}

O vetor rotacional perpendicular a direção entre duas partículas $i$ e $j$, possuindo quantidades vetoriais genéricas $\boldsymbol{\phi}_{i}$ e $\boldsymbol{\phi}_{j}$, é definido por (CHIKAZAWA; KOSHIZUKA; OKA, 2001)

$$
\langle\nabla \times \boldsymbol{\phi}\rangle_{i}=\frac{d}{n_{i}^{0}} \sum_{j \neq i} \frac{\left(\phi_{j}-\phi_{i}\right) \cdot \boldsymbol{s}_{i, j}}{\left|\boldsymbol{r}_{j}-\boldsymbol{r}_{i}\right|} w\left(\left|\boldsymbol{r}_{i, j}\right|\right)
$$

onde $\boldsymbol{s}_{i, j}$ é o vetor unitário perpendicular ao vetor $\boldsymbol{r}_{i, j}$.

\subsubsection{Interação entre partículas}

O vetor distância inicial entre duas partículas é definido pela subtração das posições iniciais da partícula $j$ e partícula $i$, Eq. (3.28).

$$
\boldsymbol{r}_{i, j}^{0}=\boldsymbol{r}_{j}^{0}-\boldsymbol{r}_{i}^{0}
$$

Após o movimento das partículas, elas se encontram em uma nova posição e o novo vetor distância é obtido como

$$
\boldsymbol{r}_{i, j}=\boldsymbol{r}_{j}-\boldsymbol{r}_{i}
$$

Considerando o sistema referencial local de cada partícula, os referenciais podem sofrer rotações após o movimento das partículas. Para trabalharmos com o sistema referencial local de cada partícula, a cada movimento realizado o vetor distância inicial fica representado da seguinte forma 


$$
\boldsymbol{r}_{i, j}^{\theta}=R(\theta) \cdot \boldsymbol{r}_{i, j}^{0}
$$

onde $R(\theta)$ é a matriz de rotação, em $2 \mathrm{D}$ escrita como

$$
R(\theta)=\left(\begin{array}{cc}
\cos \left(\theta_{j^{\prime}}\right) & -\operatorname{sen}\left(\theta_{j^{\prime}}\right) \\
\operatorname{sen}\left(\theta_{j^{\prime}}\right) & \cos \left(\theta_{j^{\prime}}\right)
\end{array}\right)
$$

onde $\theta_{j^{\prime}}$ é calculado na posição média entre as partículas $i$ e $j$, e obtido pela média dos ângulos dessas partículas

$$
\theta_{j^{\prime}}=\frac{\theta_{i}+\theta_{j}}{2}
$$

Para casos 2D, o vetor deslocamento entre $i$ e $j$ pode ser obtido pela subtração de $\boldsymbol{r}_{i, j}$ por $\boldsymbol{r}_{i, j}^{\theta}$

$$
\boldsymbol{u}_{i, j}=\boldsymbol{r}_{i, j}-\boldsymbol{r}_{i, j}^{\theta}
$$

Para casos 3D, $R$ é obtida em função de um quaternion $\boldsymbol{q}$, que será detalhado na seção 3.5. Desta forma, o vetor deslocamento entre $i$ e $j$ é calculado como

$$
\boldsymbol{u}_{i, j}=\frac{1}{2}\left[\left(\boldsymbol{r}_{i, j}-R\left(q_{i}\right) \boldsymbol{r}_{i, j}^{0}\right)+\left(\boldsymbol{r}_{i, j}-R\left(q_{j}\right) \boldsymbol{r}_{i, j}^{0}\right)\right]
$$

No plano contendo as posições das partículas $i$ e $j$, o vetor deslocamento pode ser decomposto em uma componente normal $\left(\boldsymbol{u}_{i, j}\right)_{n}$, Eq. 3.35, e outra componente perpendicular $\left(\boldsymbol{u}_{i, j}\right)_{s}$, Eq. 3.36, apresentadas na Figura 3.3.

$$
\begin{gathered}
\left(\boldsymbol{u}_{i, j}\right)_{n}=\frac{\left(\boldsymbol{u}_{i, j} \cdot \boldsymbol{r}_{i, j}\right)}{\left|\boldsymbol{r}_{i, j}\right|} \frac{\boldsymbol{r}_{i, j}}{\left|\boldsymbol{r}_{i, j}\right|} \\
\left(\boldsymbol{u}_{i, j}\right)_{s}=\boldsymbol{u}_{i, j}-\left(\boldsymbol{u}_{i, j}\right)_{n}
\end{gathered}
$$

Dessa forma, obtêm-se os vetores deformação normal $\left(\boldsymbol{\varepsilon}_{i, j}\right)_{n}$ e deformação cisalhante $\left(\varepsilon_{i, j}\right)_{s}$

$$
\left(\varepsilon_{i, j}\right)_{n}=\frac{\left(\boldsymbol{u}_{i, j}\right)_{n}}{\left|\boldsymbol{r}_{i, j}^{0}\right|}
$$




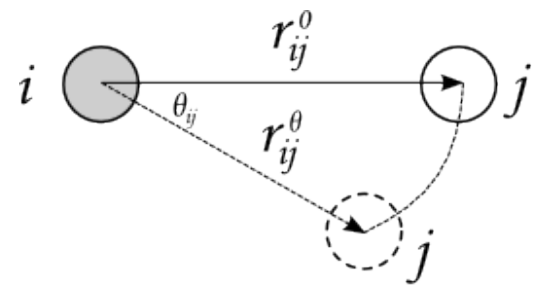

rotação

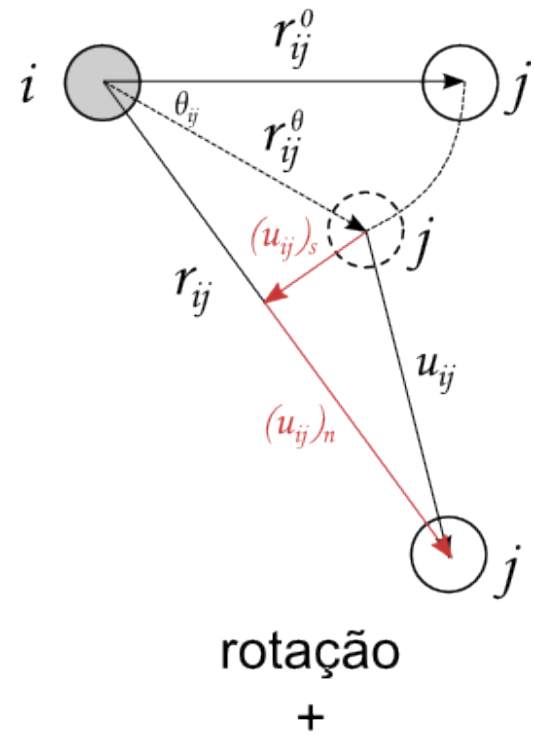

translação

Figura 3.3: Modelo MPS para sólidos elásticos (SONG; KOSHIZUKA; OKA, 2003).

$$
\left(\varepsilon_{i, j}\right)_{s}=\frac{\left(\boldsymbol{u}_{i, j}\right)_{s}}{\left|\boldsymbol{r}_{i, j}^{0}\right|}
$$

A deformação volumétrica $\operatorname{tr}(\varepsilon)$ é representada pelo divergente do vetor deslocamento

$$
\operatorname{tr}(\varepsilon)=\nabla \cdot\left(\boldsymbol{u}_{i, j}\right)
$$

O divergente do deslocamento pode ser calculado usando o operador divergente do MPS

$$
\operatorname{tr}(\boldsymbol{\varepsilon})=\nabla \cdot\left(\boldsymbol{u}_{i, j}\right)=\frac{d}{n_{i}^{0}} \sum_{j \neq i} \frac{\boldsymbol{u}_{i, j} \cdot \boldsymbol{r}_{i, j}}{\left|\boldsymbol{r}_{i, j}^{0}\right|\left|\boldsymbol{r}_{i, j}\right|} w\left(\left|\boldsymbol{r}_{i, j}^{0}\right|\right)
$$

Através dos vetores deformação, os componentes de tensão normal $\left(\boldsymbol{\sigma}_{i, j}\right)_{n}$, de cisalhamento $\left(\boldsymbol{\sigma}_{i, j}\right)_{s}$ e pressão interna $p_{i}$ são determinados para o sólido, Eqs. (3.41), (3.42) e (3.43).

$$
\begin{gathered}
\left(\boldsymbol{\sigma}_{i, j}\right)_{n}=2 \mu\left(\boldsymbol{\varepsilon}_{i, j}\right)_{n} \\
\left(\boldsymbol{\sigma}_{i, j}\right)_{s}=2 \mu\left(\boldsymbol{\varepsilon}_{i, j}\right)_{s}
\end{gathered}
$$




$$
p_{i}=-\lambda \operatorname{tr}(\varepsilon)
$$

Os três termos calculados, $\left(\boldsymbol{\sigma}_{i, j}\right)_{n},\left(\boldsymbol{\sigma}_{i, j}\right)_{s}$ e $p_{i}$, contribuem para o movimento de translação de cada partícula, Eq. (3.10). Aplicando o modelo do divergente para o deslocamento, representado pelas tensões normal e de cisalhamento, e aplicando o modelo do gradiente para a pressão interna, têm-se três equações para o cálculo da aceleração de cada partícula, Eqs. (3.44), (3.45) e (3.46).

$$
\begin{gathered}
\rho\left(\frac{\partial \boldsymbol{v}_{i}}{\partial t}\right)_{n}=\frac{2 d}{n_{i}^{0}} \sum_{j \neq i} \frac{\left(\boldsymbol{\sigma}_{i, j}\right)_{n}}{\left|\boldsymbol{r}_{i, j}^{0}\right|} w\left(\left|\boldsymbol{r}_{i, j}^{0}\right|\right) \\
\rho\left(\frac{\partial \boldsymbol{v}_{i}}{\partial t}\right)_{s}=\frac{2 d}{n_{i}^{0}} \sum_{j \neq i} \frac{\left(\boldsymbol{\sigma}_{i, j}\right)_{s}}{\left|\boldsymbol{r}_{i, j}^{0}\right|} w\left(\left|\boldsymbol{r}_{i, j}^{0}\right|\right) \\
\rho\left(\frac{\partial \boldsymbol{v}_{i}}{\partial t}\right)_{p}=\frac{2 d}{n_{i}^{0}} \sum_{j \neq i} \frac{p_{j^{\prime}}}{\left|\boldsymbol{r}_{i, j}^{0}\right|^{2}} \boldsymbol{r}_{i, j} w\left(\left|\boldsymbol{r}_{i, j}^{0}\right|\right)
\end{gathered}
$$

onde $p_{j^{\prime}}$ é a pressão calculada na posição média entre as partículas $i$ e $j$, obtida pela média entre as pressões dessas partículas, Eq. (3.47).

$$
p_{j^{\prime}}=\frac{p_{i}+p_{j}}{2}
$$

Em relação ao movimento de rotação de cada partícula, o momento angular não é conservado no modelo de discretização do MPS. Para garantir a conservação do momento angular, o momento entre os pares de partículas são cancelados pelo momento devido a força de cisalhamento entre as partículas, calculado na Eq. (3.52), e velocidade e variação angular são obtidos para cada partícula. Considerando a conservação do momento angular para cada partícula, tem-se a seguinte equação

$$
\boldsymbol{L}_{i}=I_{i} \boldsymbol{\omega}_{i}
$$

onde $\boldsymbol{L}_{i}$ é o vetor momento angular, $I_{i}$ o momento de inércia e $\boldsymbol{\omega}_{i}$ o vetor velocidade angular. A variação do momento angular em relação ao tempo fica

$$
\frac{\partial \boldsymbol{L}_{i}}{\partial t}=\frac{\partial I_{i}}{\partial t} \boldsymbol{\omega}_{i}+I_{i} \frac{\partial \boldsymbol{\omega}_{i}}{\partial t}
$$




$$
\sum_{j \neq i} \boldsymbol{M}_{i, j}=\frac{\partial I_{i}}{\partial t} \boldsymbol{\omega}_{i}+I_{i} \frac{\partial \boldsymbol{\omega}_{i}}{\partial t}
$$

onde $\boldsymbol{M}_{i, j}$ é o vetor momento causado pelo vetor forças externas.

A força devido o cisalhamento é obtida pela média ponderada das contribuições calculadas no ponto médio entre as partículas $i$ e $j$

$$
\boldsymbol{F}_{j^{\prime}}=\frac{2 d l_{o}^{d}}{n_{i}^{0}} \frac{\left(\boldsymbol{\sigma}_{i, j}\right)_{s}}{\left|\boldsymbol{r}_{i, j}^{0}\right|} w\left(\left|\boldsymbol{r}_{i, j}^{0}\right|\right)
$$

e o momento gerado por essa força, entre cada par de partículas, é obtido por

$$
\boldsymbol{M}_{j^{\prime}}=-\left(\boldsymbol{r}_{j}-\boldsymbol{r}_{i}\right) \times \boldsymbol{F}_{j^{\prime}}
$$

Admitindo-se que a variação do momento de inércia com o tempo é desprezível, para cada partícula, a sua aceleração angular é obtida pela equação geral da conservação do momento angular, Eq. (3.50)

$$
I_{i} \frac{\partial \boldsymbol{\omega}_{i}}{\partial t}=-\frac{1}{2} \sum_{j \neq i} \boldsymbol{M}_{j^{\prime}}
$$

onde o momento de inércia $I_{i}$ é calculado como:

$$
I_{i}=m \frac{\left(l_{o}\right)^{2}}{6}=\frac{\rho\left(l_{o}\right)^{2+d}}{6}
$$

onde $m$ é a massa de cada partícula.

\subsection{Velocidades e posições}

As velocidades de um instante posterior $\left(\boldsymbol{v}_{i}{ }^{k+1}\right)$, podem ser calculadas através da aceleração do instante atual e as posições $\left(\boldsymbol{r}_{i}{ }^{k+1}\right)$, através das velocidades do instante posterior. A velocidade e posição são calculadas, considerando o método explícito, Eq. (3.55), e implícito de Euler, Eq. (3.56), respectivamente.

$$
\boldsymbol{v}_{i}^{k+1}=\boldsymbol{v}_{i}^{k}+\Delta t\left(\frac{\partial \boldsymbol{v}_{i}}{\partial t}\right)^{k}
$$




$$
\boldsymbol{r}_{i}^{k+1}=\boldsymbol{r}_{i}^{k}+\Delta t \boldsymbol{v}_{i}^{k+1}
$$

Semelhante as velocidades e posições calculadas anteriormente, a rotação é obtida pela velocidade angular $\boldsymbol{\omega}_{i}^{k+1}$ e o ângulo de cada partícula $\boldsymbol{\theta}_{i}^{k+1}$, conforme descrevem as Eqs. (3.57) e (3.58).

$$
\begin{gathered}
\boldsymbol{\omega}_{i}^{k+1}=\boldsymbol{\omega}_{i}^{k}+\Delta t\left(\frac{\partial \boldsymbol{\omega}_{i}}{\partial t}\right)^{k} \\
\boldsymbol{\theta}_{i}^{k+1}=\boldsymbol{\theta}_{i}^{k}+\Delta t \boldsymbol{\omega}_{i}^{k+1}
\end{gathered}
$$

\subsection{Quaternions}

No caso tridimensional, os ângulos são calculados pela álgebra dos quaternions de Hamilton, evitando erros de singularidades causados por ângulos no sistema Euleriano.

Um quaternion arbitrário $\boldsymbol{q}$ pode ser expresso como

$$
\boldsymbol{q}=\left[\begin{array}{llll}
q_{x} & q_{y} & q_{z} & s
\end{array}\right]=\left[\eta_{x} \sin \left(\frac{\theta}{2}\right) \eta_{y} \sin \left(\frac{\theta}{2}\right) \eta_{z} \sin \left(\frac{\theta}{2}\right) \cos \left(\frac{\theta}{2}\right)\right]
$$

onde $\left(\eta_{x} \eta_{y} \eta_{z}\right)$ representa um vetor unitário de rotação e $\theta$ o angulo de rotação.

O vetor unitário de rotação $\boldsymbol{\eta}_{j^{\prime}}$, entre cada par de partículas, é definido como

$$
\boldsymbol{\eta}_{j^{\prime}}=\frac{\boldsymbol{\omega}_{j^{\prime}}}{\left|\boldsymbol{\omega}_{j^{\prime}}\right|}
$$

onde $\boldsymbol{\omega}_{j^{\prime}}$ a velocidade angular média entre as partículas, Eq. (3.61)

$$
\boldsymbol{\omega}_{j^{\prime}}=\frac{\boldsymbol{\omega}_{i}+\boldsymbol{\omega}_{j}}{2}
$$

A atualização do quaternion se dá pelo produto do quaternion anterior pelo quaternion atual, Eq. (3.62).

$$
\boldsymbol{q}^{k+1}=\boldsymbol{q}^{k-1} \times \boldsymbol{q}^{k}
$$


Dessa forma, a matriz de rotação $R(q)$ pode ser determinada em função do quaternion (BARAFF, 1997), Eq. (3.63).

$$
R(q)=\left(\begin{array}{ccc}
1-2 q_{y}^{2}-2 q_{z}^{2} & 2 q_{x} q_{y}-2 s q_{z} & 2 q_{x} q_{z}+2 s q_{y} \\
2 q_{x} q_{y}+2 s q_{z} & 1-2 q_{x}^{2}-2 q_{z}^{2} & 2 q_{y} q_{z}-2 s q_{x} \\
2 q_{x} q_{z}-2 s q_{y} & 2 q_{y} q_{z}+2 s q_{x} & 1-2 q_{x}^{2}-2 q_{y}^{2}
\end{array}\right)
$$

\subsection{Fragmentação}

Uma condição simplificada de fragmentação linear elástica foi implementada permitindo a simulação de casos envolvendo fragmentação de sólidos. Pelo método de identificação de fragmentação adotado, a condição somente pode ser utilizada para casos onde há possibilidade de ocorrer o rompimento sem que esse seja precedido de extensa deformação plástica.

Quando a deformação entre um par de partículas $i$ e $j$ excede um valor limite $\varepsilon_{\max }$, previamente definido, a função peso entre essas partículas é zerada, Eq. (3.64). Desta forma, as duas partículas perdem sua conexão, caracterizando rompimento do sólido nesse ponto.

$$
\varepsilon_{i, j}=\frac{\left|\boldsymbol{r}_{i, j}\right|-\left|\boldsymbol{r}_{i, j}^{0}\right|}{\left|\boldsymbol{r}_{i, j}^{0}\right|}>\varepsilon_{\max } \Longrightarrow w\left(\left|\boldsymbol{r}_{i, j}\right|\right)=0
$$

\subsection{Interação fluido-estrutura}

Neste trabalho, todo o domínio físico, representando sólidos elásticos e fluidos, é discretizado por partículas, e suas equações governantes são representadas pelos operadores diferenciais do MPS. Para simularmos a interação fluido-estrutura, um algoritmo particionado é utilizado.

Primeiramente são realizados os cálculos envolvendo as equações governantes do fluido (KOSHIZUKA; TAMAKO; OKA, 1995), acrescentando as partículas de superfície do sólido elástico ao domínio representativo do fluido. O Anexo A apresenta os detalhes sobre a formulação da dinâmica dos fluídos utilizando o MPS. A implementação e validação do código computacional para simulação dos fluidos, podem ser encontrados em Tsukamoto (2006). Depois que os valores das pressões $P_{i}$ são obtidos para as partículas vizinhas de fluido e partículas de superfície do sólido elástico, eles são utilizados como componente 
adicional no cálculo do movimento do sólido elástico, pela introdução de uma força externa de volume $\boldsymbol{F}_{f s i}$ na equação governante do sólido elástico Eq. (3.65) para as partículas de superfície.

$$
\rho \frac{D \boldsymbol{v}}{D t}=\nabla \cdot(2 \mu \varepsilon+\lambda \operatorname{tr}(\boldsymbol{\varepsilon}) \boldsymbol{I})+\boldsymbol{b}+\boldsymbol{F}_{f s i}
$$

onde a força de volume $\boldsymbol{F}_{f s i}$ é calculada como

$$
\boldsymbol{F}_{f s i}=\frac{2 d}{n_{i}^{*}} \sum_{j * \neq i} \frac{P_{i, j *}}{\left|\boldsymbol{r}_{j *}-\boldsymbol{r}_{i}\right|^{2}}\left(\boldsymbol{r}_{j *}-\boldsymbol{r}_{i}\right) w\left(\left|\boldsymbol{r}_{i, j *}\right|\right)
$$

onde $j *$ representa as partículas de fluido e de superfície sólida na vizinhança de interação da partícula $i$, desconsiderando as partículas dummy, e $P_{i, j *}$ é a pressão calculada na posição média entre as partículas $i$ e $j *$, obtida pela média entre as pressões dessas partículas, Eq. (3.67).

$$
P_{i, j *}=\frac{P_{i}+P_{j *}}{2}
$$

Vale ressaltar que a densidade de partículas $n_{i}^{*}$ contabiliza apenas as partículas de fluido e de superfície de sólido elástico, sendo obtida pela subtração entre a densidade de partículas total e densidade de partículas internas do sólido

$$
n_{i}^{*}=\left(n_{i}\right)_{\text {total }}-\left(n_{i}^{0}\right)_{\text {solido }}
$$

A Figura 3.4 apresenta o acoplamento entre as partículas de fluído e sólido elástico.

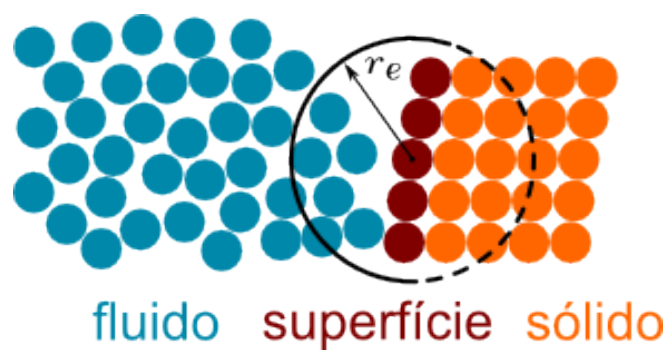

Figura 3.4: Interação entre partículas de fluido, superfície e sólidas.

Após a inclusão da força externa de volume $\boldsymbol{F}_{f s i}$ e outras possíveis forças externas, como gravidade, viscosidade, forças impostas, etc, são realizados os cálculos devido as deformações internas no sólido elástico, e a posição das partículas do sólido são atualizadas. Atualizado as posições de partículas de fluido e sólido, as partículas de superfície do 
sólido elástico novamente são consideradas como partículas de fluido, e são realizados os cálculos das equações governantes dos fluidos no novo instante de tempo, precedendo as etapas de interação fluido-estrutura explicadas anteriormente. Desta forma, é realizado o acoplamento fluido-estrutura ao longo do tempo na simulação. 


\section{Implementação Numérica}

Neste capítulo são apresentados os algoritmos implementados para simular a dinâmica de sólidos elásticos, detecção de contato entre sólidos e interação fluido-estrutura.

\subsection{Algoritmo sólido elástico}

O fluxograma do algoritmo explícito baseado no método MPS para simular a dinâmica de sólidos elásticos é apresentado na Fig. (4.1).

Condições iniciais - Primeiramente, todas as entradas do sistema são fornecidas ao simulador. Entradas de tipo de materiais (fluido ou sólido), posições, velocidades, passo de tempo, tempo de simulação, propriedades do material, etc.

Fornecidos os dados iniciais, os cálculos de cada passo de tempo (time step) são agrupados nas seguintes etapas:

Deslocamento relativo - Para cada partícula $i$, os deslocamentos relativos entre ela e suas vizinhas $j$ são atualizados. Obtido o deslocamento, uma componente normal e outra componente perpendicular são obtidas para cada par de partículas.

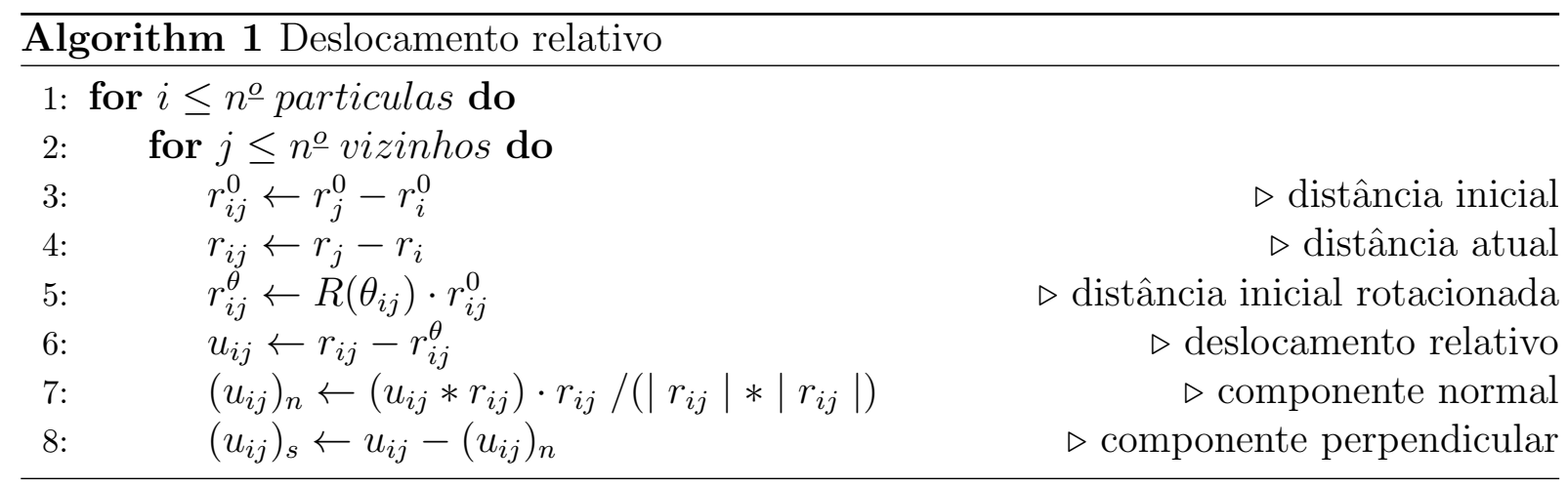

Deformações - Através da distância inicial e do deslocamento relativo, as deformações entre partículas são obtidas. 


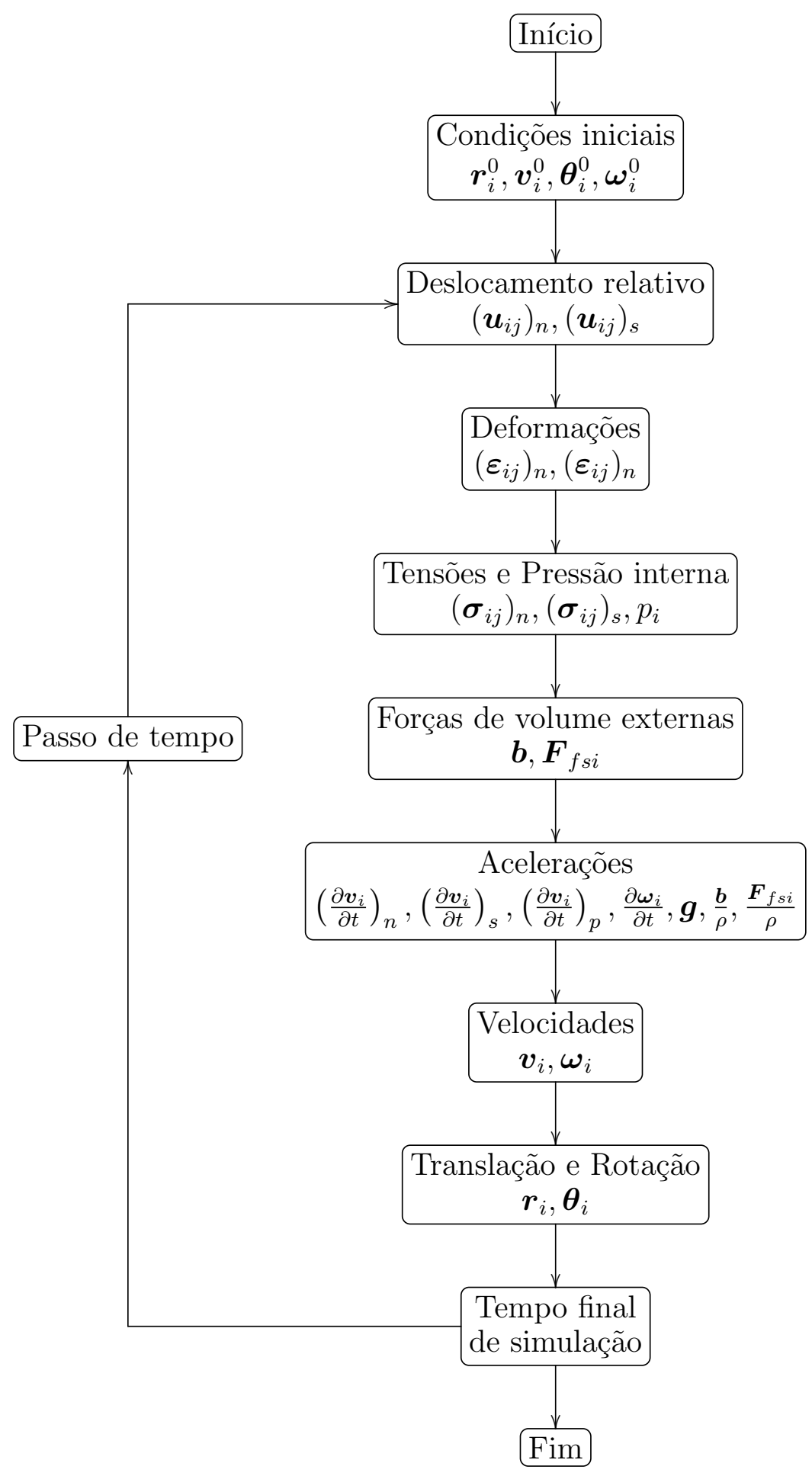

Figura 4.1: Fluxograma do algoritmo MPS para sólidos elásticos. 


\begin{tabular}{crr}
\hline \multicolumn{2}{l}{ Algorithm 2 Deformações } & \\
\hline $9:$ & $\left(\varepsilon_{i j}\right)_{n} \leftarrow\left(u_{i j}\right)_{n} /\left|r_{i j}^{0}\right|$ & $\triangleright$ componente normal \\
10: & $\left(\varepsilon_{i j}\right)_{s} \leftarrow\left(u_{i j}\right)_{s} /\left|r_{i j}^{0}\right|$ & $\triangleright$ componente cisalhamento \\
$11:$ & $\left(\varepsilon_{i j}\right)_{v o l} \leftarrow \operatorname{div}\left(u_{i j}\right)$ & $\triangleright$ defomação volumétrica \\
\hline
\end{tabular}

Tensões e Pressão interna - As deformações normal, cisalhante e volumétrica, possibilitam o cálculo das tensões e pressão interna.

\begin{tabular}{llr}
\hline Algorithm 3 Tensões e Pressão interna & \\
\hline 12: & $\left(\sigma_{i j}\right)_{n} \leftarrow 2 * \mu *\left(\varepsilon_{i j}\right)_{n}$ & $\triangleright$ tensão normal \\
13: & $\left(\sigma_{i j}\right)_{s} \leftarrow 2 * \mu *\left(\varepsilon_{i j}\right)_{s}$ & $\triangleright$ tensão cisalhamento \\
14: & $p_{i} \leftarrow \lambda *\left(\varepsilon_{i j}\right)_{v o l}$ & $\triangleright$ pressão interna \\
\hline
\end{tabular}

Forças de volume externas - Forças impostas ou calculadas pelos valores do instante anterior são aplicadas as partículas.

\begin{tabular}{llr}
\hline Algorithm 4 Forças de volume externas & \\
\hline $15:$ & $n_{i}^{*} \leftarrow\left(n_{i}\right)_{\text {total }}-\left(n_{i}^{0}\right)_{\text {solido }}$ & \\
$16:$ & $P_{i j *} \leftarrow\left(P_{i}+P_{j *}\right) / 2$ & $\triangleright$ pressão FSI \\
$17:$ & $F_{f s i} \leftarrow F_{f s i}+2 * d * P_{i j *} * r_{i j *} * \omega_{i j *} /\left(n_{i}^{*} *\left|r_{i j *}\right| *\left|r_{i j *}\right|\right)$ & $\triangleright$ força FSI \\
\hline
\end{tabular}

Acelerações - Com base nos operadores diferenciais do MPS, as tensões e pressão interna fornecem as acelerações das partículas.

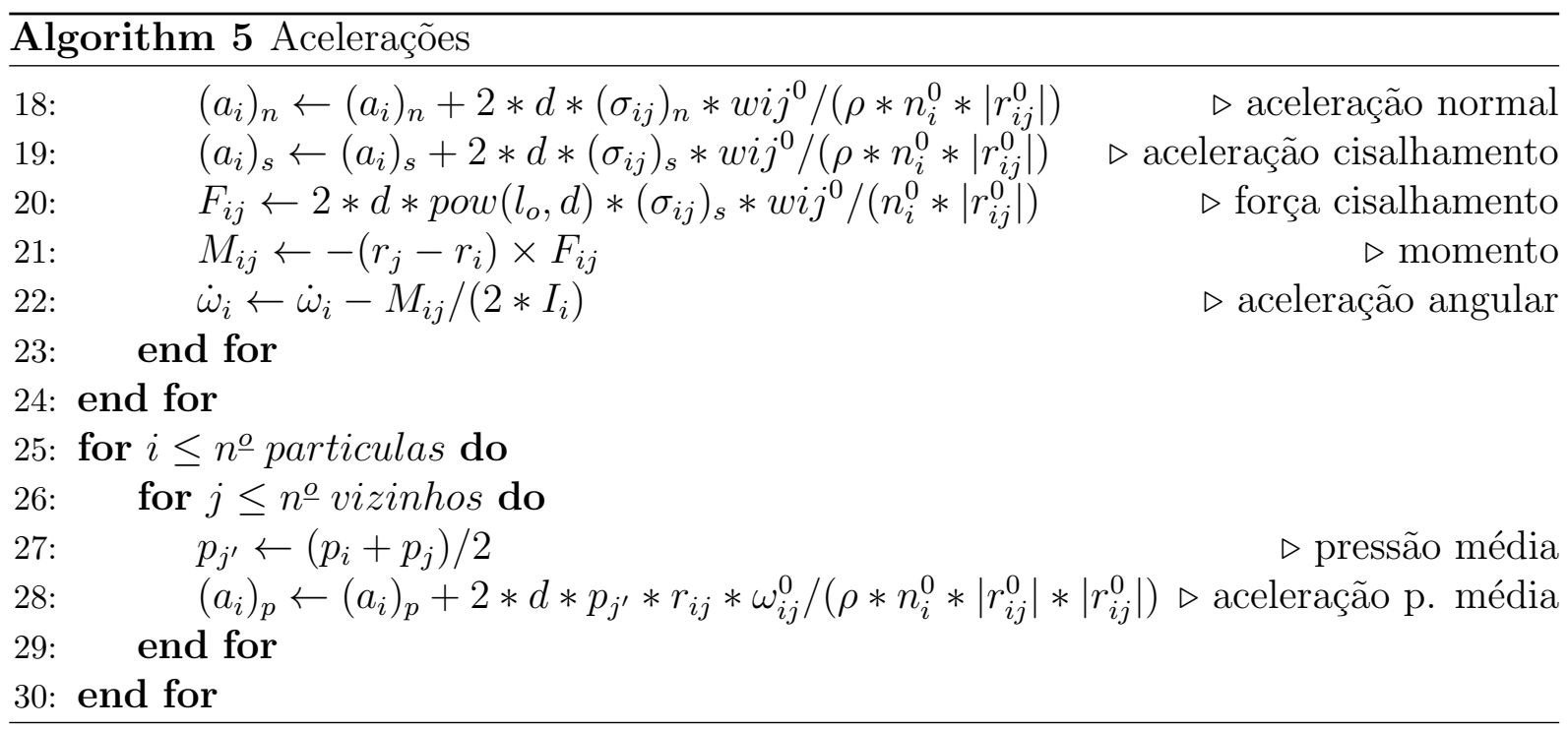

Velocidades - Pela integração explícita das acelerações, as velocidades das partículas são atualizadas. 


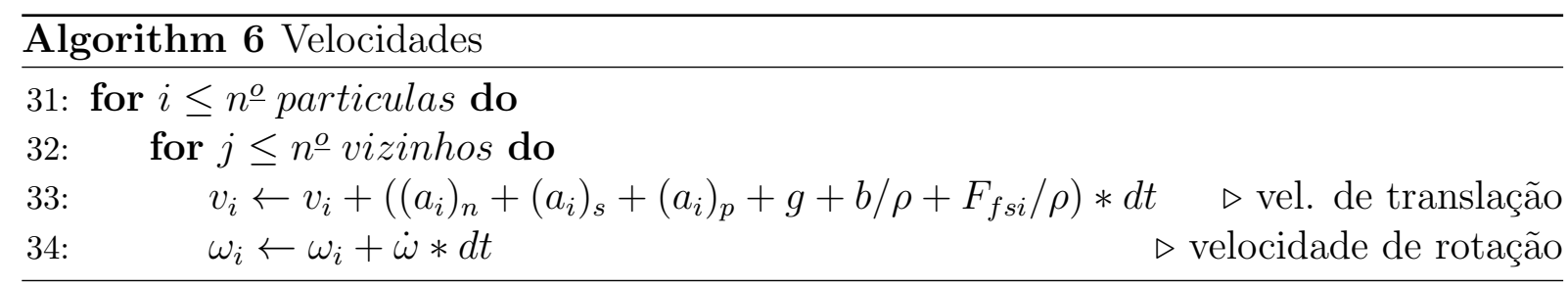

Translação e Rotação - Pela integração explícita das acelerações, as velocidades e posições das partículas são atualizadas e o movimento de translação e rotação do sólido é realizado.

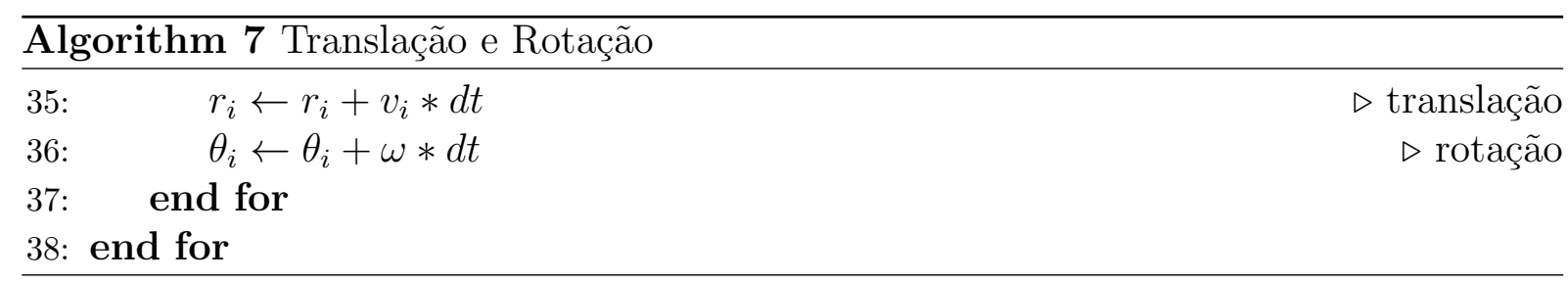

Tempo final de simulação - Verificação do fim da simulação. Caso não tenha acabado, os dados são enviados para que seja realizado novamente todo o cálculo.

\subsection{Algoritmo de fragmentação e detecção de contato}

Em primeiro lugar, as partículas de cada sólido são divididas em partículas de superfície e partículas internas.

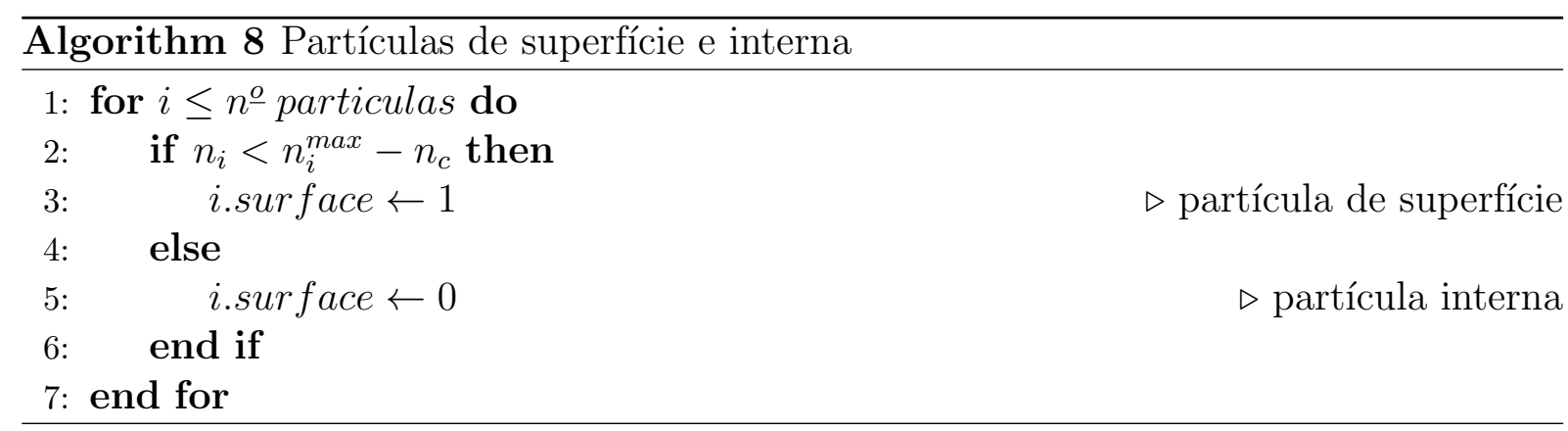

Semelhante a condição de superfície livre para fluidos (KOSHIZUKA; OKA, 1996), a densidade do número de partículas $n_{i}$ é utilizada para diferenciar partículas internas de partículas de superfície. As partículas com $n_{i}$ menor do que um valor estabelecido são classificadas como partículas de superfície e as restantes como partículas internas, como apresentado na Eq. (4.1).

$$
n_{i}<n_{i}^{\max }-n_{c}
$$


onde $n_{i}^{\max }$ é o máximo valor do número de densidade de partículas no domínio e $n_{c}$ um valor constante. Neste trabalho é utilizado $n_{c}=0.5$.

Além disso, para cada partícula $i$, são guardados os índices e relação de ligação das partículas vizinhas $j$ num raio de interação $\sqrt{2}$ para casos bidimensionais e $\sqrt{3}$ para casos tridimensionais, quando as partículas $i$ e $j$ pertencem a um mesmo material. Com isso, é verificado se duas partículas de superfície fragmentaram ou ainda continuam conectadas.

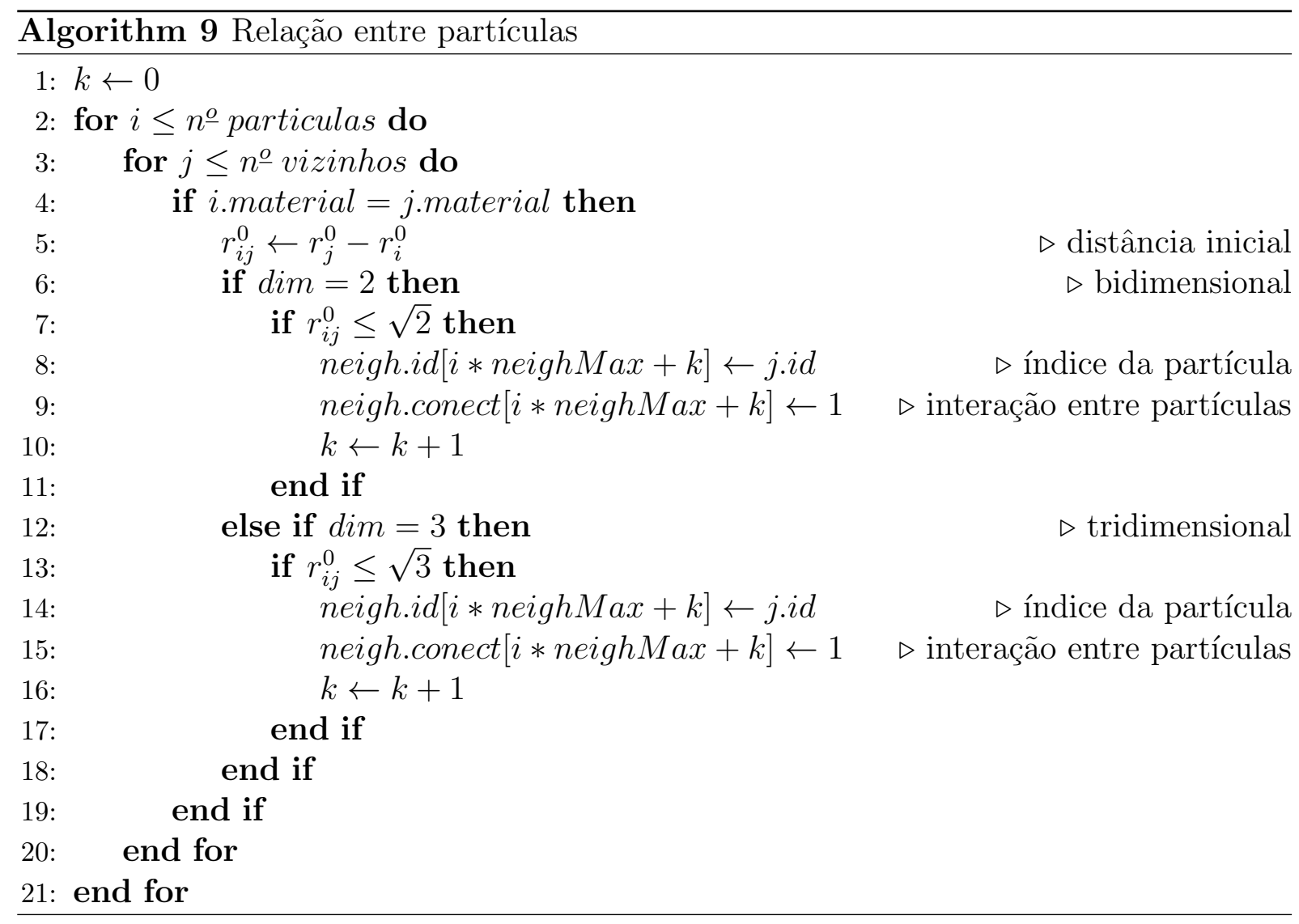

No caso de fragmentação, partículas internas que sofram fragmentação são reclassificadas como partículas de superfície, como apresentado na Figura 4.2, e para partículas inicialmente conectadas, a sua relação de interação é modificada.
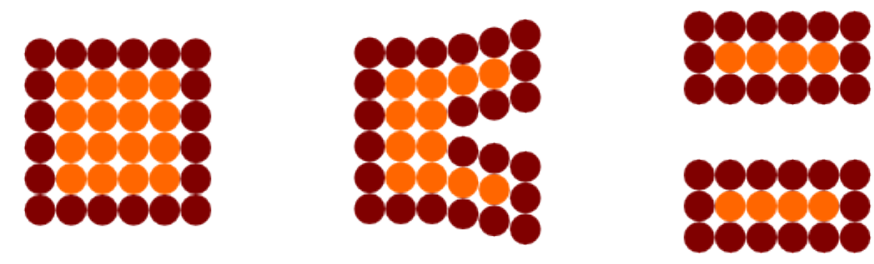

Figura 4.2: Partículas de superfície (vermelho) e particulas internas (laranja) durante a fragmentação. 


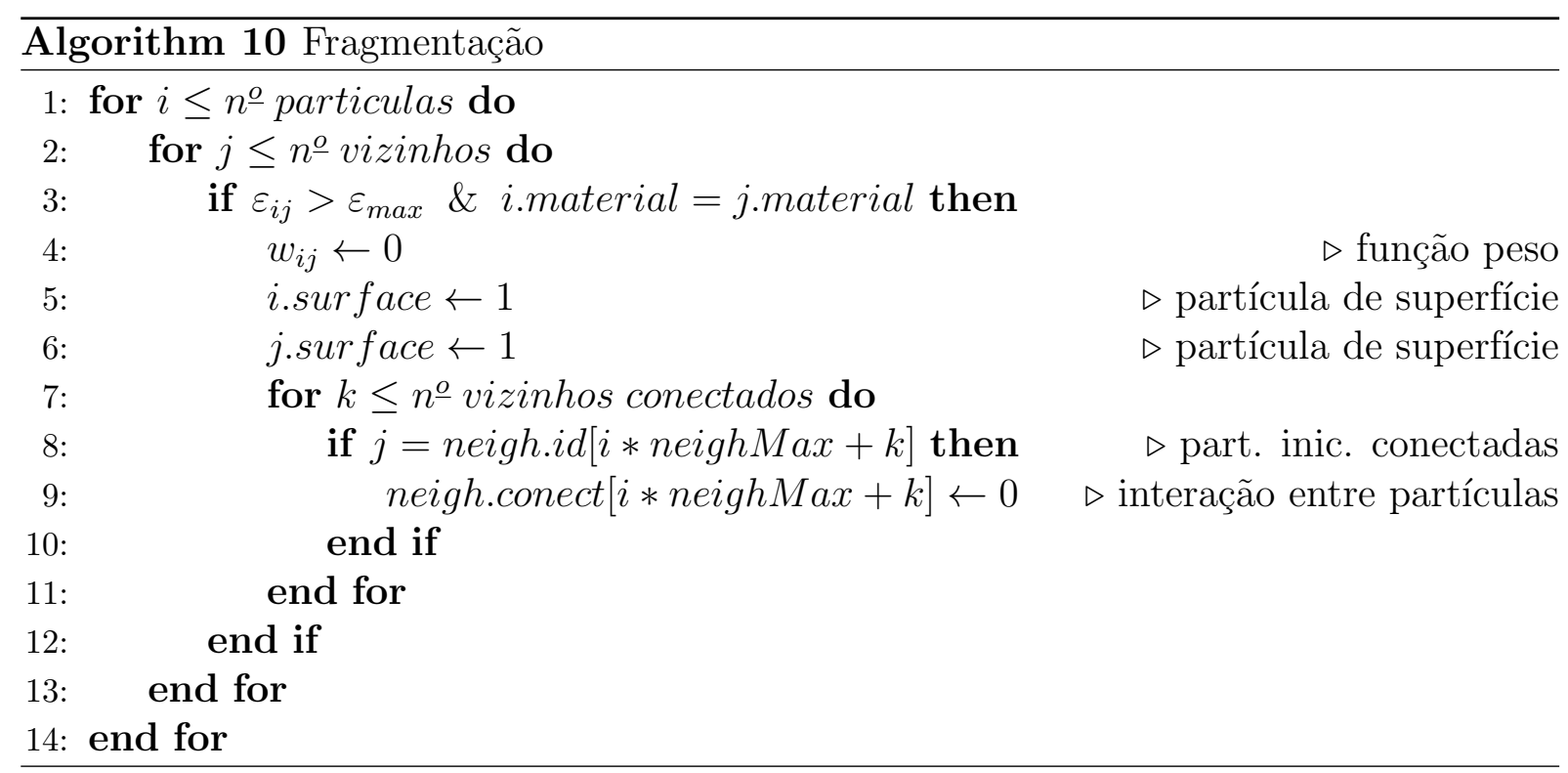

Para verificar colisão entre um par de partículas, primeiramente a função peso e a relação de interação são verificadas. Se as partículas estavam conectadas inicialmente e a função peso entre elas é diferente de zero, significa que as partículas são de superfície pertencentes a um mesmo sólido. Dessa forma, as partículas são tratadas como partículas internas e nenhum tratamento de colisão é utilizado para os cálculos de interação. Se as partículas estavam conectadas inicialmente e a função peso é zero, ocorreu a fragmentação entre essas duas partículas e a interação entre elas é levada em conta apenas quando a distância for menor do que a distância inicial $l_{0}$, ou seja, quando estão em compressão. Com isso, as forças de repulsão evitam a interpenetração das partículas e também evitase o problema de falsa detecção de fragmentação para partículas de superfície que não sofreram fragmentação entre si, mas apenas com outras partículas.

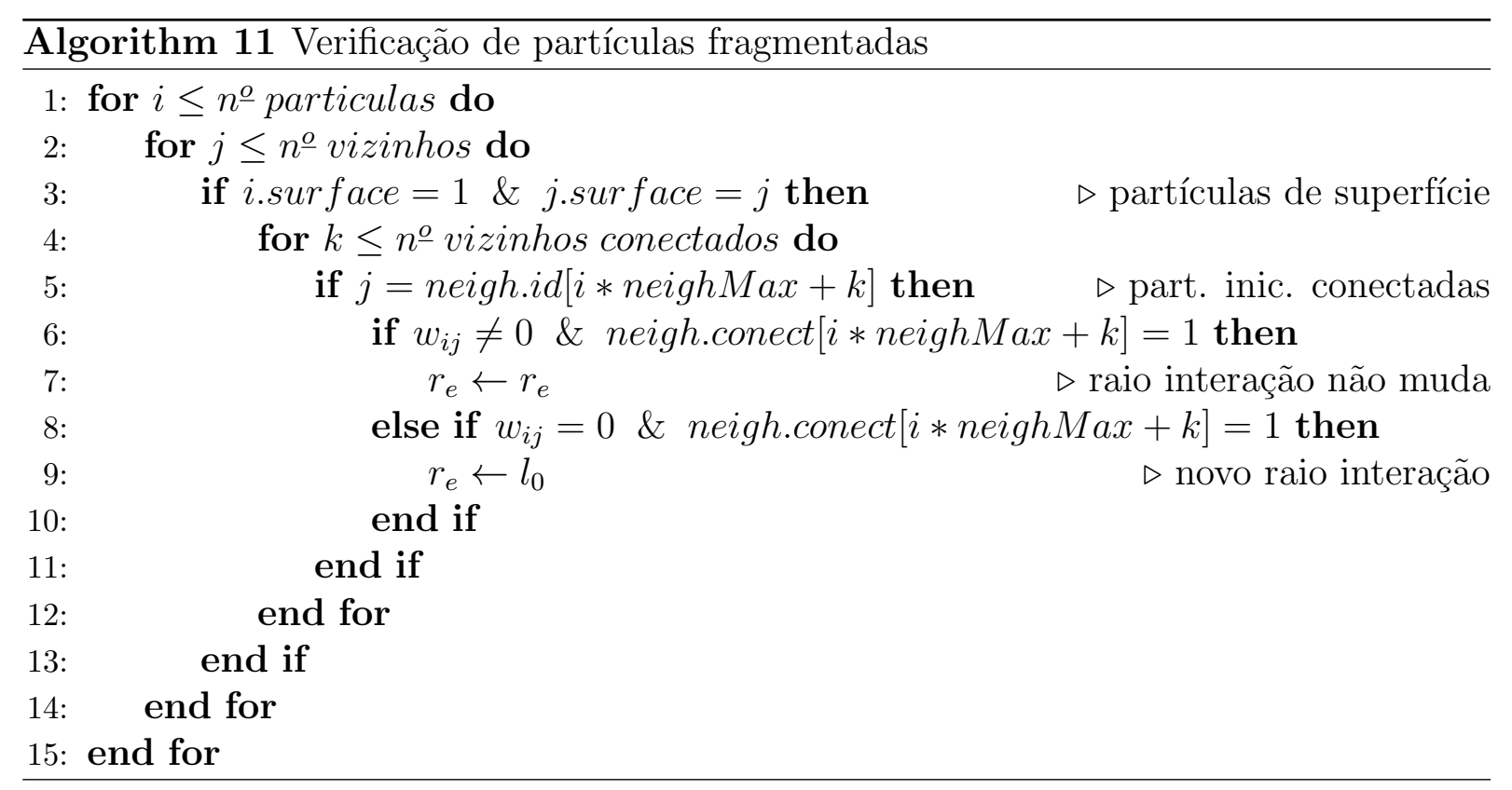




\subsection{Algoritmo interação fluido-estrutura}

A interação entre sólidos e fluidos com base no método MPS é realizado com o acoplamento dos simuladores para sólido e fluido. Uma adaptação necessária é a distinção entre os passos de tempo para sólidos $\Delta t_{\text {solido }}$ e para fluídos $\Delta t_{\text {fluido }}$. Para simulação de fluidos o método é realizado com integrações implícitas e explicitas enquanto que para simulação dinâmica de sólidos, somente a integração explicita é utilizada. Dependendo da frequência de vibração do sólido simulado, o valor de $\Delta t_{\text {solido }}$ deve obedecer a condição de estabilidade Courant-Friedrichs-Lewy (condição CFL) e pode ser menor do que $\Delta t_{\text {fluido. }}$ Para evitar que se utilize o menor passo de tempo para toda simulação, elevando o custo computacional, é realizada a subciclagem do simulador de sólidos. A Figura (4.3) apresenta o processo de subciclagem.

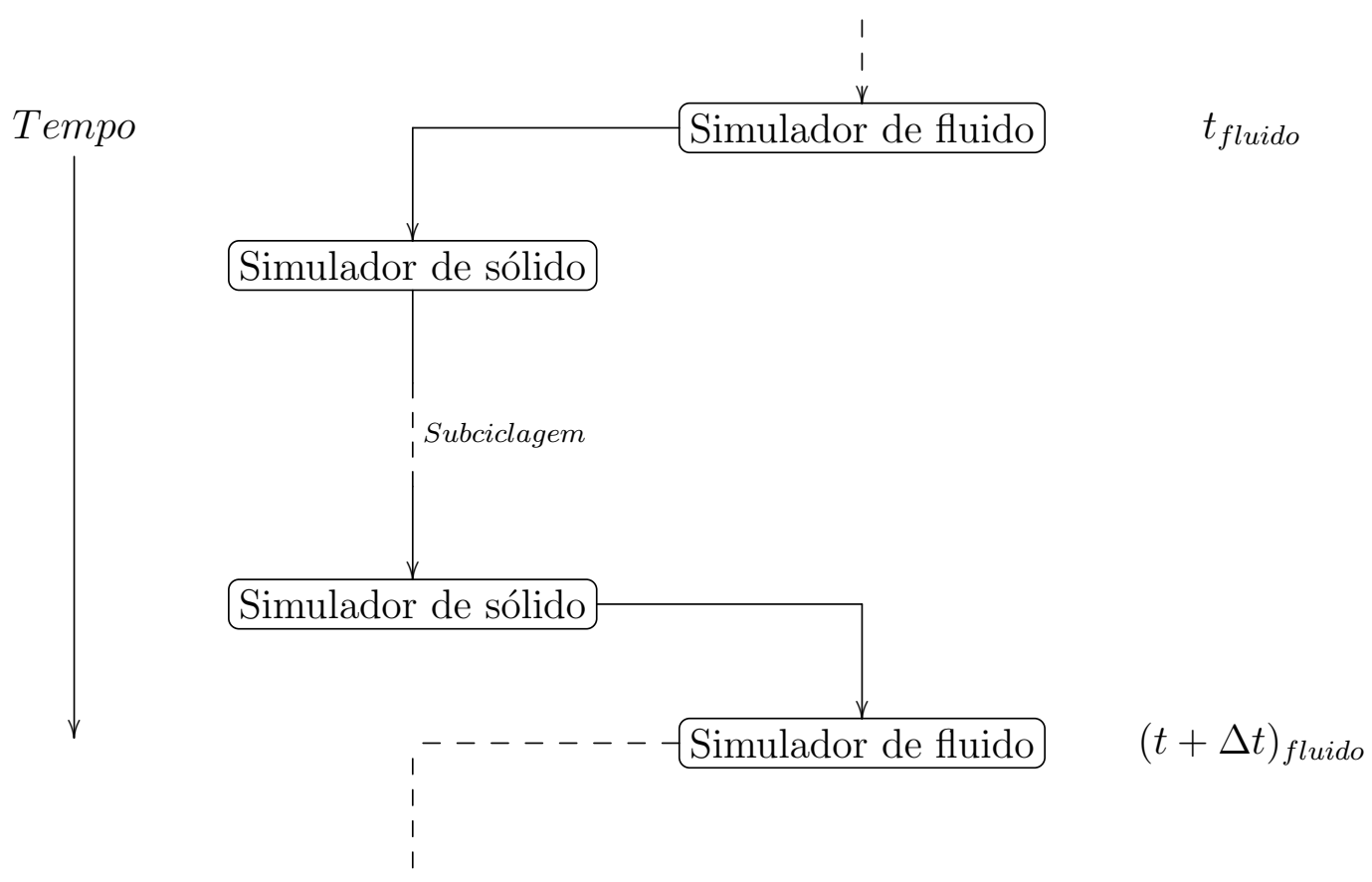

Figura 4.3: Subciclagem para simulação de interação fluido-estrutura.

Após o cálculo das pressões no Simulador de fluido, pela resolução da equação de Poisson para a pressão, os valores de pressão são utilizados como condição de contorno no sólido elástico no Simulador de sólido, através da introdução de uma força externa de volume, como detalhado na seção 3.7. Durante a subciclagem, o valor de pressão é mantido constante. Após a subciclagem, a simulação prossegue para o próximo passo no tempo, realizando aos cálculos no Simulador de fluido.

Deve ser salientado que tanto o algoritmo de fluido, quanto o de sólido, consideram apenas partículas de mesmo tamanho, sem nenhum tratamento para simulação com 
domínios discretizados distintamente, i.e., partículas de fluido com tamanho diferente das partículas de sólido.

\subsection{Condição CFL}

A condição de Courant-Friedrichs-Lewy (condição CFL) (COURANT; FRIEDRICHS; LEWY, 1967), é utilizada como condição de estabilidade numérica para simular os casos apresentados nesse trabalho. A condição CFL adotada para o passo de tempo $\Delta t$ é dada pela seguinte equação

$$
\Delta t<\frac{l_{0} C}{|v|_{\max }}, \quad 0<C \leq 1
$$

onde $|v|_{\max }$ é o valor da velocidade máxima e $C$ o número de Courant.

Para os casos dinâmicos de sólidos elásticos, $|v|_{\max }$ é obtida pela velocidade da onda de propagação elástica transversal do material aproximada por

$$
|v|_{\text {max }} \simeq \sqrt{\frac{E}{\rho}}
$$

Para fluidos, $|v|_{\text {max }}$ é aproximada por

$$
|v|_{\max } \simeq \sqrt{2 g h}
$$

onde $h$ é a altura da coluna de fluido. 


\section{Resultados}

Para validação do método implementado, foram simulados casos envolvendo as condições estática, dinâmica e de fragmentação e modelos hidroelásticos. Os resultados obtidos pelo MPS foram comparados com outros métodos numéricos, soluções analíticas e resultados experimentais presentes na literatura.

\subsection{Estático}

Uma barra tridimensional, apresentada na Figura 5.1, com seção quadrada de lado $b=$ $0.2 \mathrm{~m}$ e comprimento $l=1.0 \mathrm{~m}$, presa na direção longitudinal em uma extremidade e livre na outra, foi submetida a seu peso próprio pela ação da gravidade local. Os valores adotados para as propriedades do material foram: densidade $\rho=1000 \mathrm{~kg} / \mathrm{m}^{3}$, módulo de Young $E=10 \mathrm{MPa}$ e coeficiente de Poisson $\nu=0.3$. Como parâmetros de simulação foram utilizadas distâncias entre partículas $d p=25.0$ (2560 partículas), 20.0 (5000 partículas), 10.0 (4000 partículas) e $5.0 \mathrm{~mm}$ (320000 partículas), correspondendo razões $b / d p=8,10,20$ e 40 , e incremento de tempo $\Delta t=2 \times 10^{-5} s$ para todos as distâncias entre partículas.

As soluções analíticas dos deslocamentos transversais nos eixos $x$ e $y$ obtidas pelas Eqs. (5.1) e (5.2), respectivamente, e deslocamento longitudinal no eixo $z$ obtida pela Eq. (5.3), foram adotadas para comparação com os resultados obtidos pelo MPS.

$$
\begin{gathered}
u_{x}(x, y, z)=-\frac{\nu \rho g}{E} x(l-z) \\
u_{y}(x, y, z)=-\frac{\nu \rho g}{E} y(l-z) \\
u_{z}(x, y, z)=-\frac{\rho g}{2 E} z^{2}+\frac{\nu \rho g}{2 E}\left(x^{2}+y^{2}\right)
\end{gathered}
$$



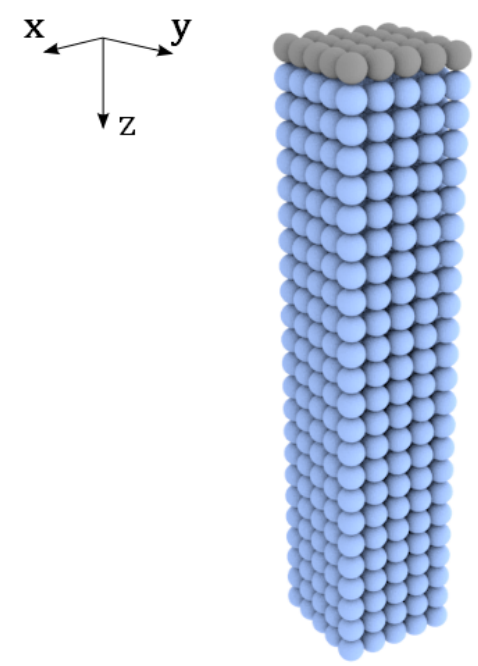

$\vec{g} \downarrow$

$0.2 \times 0.2 \times 1.0 \mathrm{~m}$

$\rho=1000 \mathrm{~kg} / \mathrm{m}^{3}$

$\mathrm{E}=10 \mathrm{MPa}$

$v=0.3$

\section{Engaste}

Figura 5.1: Caso estático de barra tridimensional.

Devido o caráter dinâmico da simulação obtida pelo método implementado, a função $g(t)$, obtida pela Eq. (5.4), foi aplicada na barra simulando aumento gradativo da ação da gravidade, como apresentado na Figura 5.2. Desta forma, estabilizado o comportamento da barra, pode-se comparar os resultados obtidos pelo MPS com os resultados analíticos para casos estáticos.

$$
g(t)=\left\{\begin{array}{cc}
G\left[0.5-0.5 \cos \left(5 \pi \frac{t}{T}\right)\right], & t \leq 0.2 T \\
G, & t>0.2 T
\end{array}\right.
$$

onde $G$ é o valor da gravidade igual a $9.81 \mathrm{~m} / \mathrm{s}^{2}$.

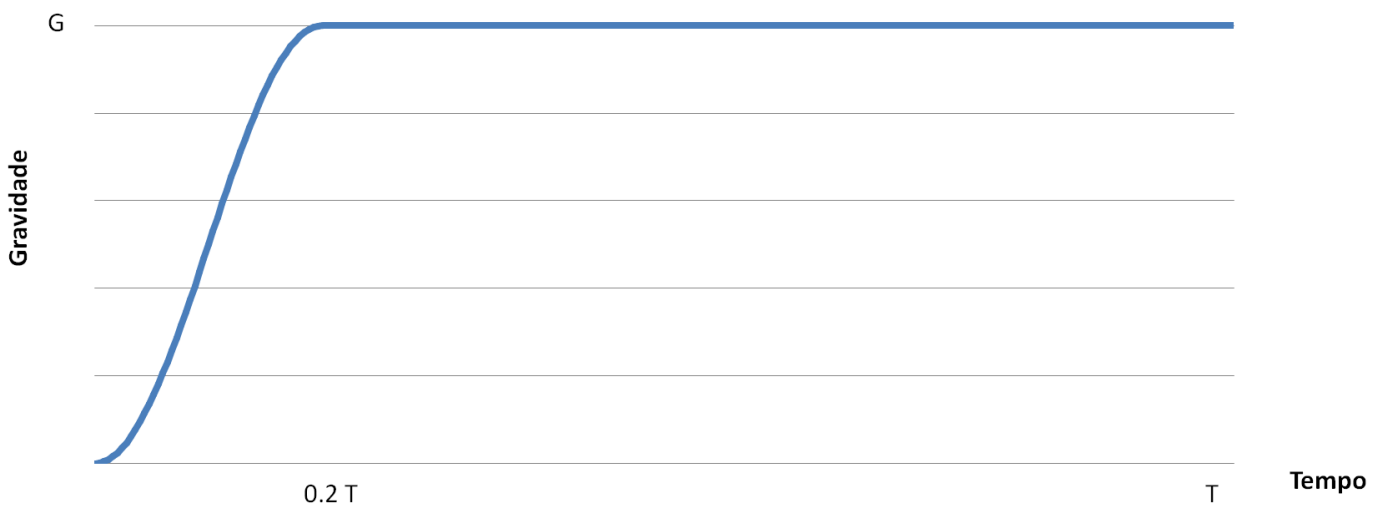

Figura 5.2: Função gravidade.

A Figura 5.3 apresenta os resultados do deslocamento $u_{x}(x, y, z)$ e a Figura 5.4 os 
resultados do deslocamento $u_{z}(x, y, z)$, considerando as diferentes distâncias de partículas adotadas e a solução analítica, onde o eixo horizontal corresponde à direção $z$ ao longo do comprimento da barra e o eixo vertical representa os deslocamentos. Tomando como origem dos eixos o centro da seção quadrada da barra no plano preso na direção longitudinal, o deslocamento $u_{x}(x, y, z)$ foi obtido na posição $x=0.1 m$ e o deslocamento $u_{z}(x, y, z)$ foi obtido na posição $x=0.1, y=0.0 \mathrm{~m}$. A seguinte equação foi adotada para o cálculo da discrepância entre os resultados do MPS e a solução analítica

$$
\text { Discrepância }=\max \left|\frac{\left(\left|x_{\text {analitico }}\right|-\left|x_{\text {mps }}\right|\right)}{\max \left|x_{\text {analitico }}\right|}\right| \times 100
$$

onde $x_{\text {analitico }}$ e $x_{m p s}$ são os valores obtidos pela solução analítica e MPS, respectivamente.

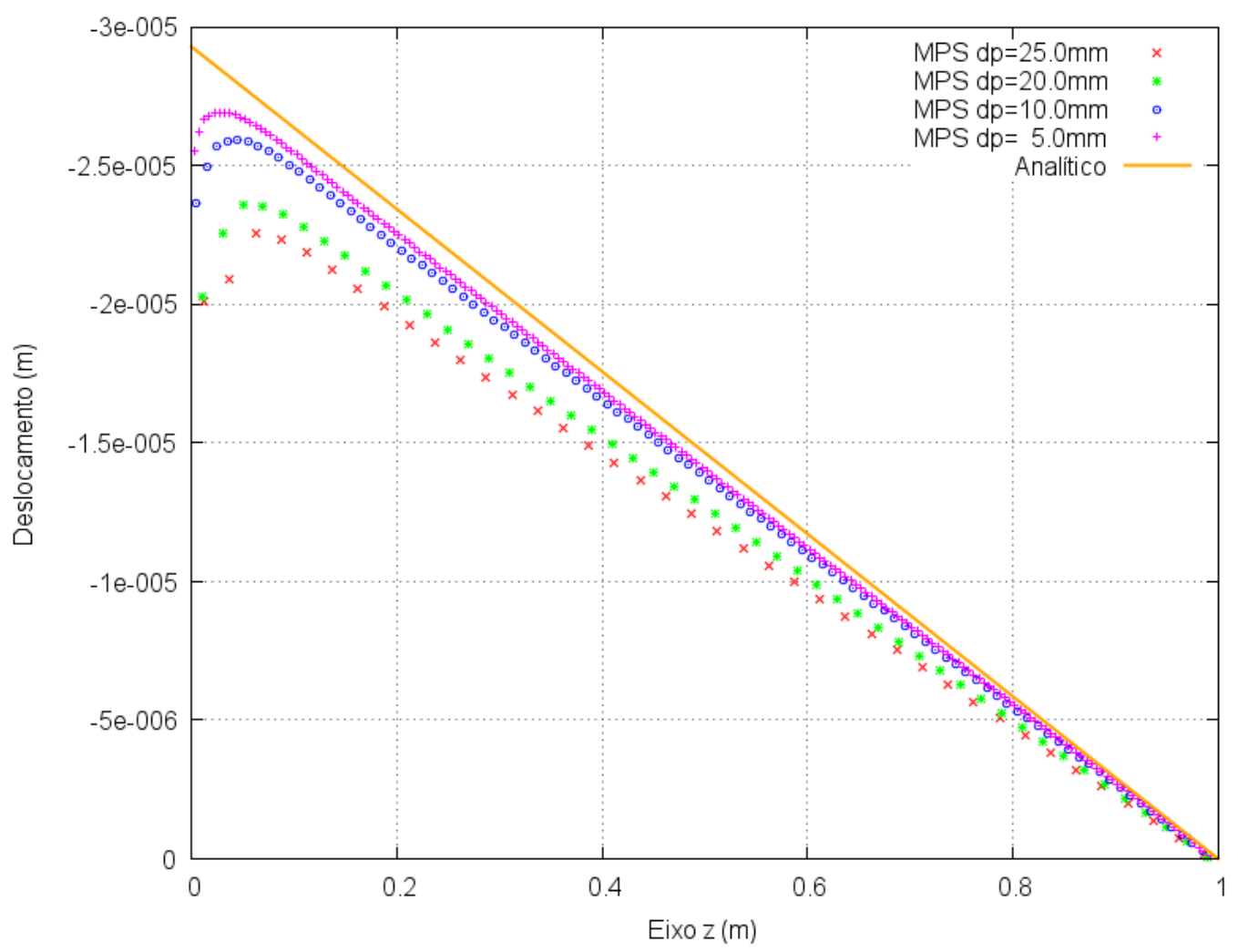

Figura 5.3: Deslocamento transversal $u_{x}(x, y, z)$.

Pela Tabela 5.1, nota-se que a resolução influência diretamente os resultados do MPS, aproximando-os da solução analítica quando o espaçamento entre as partículas é reduzido. Para uma razão $b / d p=40$ as discrepâncias apresentam valores abaixo de $4.71 \%$, garantindo uma boa aproximação, considerando casos estáticos. A condição de contorno para o modelo numérico, foi de restrição na direção longitudinal da barra, sem imposição de tensões nulas. Com isso, uma diferença pode ser observada no gráfico da Figura 5.3, onde 


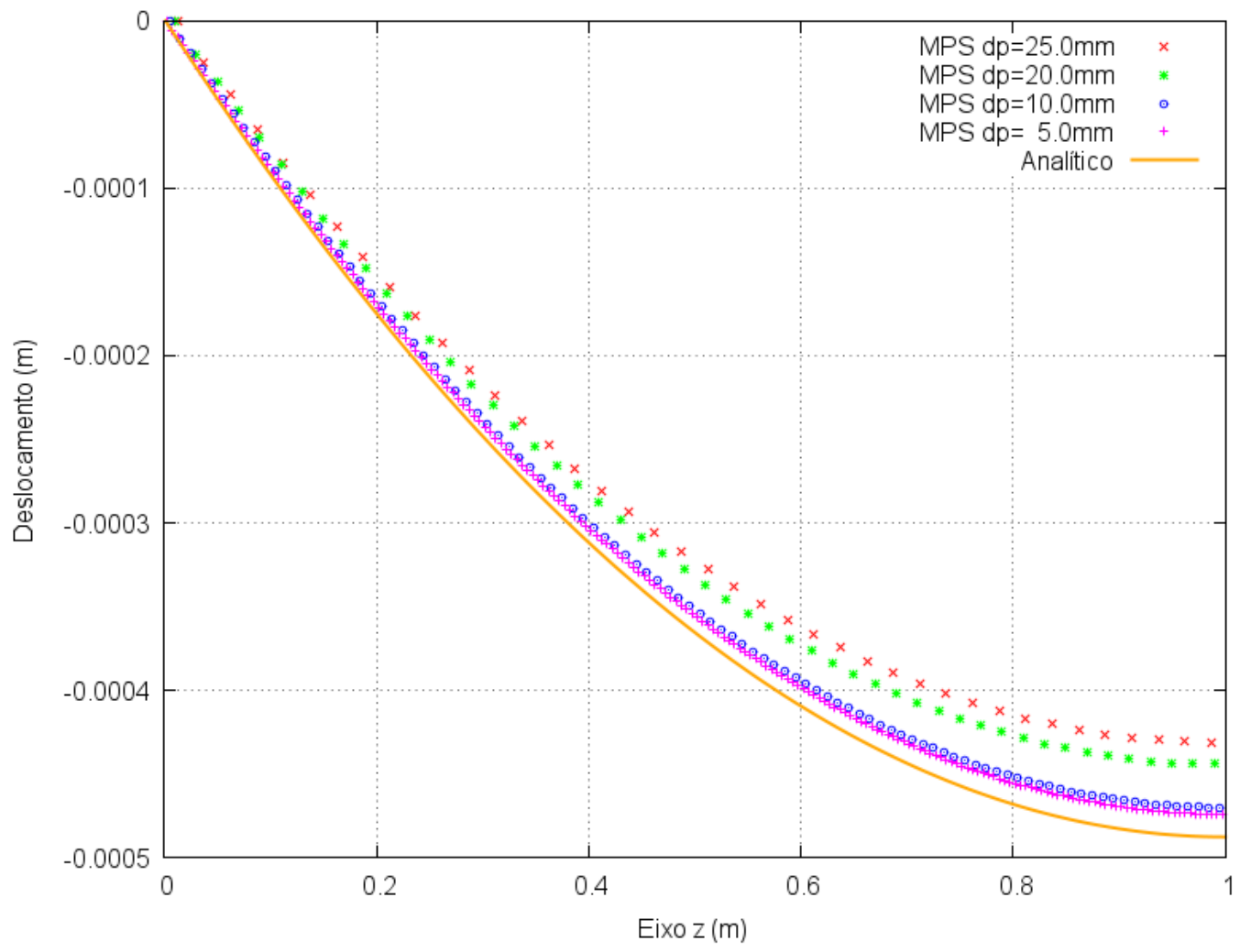

Figura 5.4: Deslocamento longitudinal $u_{z}(x, y, z)$.

os deslocamentos transversais para os pontos em $z<0.1 m$ se afastam da tendência da solução analítica. Apesar dessa diferença, os resultados numérico e analítico se aproximam fora dessa região. Esses pontos não foram considerados no cálculo da discrepância.

Tabela 5.1: Discrepância MPS x Analítico.

\begin{tabular}{cccc}
\hline$d p(\mathrm{~mm})$ & $b / d p$ & Discrepância $u_{x}(\%)$ & Discrepância $u_{z}(\%)$ \\
\hline \hline 25.0 & 8 & 18.48 & 11.86 \\
20.0 & 10 & 16.05 & 9.20 \\
10.0 & 20 & 7.83 & 3.88 \\
5.0 & 40 & 4.71 & 3.06 \\
\hline
\end{tabular}




\subsection{Dinâmico}

Uma viga tridimensional de comprimento $l=1.0 \mathrm{~m}$ e seção quadrada de lado $b=0.225 \mathrm{~m}$, apresentada na Figura 5.5, bi-engastada, foi submetida a seu peso próprio pela ação da gravidade. Os valores adotados para as propriedades do material foram: densidade $\rho=1000 \mathrm{~kg} / \mathrm{m}^{3}$, módulo de Young $E=6 \mathrm{MPa}$ e coeficiente de Poisson $\nu=0.3$. Como parâmetros de simulação para o MPS foram utilizados: distância entre partículas $d p=25.0$ (3240 partículas), 15.0 (14850 partículas), 9.0 (69375 partículas) e $5.0 \mathrm{~mm}$ (405000 partículas), apresentando razões $b / d p=9,15,25$ e 45, e incremento de tempo $\Delta t=2 \times 10^{-5} s$ para todas as distâncias entre partículas.

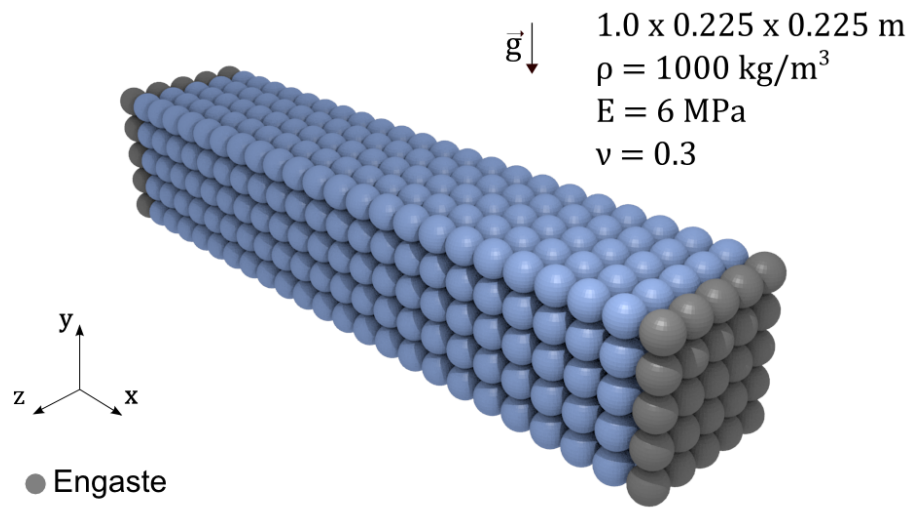

Figura 5.5: Viga bi-engastada.

Pela adoção de dimensões consideráveis da seção transversal em relação ao comprimento da viga, as deformações dos esforços cortantes devem ser considerados neste caso. Como solução analítica para comparação com o modelo MPS, o modelo de viga foi baseado na Teoria de Timoshenko (Timoshenko, 1921). Desta forma, a equação da linha elástica $(h)$ de uma viga bi-engastada, de seção retangular e submetida a uma carga distribuída $(\omega)$ em função da posição $(x)$ ao longo do seu comprimento é dada por (GHUGAL; SHARMA, 2011)

$$
h(x)=\frac{\omega l^{4}}{24 E I}\left(\frac{x^{4}}{l^{4}}-2 \frac{x^{3}}{l^{3}}+\frac{x^{2}}{l^{2}}\right)+\frac{3}{5} \frac{\omega l^{2}}{G A}\left[\frac{x}{l}-\frac{x^{2}}{l^{2}}-\frac{\cosh (\lambda l / 2)-\cosh \lambda(l / 2-x)}{\lambda l \sinh (\lambda l / 2)}\right]
$$

onde $I$ é o momento de inércia de área da seção transversal, $l$ o comprimento e $G$ o módulo de cisalhamento dado por

$$
G=\frac{E}{2(1-\nu)}
$$


Para obtenção da constante $\lambda$, a seguinte equação é apresentada no trabalho de Ghugal e Sharma (2011)

$$
\lambda^{2}=\frac{0.00874}{0.1024} \frac{G A}{E I}
$$

A amplitude máxima $h_{\max }$ no centro da viga $(x=l / 2)$ obtido pela Eq. (5.6) é dado por

$$
h(x)=\frac{\omega l^{4}}{384 E I}\left[1+9.6(1+\nu) \frac{b^{2}}{l^{2}}\right]
$$

onde $b$ é o lado da seção transversal.

A linha elástica da viga obtida pelo MPS, com diferentes distâncias entre partículas, e solução analítica, pode ser vista na Figura (5.6).

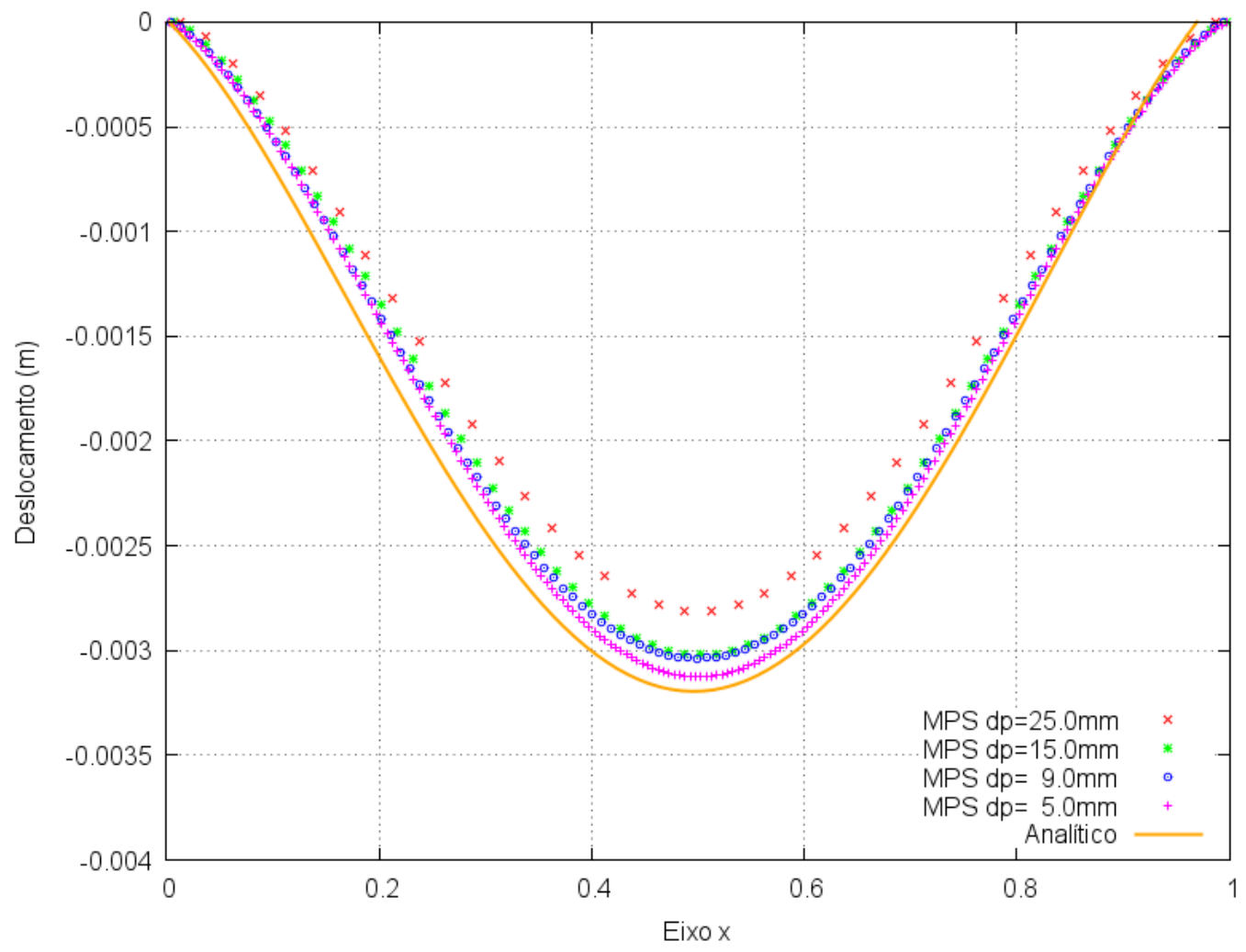

Figura 5.6: Linha elástica da viga.

A frequência natural $f$ e período $T$ do primeiro modo de vibração da viga, obtidos com o MPS, foram comparados com os valores obtidos pelas soluções analíticas, considerando a teoria de Timoshenko e apresentadas pelas seguintes equações (LEE; SCHULTZ, 2004) 


$$
\begin{gathered}
f=\frac{4.157^{2}}{2 \pi l^{2}} \sqrt{\frac{E I}{m}} \\
T=\frac{1}{f}
\end{gathered}
$$

onde $m$ é a massa da viga.

A Figura 5.7 apresenta os gráficos obtidos pelos 2 métodos. A Tabela 5.2 contém os resultados do período natural, frequência e amplitude máxima e a tabela 5.3 apresenta as discrepâncias, nos casos de comparação MPS x Solução Analítica, obtidos pela Eq. (5.5).

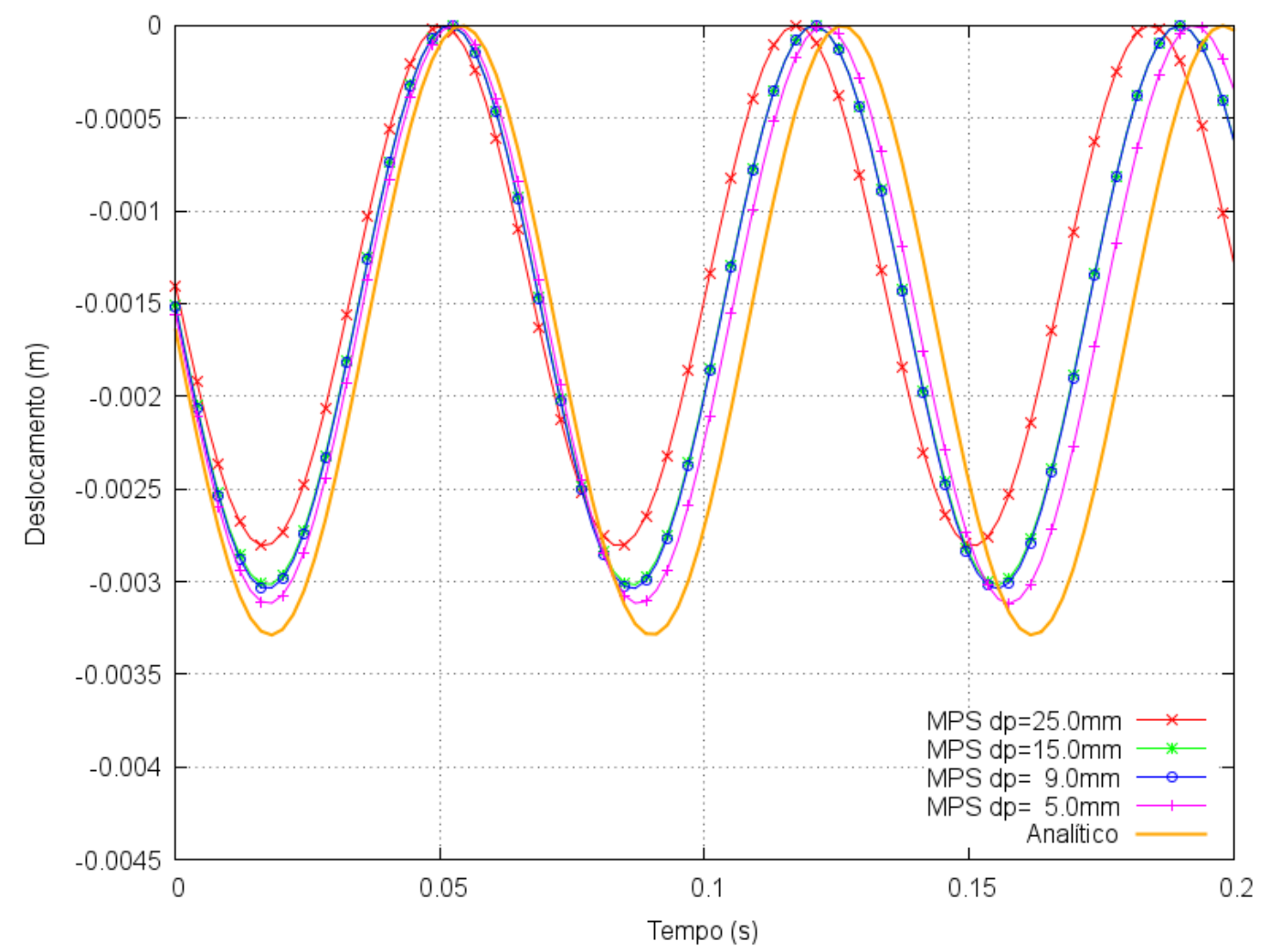

Figura 5.7: Amplitude do primeiro modo de vibração.

Tabela 5.2: Resultados do primeiro modo de vibração.

\begin{tabular}{cccc}
\hline Modelo & Período natural $(\mathrm{s})$ & Frequência $(\mathrm{Hz})$ & Amplitude máxima $(\mathrm{m})$ \\
\hline \hline MPS $(\mathrm{dp}=25.0 \mathrm{~mm})$ & 0.067 & 14.93 & -0.00281 \\
MPS $(\mathrm{dp}=15.0 \mathrm{~mm})$ & 0.069 & 14.49 & -0.00302 \\
MPS $(\mathrm{dp}=9.0 \mathrm{~mm})$ & 0.069 & 14.49 & -0.00304 \\
MPS $(\mathrm{dp}=5.0 \mathrm{~mm})$ & 0.070 & 14.29 & -0.00312 \\
Analítico & 0.072 & 13.83 & -0.00329 \\
\hline
\end{tabular}

Pela Tabela 5.3 nota-se que o resultados do período e frequência natural obtidos pelo MPS apresentaram uma pequena discrepância para razão $b / d p=45$, com diferenças rela- 
tivas abaixo de $3.40 \%$ comparados com a solução analítica. A amplitude máxima obtida pelo MPS apresentou diferenças abaixo de $5.20 \%$ para a razão $b / d p=45$, demonstrando uma boa concordância e a convergência do MPS para a simulação dinâmica.

Tabela 5.3: Discrepância.

\begin{tabular}{ccccc}
\hline$d p(\mathrm{~mm})$ & $b / d p$ & $T(\%)$ & $f(\%)$ & $h_{\max }(\%)$ \\
\hline \hline 25.0 & 9 & 7.94 & 6.94 & 14.59 \\
15.0 & 15 & 4.77 & 4.17 & 8.21 \\
9.0 & 25 & 4.77 & 4.17 & 7.60 \\
5.0 & 45 & 3.33 & 2.78 & 5.17 \\
\hline
\end{tabular}




\subsection{Colisão}

Uma colisão entre três sólidos diferentes foi simulada para demonstrar qualitativamente a capacidade do MPS para diferentes situações dinâmicas envolvendo sólidos elásticos. O arranjo inicial do caso é apresentado na Figura 5.8. As propriedades dos sólidos estão especificadas na Tabela 5.4. Como parâmetros de simulação foram utilizados: distância entre partículas $d p=25.0 \mathrm{~mm}$ (18560 partículas) e incremento de tempo $\Delta t=10^{-6} \mathrm{~s}$.

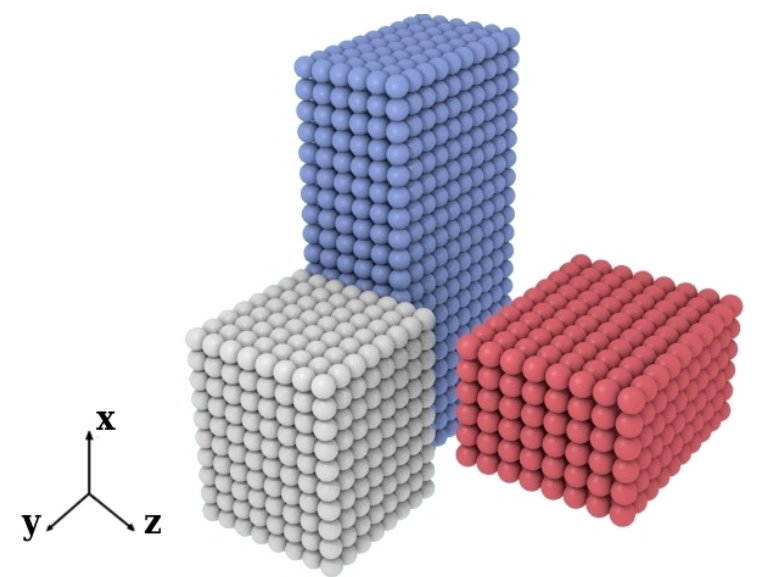

Figura 5.8: Condições inciais do caso de colisão.

Tabela 5.4: Propriedades.

\begin{tabular}{ccccccc}
\hline Sólido & $\mathrm{x}(\mathrm{m})$ & $\mathrm{y}(\mathrm{m})$ & $\mathrm{z}(\mathrm{m})$ & $\rho\left(\mathrm{kg} / \mathrm{m}^{3}\right)$ & $\mathrm{E}(\mathrm{MPa})$ & $\nu$ \\
\hline \hline Cinza & 0.5 & 0.4 & 0.4 & 1000 & 0.35 & 0.45 \\
\hline Azul & 1.0 & 0.5 & 0.3 & 960 & 20 & 0.40 \\
\hline Vermelho & 0.3 & 0.5 & 0.4 & 960 & 0.3 & 0.47 \\
\hline
\end{tabular}

Neste exemplo, o sólido de cor vermelha é submetido a uma velocidade inicial de $5 \mathrm{~m} / \mathrm{s}$ na direção do eixo $z$ e no sentido dos outros sólidos cinza e azul, inicialmente parados. Os resultados da simulação estão apresentados por uma sequência de quadros durante $0.3 \mathrm{~s}$ nas Figuras 5.9 e 5.10. O sólido vermelho colide na parte central, em relação ao eixo $x$, e esquerda, em relação ao eixo $y$, do sólido azul. Desta forma, o sólido azul rotaciona em torno do eixo $x$ e se deforma em torno do eixo $y$. O sólido cinza é atingido na sua parte superior, em relação ao eixo $x$, e direita, em relação ao eixo $y$. Assim, ele rotaciona em torno do eixo $x$ e $y$, uma composição de rotações. Sua deformação acontece também em torno desses dois eixos. O sólido vermelho sofre um torque significativo em torno do eixo $x$ e um pequeno torque em torno do eixo $y$ devido ao local da sua colisão com o sólido cinza. Com isso, a rotação em torno de $x$ é bem mais evidente do que em torno de $y$. Devido a maior elasticidade do sólido azul, esse se deforma mais do que os outros sólidos. Em contrapartida, os outros sólidos rotacionam mais do que o sólido azul. 


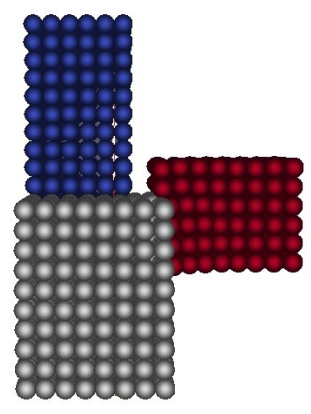

$t=0.05 s$

$$
t=0.05 \mathrm{~s}
$$

$$
t=0.15 s
$$

Figura 5.9: Colisão entre os sólidos elásticos de $0.05 \mathrm{~s}$ até $0.15 \mathrm{~s}$. 


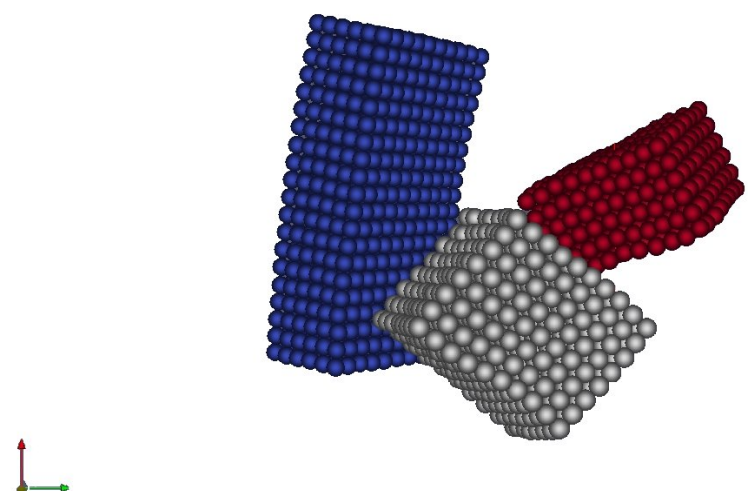

$$
t=0.20 \mathrm{~s}
$$

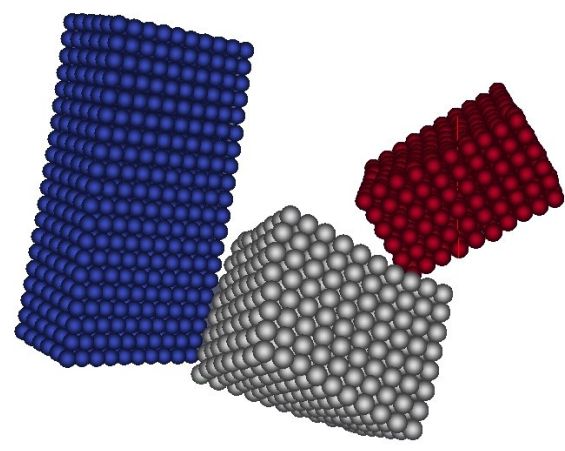

$\downarrow$

$$
t=0.25 \mathrm{~s}
$$

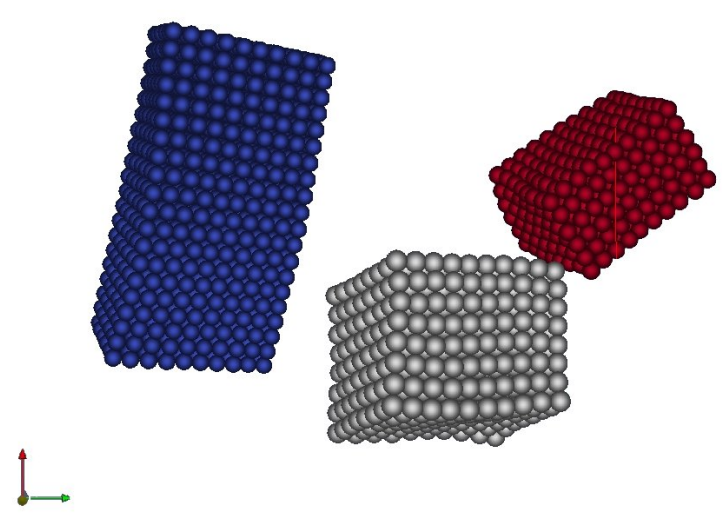

$$
t=0.30 \mathrm{~s}
$$

Figura 5.10: Colisão entre os sólidos elásticos de $0.20 \mathrm{~s}$ até $0.30 \mathrm{~s}$. 


\subsection{Fragmentação}

A Figura 5.11 apresenta as condições inciais de um caso de colisão entre dois sólidos elásticos, com condição de fragmentação adotada nas suas propriedades. As propriedades dos sólidos estão especificadas na Tabela 5.5. Como parâmetros de simulação foram utilizados: distância entre partículas $d p=50.0 \mathrm{~mm}$ e incremento de tempo $\Delta t=10^{-6} \mathrm{~s}$. O limite máximo de fratura foi adotado como $\varepsilon_{\max }=0.2$.

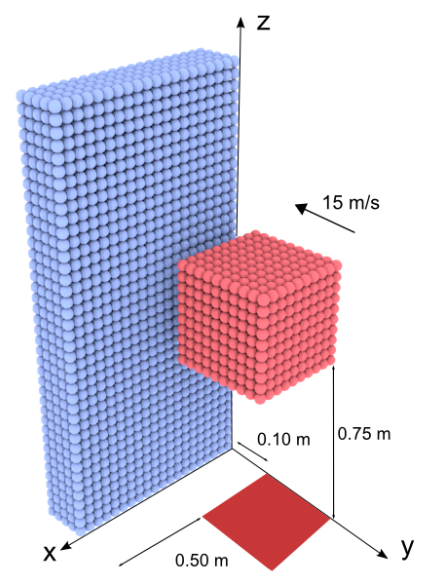

Figura 5.11: Condições iniciais do caso de fragmentação.

Tabela 5.5: Propriedades.

\begin{tabular}{ccccccc}
\hline Sólido & $\mathrm{x}(\mathrm{m})$ & $\mathrm{y}(\mathrm{m})$ & $\mathrm{z}(\mathrm{m})$ & $\rho\left(\mathrm{kg} / \mathrm{m}^{3}\right)$ & $\mathrm{E}(\mathrm{MPa})$ & $\nu$ \\
\hline \hline Salmão & 0.5 & 0.5 & 0.5 & 1000 & 6.0 & 0.3 \\
\hline Azul & 1.0 & 0.25 & 2.0 & 1000 & 10 & 0.3 \\
\hline
\end{tabular}

As Figuras 5.12 e 5.13 apresentam alguns quadros obtidos das simulações. A coluna da esquerda apresenta a simulação sem o algoritmo de detecção de contato, proposto na seção 3.6, e a coluna da direita apresenta a simulação com a aplicação do algoritmo. Inicialmente o cubo é submetido a uma velocidade de $-15 \mathrm{~m} / \mathrm{s}$ na direção do eixo y no sentido do bloco azul, inicialmente parado. A colisão entre os sólidos ocorre após $0.07 s$, aproximadamente. Logo após a fragmentação no bloco azul atingir sua lateral esquerda no instante $0.60 s$ e dividir o bloco em 2 sólidos, uma colisão é detectada nas faces resultantes da fragmentação, como pode ser observado no instante $0.70 \mathrm{~s}$. No instante $1.00 s$ pode ser observado o início da separação entre as partes fragmentadas, devido a colisão, para a simulação envolvendo a detecção de contato. A simulação com detecção de contato prossegue normalmente, com as partes fraturadas se afastando e a rotação do cubo devido ao contato com o bloco. Por outro lado, quando o algoritmo de detecção de contato não é aplicado, o contato entre as superfícies das partes fragmentadas não é 
detectado no instante $1.00 \mathrm{~s}$ e uma nova colisão ocorre no instante $1.70 \mathrm{~s}$. Por causa da ausência de detecção e tratamento de contato ocorrido, ocorre a interpenetração de partículas, a simulação diverge e é interrompida no instante $1.90 \mathrm{~s}$.
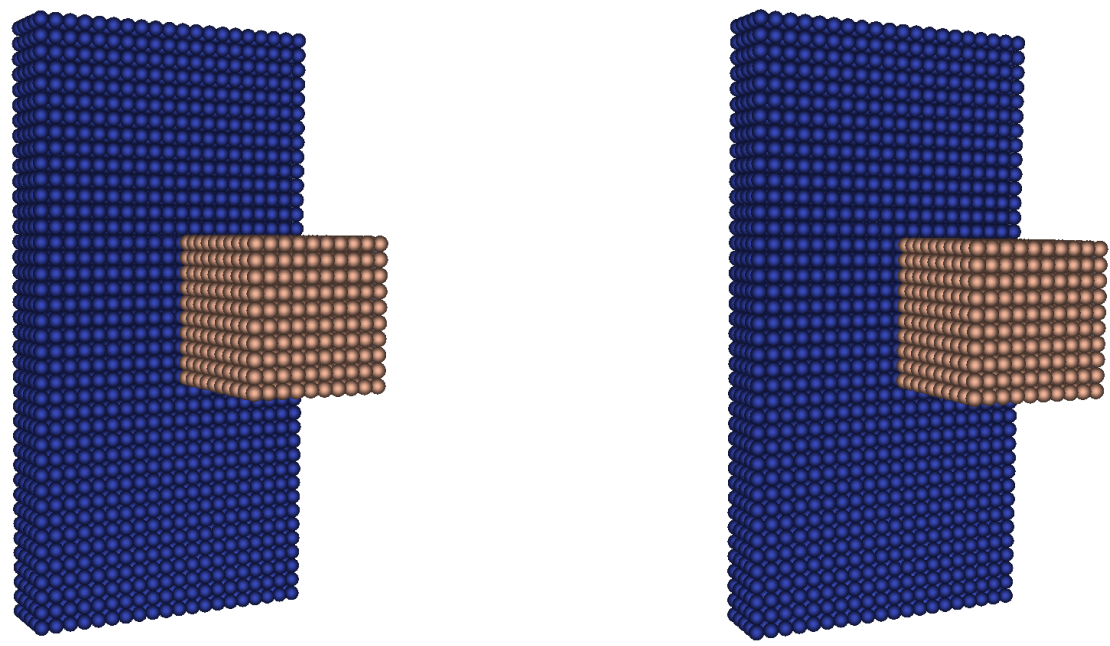

$t=0.07 s$
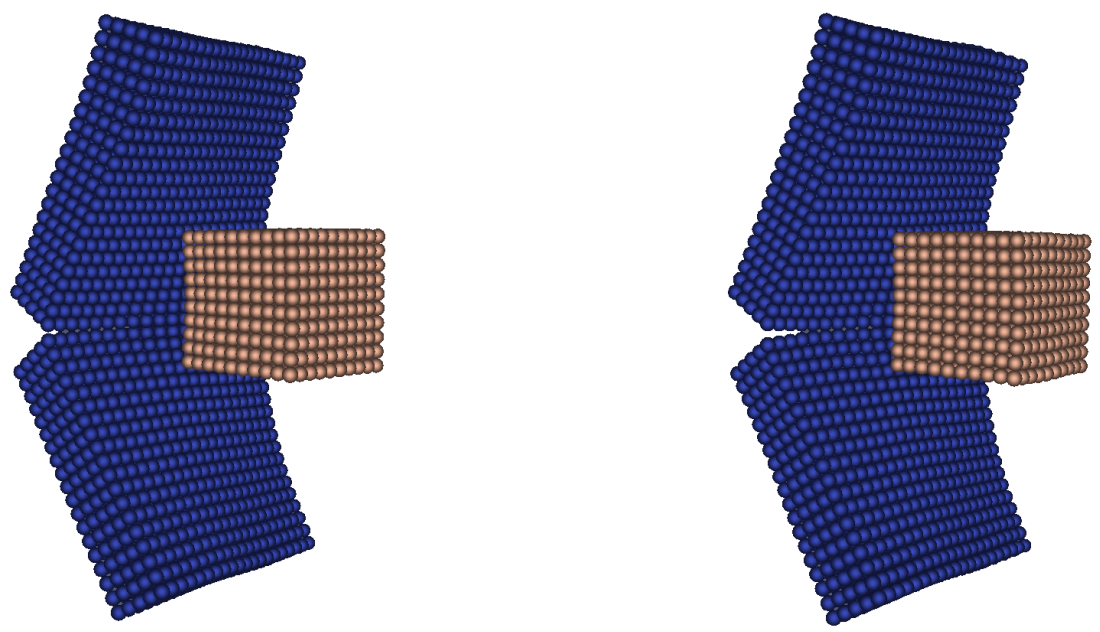

$t=0.60 \mathrm{~s}$
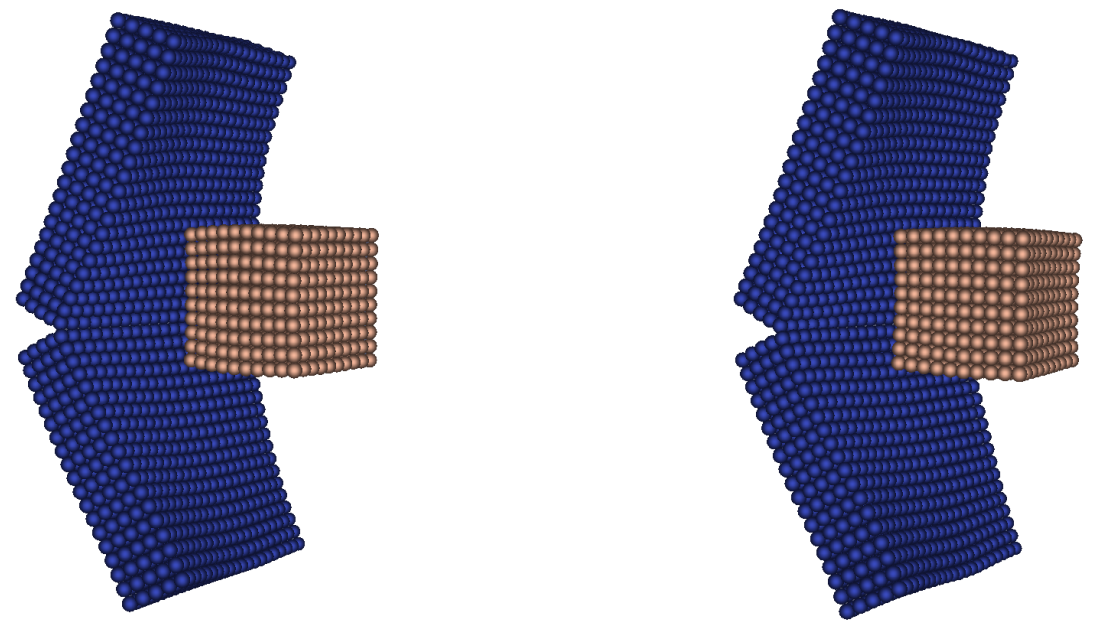

$t=0.70 \mathrm{~s}$

Figura 5.12: Esquerda: sem detecção de contato, Direita: com detecção de contato. 

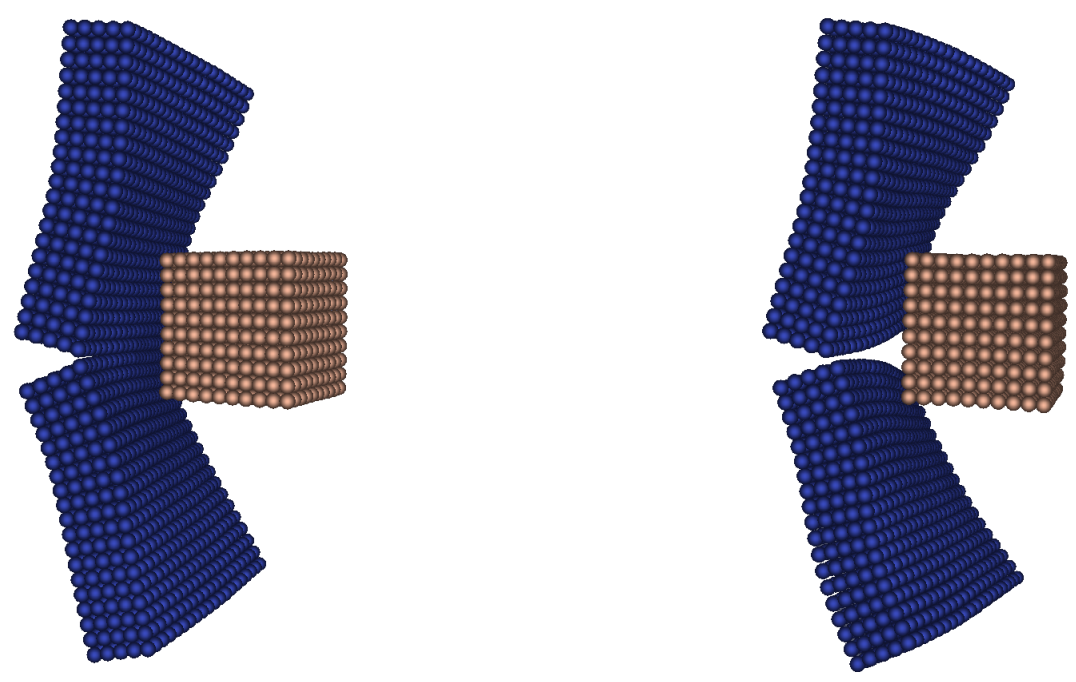

$t=1.00 \mathrm{~s}$
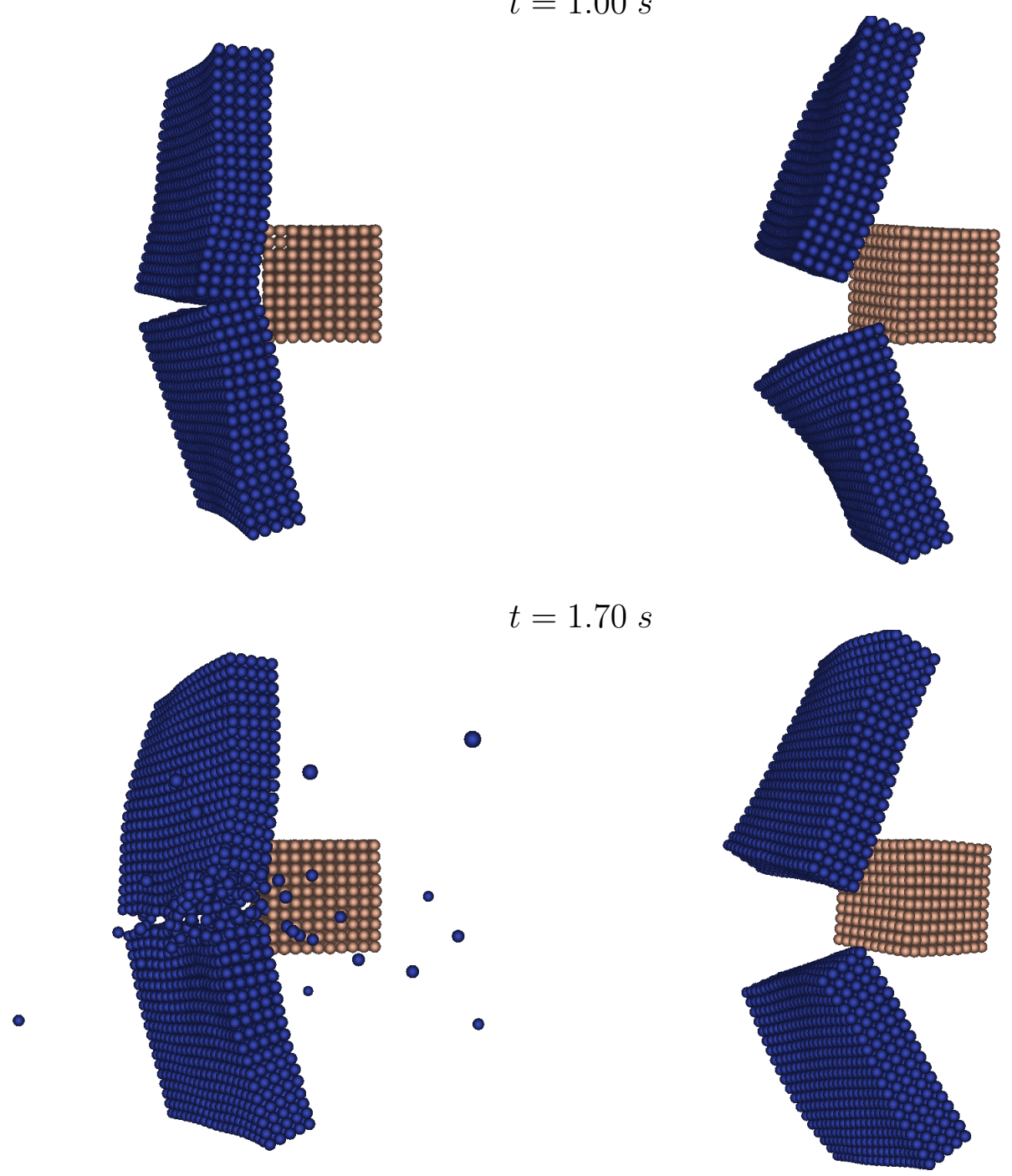

$$
t=1.90 \mathrm{~s}
$$

Figura 5.13: Esquerda: sem detecção de contato, Direita: com detecção de contato. 


\subsection{Interação fluido-estrutura}

Para avaliar a interação fluido-estrutura com o MPS, três casos foram analisados. O primeiro caso apresenta um problema de dam break 2D, onde uma coluna d'água é submetida a ação da gravidade. Neste caso a coluna d'água colapsa com uma placa elástica e o deslocamento horizontal da placa obtido pelo MPS é comparado com valores encontrados na literatura, obtidos por outros métodos. O segundo caso, consiste em uma coluna d'água confinada entre duas paredes verticais, sendo que uma parede possui uma placa elástica, possibilitando a saída de água. Os valores de deslocamento horizontal e vertical da placa elástica e altura da coluna d'água, obtidos pelo MPS, são comparados com os valores experimentais apresentados no trabalho de Antoci, Gallati e Sibilla (2007) e método numérico apresentado no trabalho de Yang, Jones e McCue (2012). No terceiro caso, um fluido é movimentado no interior de um tanque (sloshing), interagindo com uma placa elástica engastada. Para esse caso foram simuladas duas alturas de fluido. Os resultados de deslocamento horizontal obtidos pelo MPS, foram comparados com os valores disponibilizados pelo experimento realizado por Idelsohn et al. (2008a).

\subsubsection{Coluna d'água em placa elástica}

Este exemplo apresenta um problema dam break 2D semelhante ao trabalho investigado por Koshizuka, Oka e Tamako (1995), utilizando uma barreira rígida. Ao invés da barreira rígida, neste trabalho é utilizado uma placa elástica engastada, possibilitando a investigação de interação hidroelástica. A geometria inicial do problema é apresentada na Figura 5.14, sendo que a placa elástica, destacada em laranja, possui as dimensões 1.2 x $8.0 \mathrm{~cm}$. Os valores adotados para as propriedades da placa elástica foram: densidade $\rho=2500 \mathrm{~kg} / \mathrm{m}^{3}$, módulo de Young $E=1 \mathrm{MPa}$ e coeficiente de Poisson $\nu=0.0$; e para o fluído foram: densidade $\rho=1000 \mathrm{~kg} / \mathrm{m}^{3}$ e viscosidade $v=10^{-6} \mathrm{~m}^{2} / \mathrm{s}$. Os parâmetros de simulação apresentados na Tabela 5.6 foram utilizados nas simulações.

Tabela 5.6: Parâmetros de simulação.

\begin{tabular}{ccccc}
\hline$d p(\mathrm{~mm})$ & $\Delta t_{\text {fluido }}(\mathrm{s})$ & $\Delta t_{\text {solido }}(\mathrm{s})$ & Partículas de fluido & Partículas de sólido \\
\hline \hline 3.00 & $10^{-4}$ & $10^{-6}$ & 4656 & 108 \\
1.50 & $10^{-4}$ & $10^{-6}$ & 19208 & 440 \\
0.50 & $10^{-5}$ & $10^{-6}$ & 170527 & 3840 \\
\hline
\end{tabular}

As Figuras 5.15, 5.16 e 5.17 apresentam a evolução temporal dos deslocamentos horizontais do topo da barreira elástica com o MPS para distâncias entre partículas 


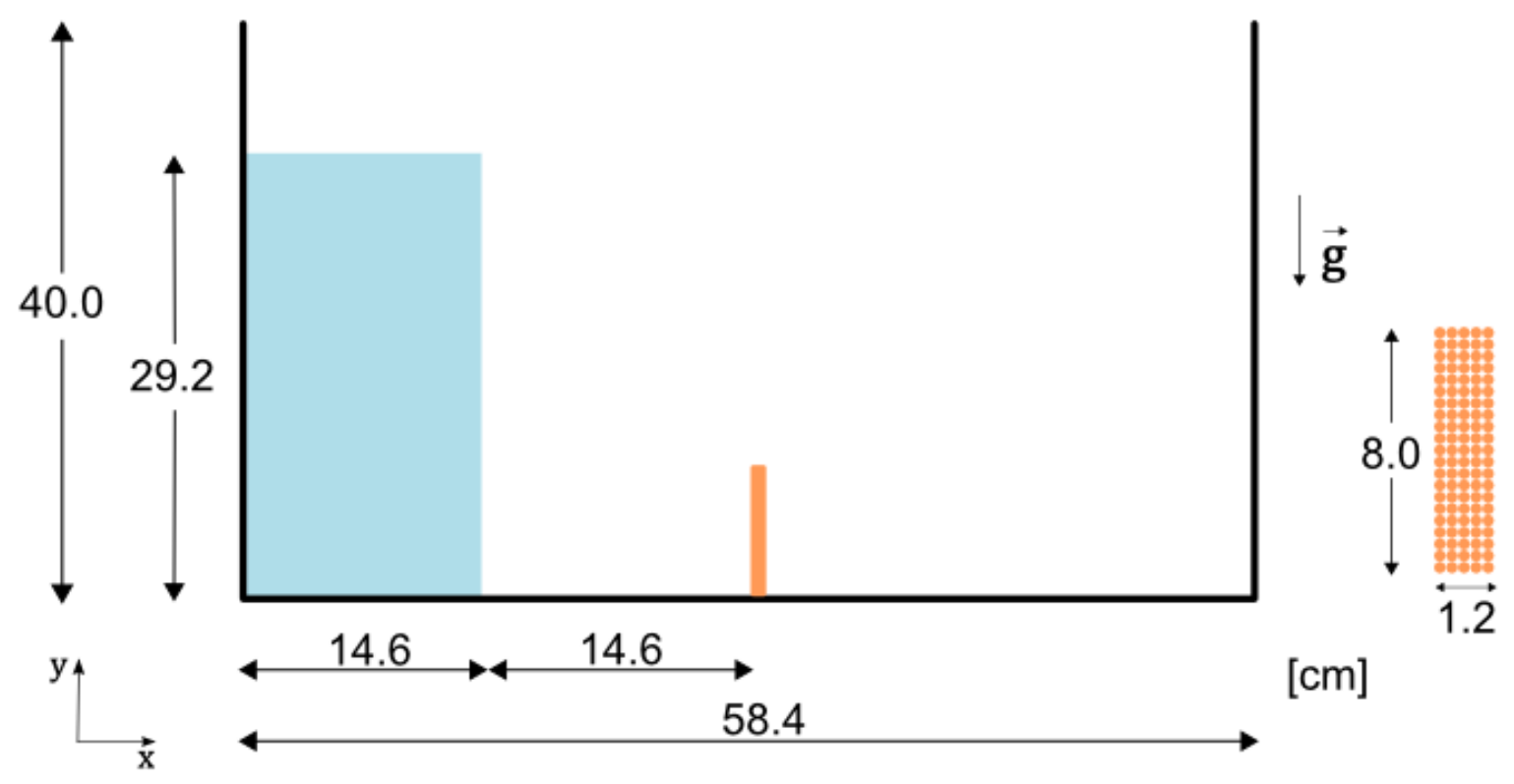

Figura 5.14: Condições iniciais da coluna d'água em placa elástica.

$d p=3.00 \mathrm{~mm}, 1.50 \mathrm{~mm}$ e $0.50 \mathrm{~mm}$, respectivamente, e os resultados presentes na literatura dos trabalhos de Walhorn et al. (2005), Marti et al. (2006), Idelsohn et al. (2008b), Amanifard, Hessan e Rahbar (2011). Comparando os resultados obtidos pelo MPS com os outros métodos, pode-se notar que as curvas inicialmente apresentam a mesma tendência. O deslocamento máximo de $4.2 \mathrm{~cm}$ obtido com o MPS se aproxima do valor obtido com o FEM e SPH, mas encontra-se abaixo dos valores obtidos com o PFEM, de aproximadamente $4.6 \mathrm{~cm}$.

Para $d p=3.00 \mathrm{~mm}$, a curva se mantém em $2.1 \mathrm{~cm}$ após o instante $0.4 \mathrm{~s}$, acima dos valores apresentados pelos outros métodos, em torno de $1.7 \mathrm{~cm}$. Após o instante $0.6 \mathrm{~s}$, o comportamento oscilatório da curva se assemelha a curva do SPH, mas com diferenças de amplitudes dos deslocamentos.

Para $d p=1.50 \mathrm{~mm}$, a curva apresenta comportamento semelhante aos outros métodos e valor máximo de $1.7 \mathrm{~cm}$ após o instante $0.4 \mathrm{~s}$. Após o instante $0.6 \mathrm{~s}$, assim como na simulação com $d p=3.00 \mathrm{~m}$, o comportamento oscilatório da curva se assemelha a curva do SPH, mas com diferenças de amplitudes dos deslocamentos.

Por último, a simulação com $d p=0.50 \mathrm{~mm}$ apresenta curva decrescente distinta das outras duas simulações, sem ocorrência de concavidade entre os instantes $0.3 s$ e $0.6 s$, chegando a um valor de $1.7 \mathrm{~cm}$ no instante $0.6 \mathrm{~s}$. Após o instante $0.6 \mathrm{~s}$, ocorrem dois picos de $-1.1 \mathrm{~cm}$ seguidos por um pico de $1.1 \mathrm{~cm}$ e outro pico de $-0.9 \mathrm{~cm}$. 


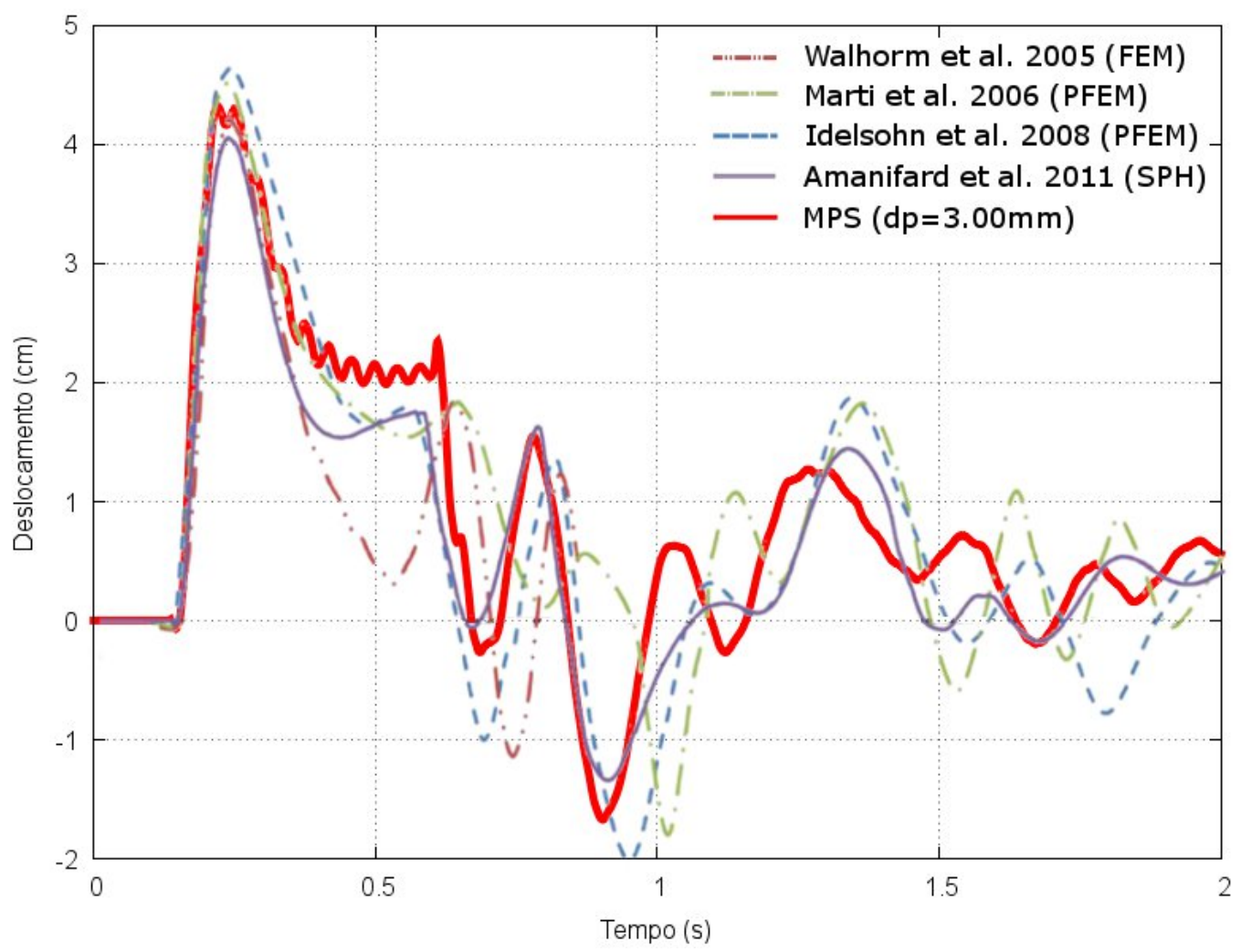

Figura 5.15: Deslocamento horizontal do topo da placa elástica para $d p=3.00 \mathrm{~mm}$.

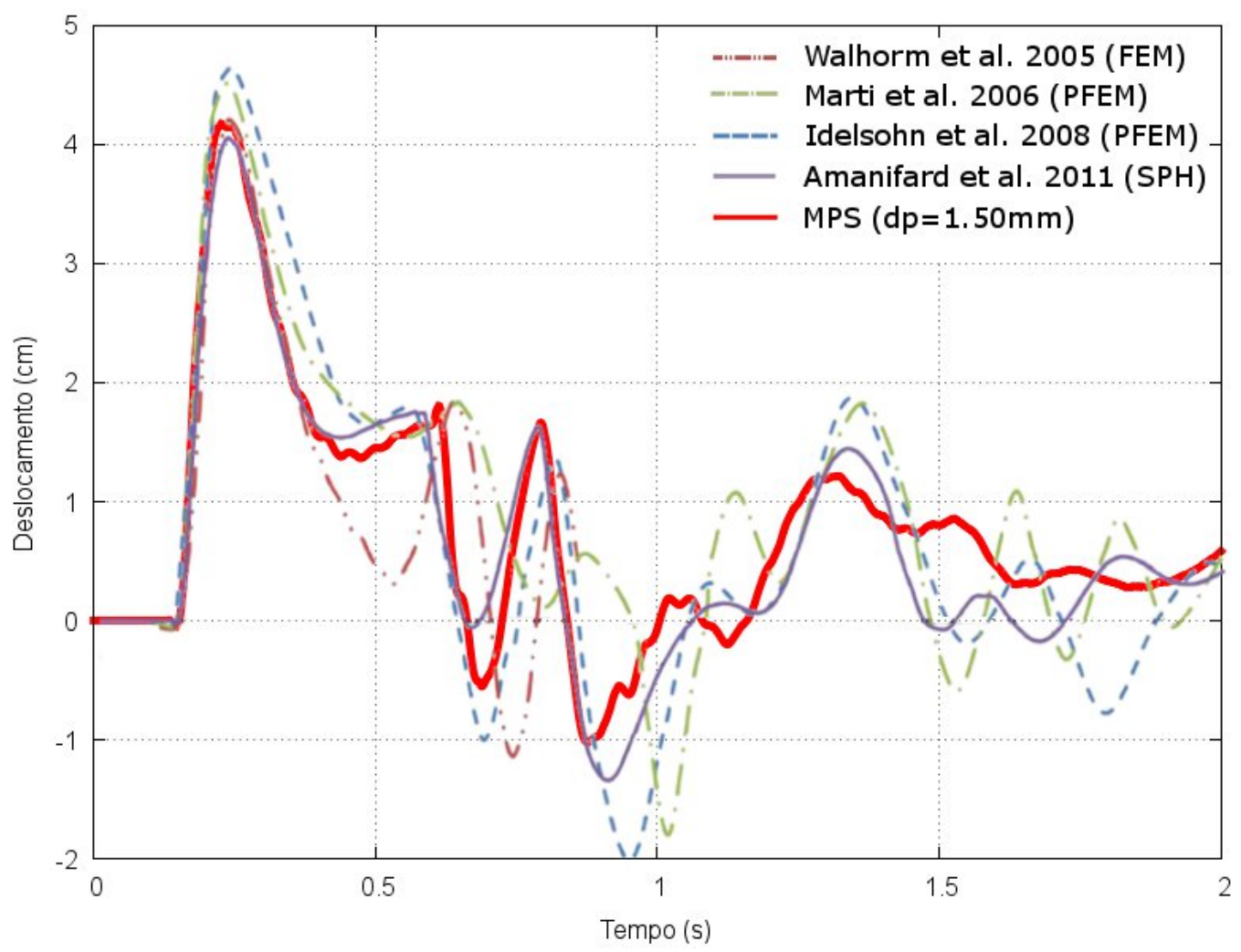

Figura 5.16: Deslocamento horizontal do topo da placa elástica para $d p=1.50 \mathrm{~mm}$. 


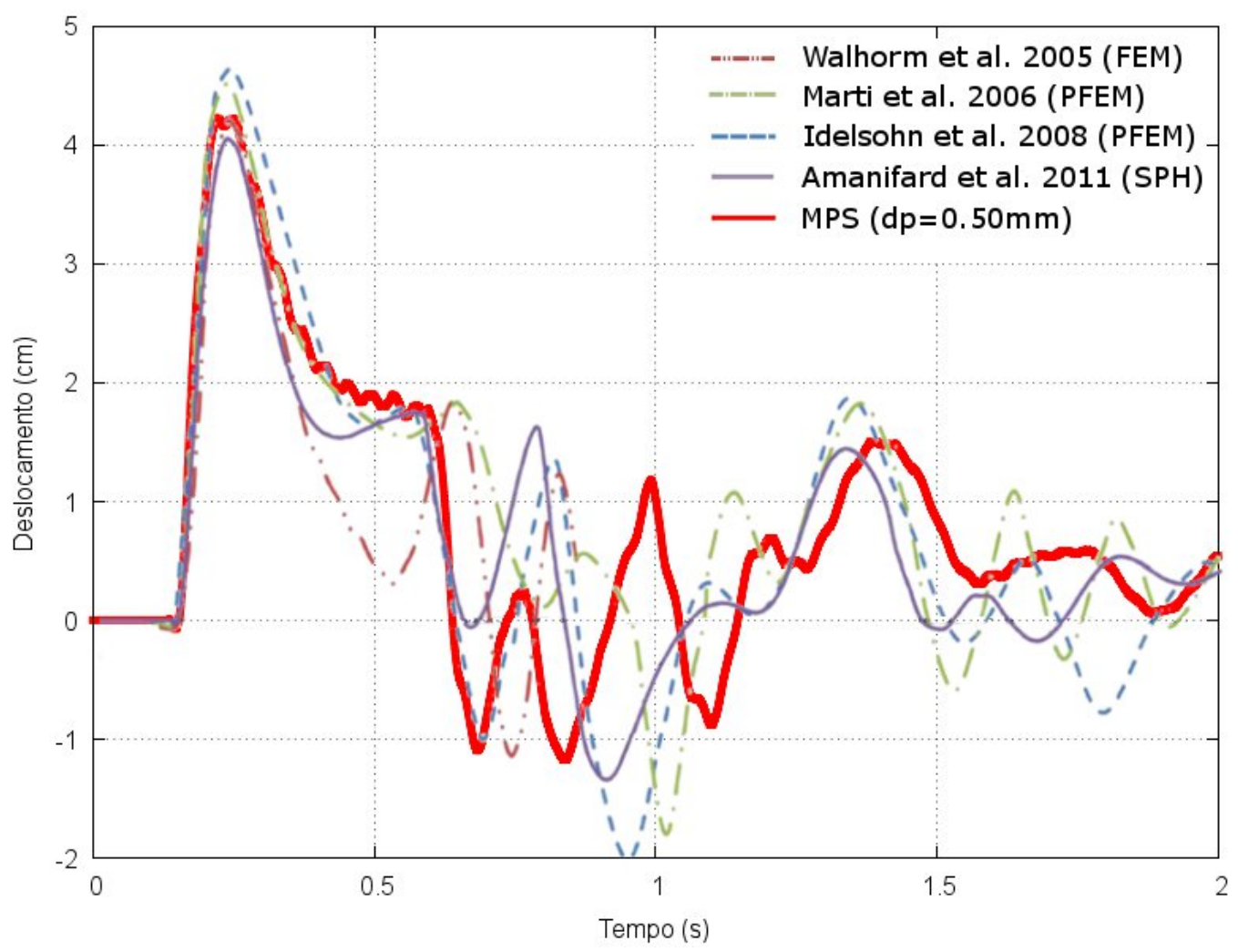

Figura 5.17: Deslocamento horizontal do topo da placa elástica para $d p=0.50 \mathrm{~mm}$.

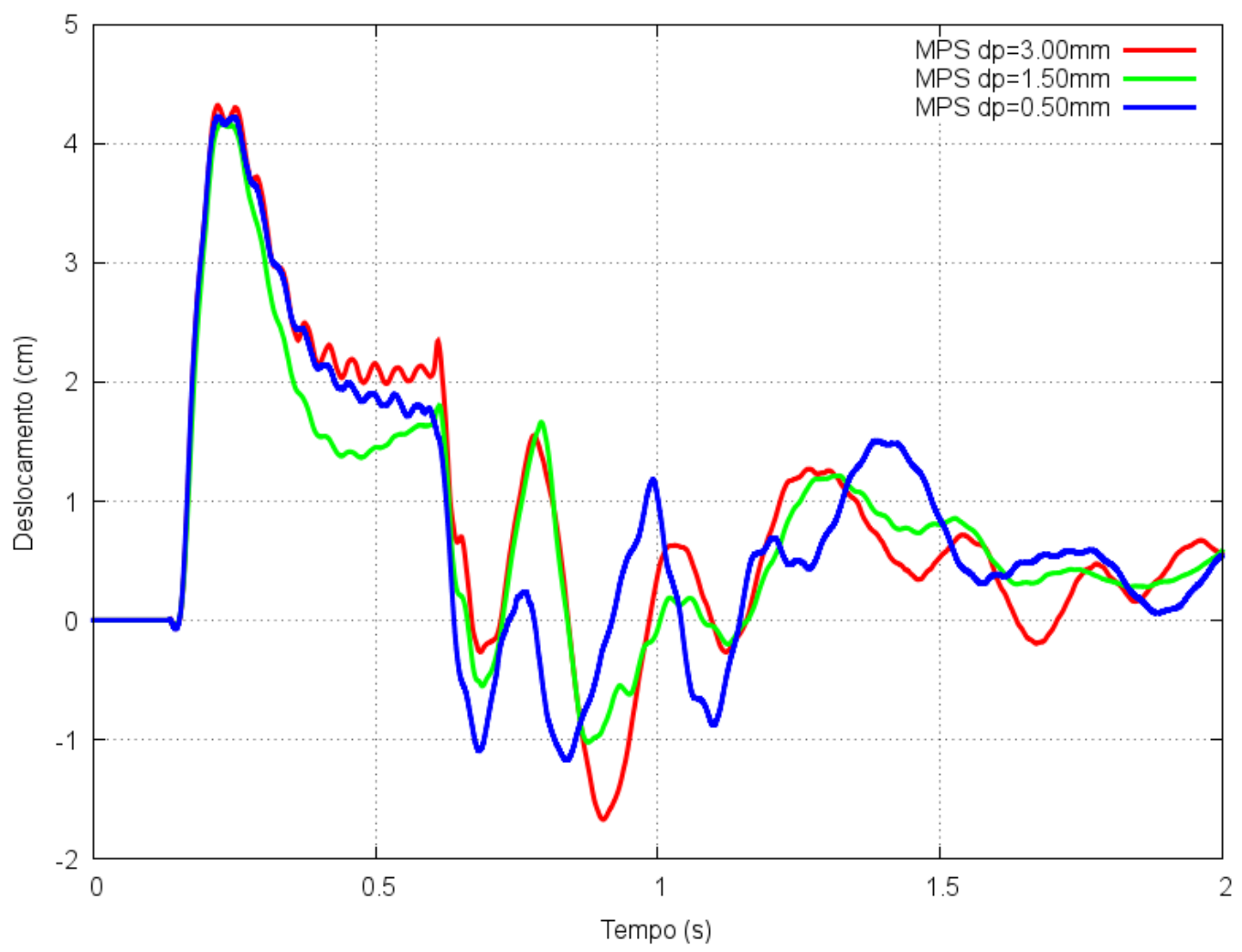

Figura 5.18: Deslocamento horizontal do topo da placa elástica para $d p=3.00 \mathrm{~mm}$, $d p=1.50 \mathrm{~mm}$ e $d p=0.50 \mathrm{~mm}$. 
A Figura 5.18 apresenta as três simulações com o MPS. Após o instante $1.0 \mathrm{~s}$, podese notar, para todos as simulações, uma tendência de equilíbrio entre o fluido e a placa elástica devido ao amortecimento da placa elástica no fluido.

As Figuras 5.19, 5.20 e 5.21 apresentam uma sequência de imagens obtidas pelo SPH (RAFIEE; THIAGARAJAN, 2009), PFEM (IDELSOHN et al., 2008b) e MPS para distâncias entre partículas $d p=3.00 \mathrm{~mm}, 1.50 \mathrm{~mm}$ e $0.50 \mathrm{~mm}$, respectivamente, e a distribuição de pressão no fluido pelo PFEM e MPS. Visualmente, pode-se observar uma boa concordância entre os métodos e melhora no campo de pressões do MPS, à medida que $d p$ diminui.

Devido a falta de resultados experimentais deste caso e tendo em conta a física do problema, os resultados mostram que, em comparação com os métodos atualmente disponíveis, a presente abordagem também é capaz de reproduzir o comportamento de problemas envolvendo escoamento de superfície livre e sólidos elásticos. 

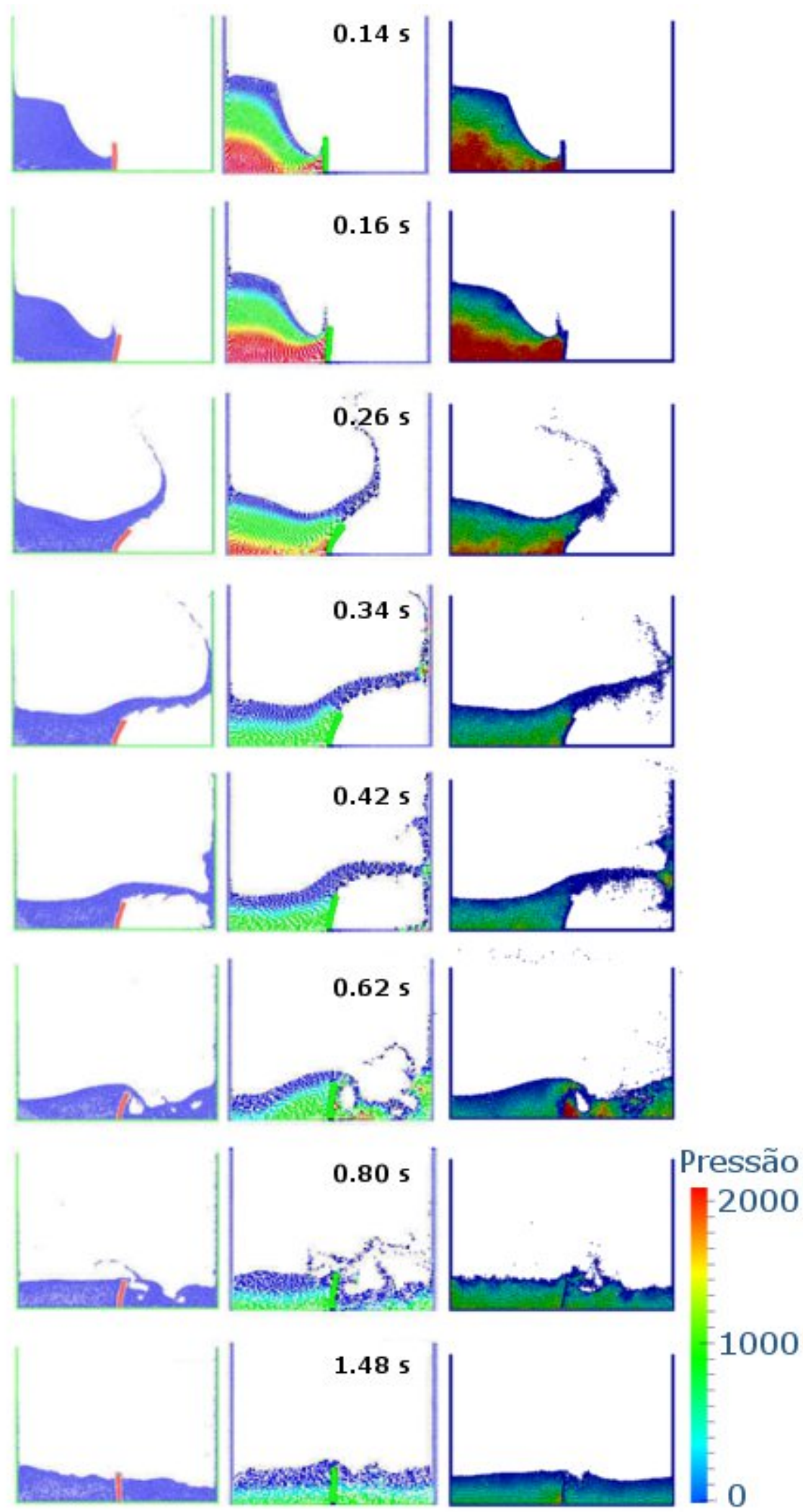

Figura 5.19: Comparação entre os métodos SPH (RAFIEE; THIAGARAJAN, 2009), PFEM (IDELSOHN et al., 2008b) e MPS com $d p=3.00 \mathrm{~mm}(0.14 \mathrm{~s}, 0.16 \mathrm{~s}, 0.26 \mathrm{~s}, 0.34 \mathrm{~s}$, $0.42 \mathrm{~s}, 0.62 \mathrm{~s}, 0.80 \mathrm{~s}, 1.48 \mathrm{~s})$. 

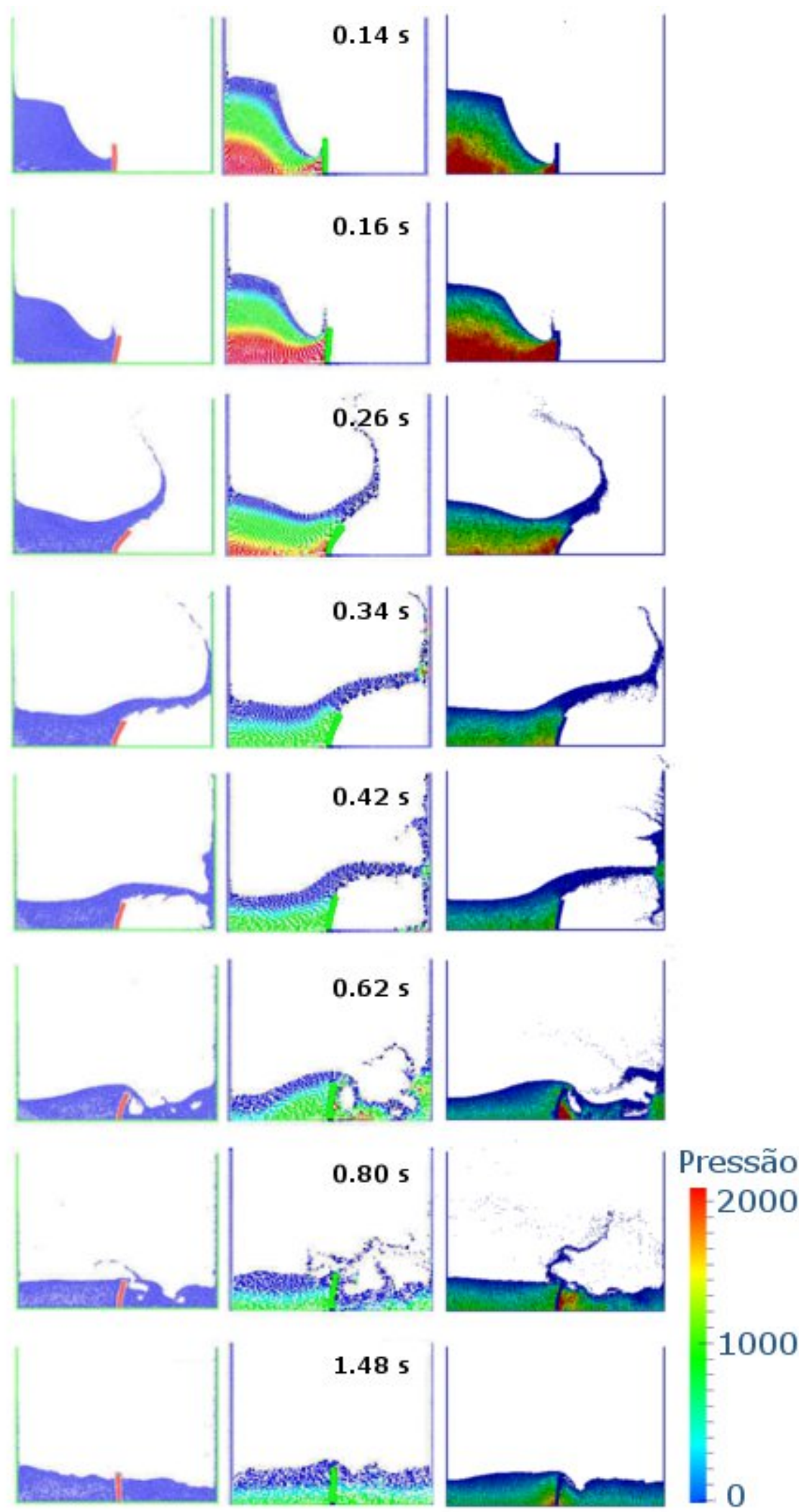

Figura 5.20: Comparação entre os métodos SPH (RAFIEE; THIAGARAJAN, 2009), PFEM (IDELSOHN et al., 2008b) e MPS com $d p=1.50 \mathrm{~mm}(0.14 \mathrm{~s}, 0.16 \mathrm{~s}, 0.26 \mathrm{~s}, 0.34 \mathrm{~s}$, $0.42 \mathrm{~s}, 0.62 \mathrm{~s}, 0.80 \mathrm{~s}, 1.48 \mathrm{~s})$. 

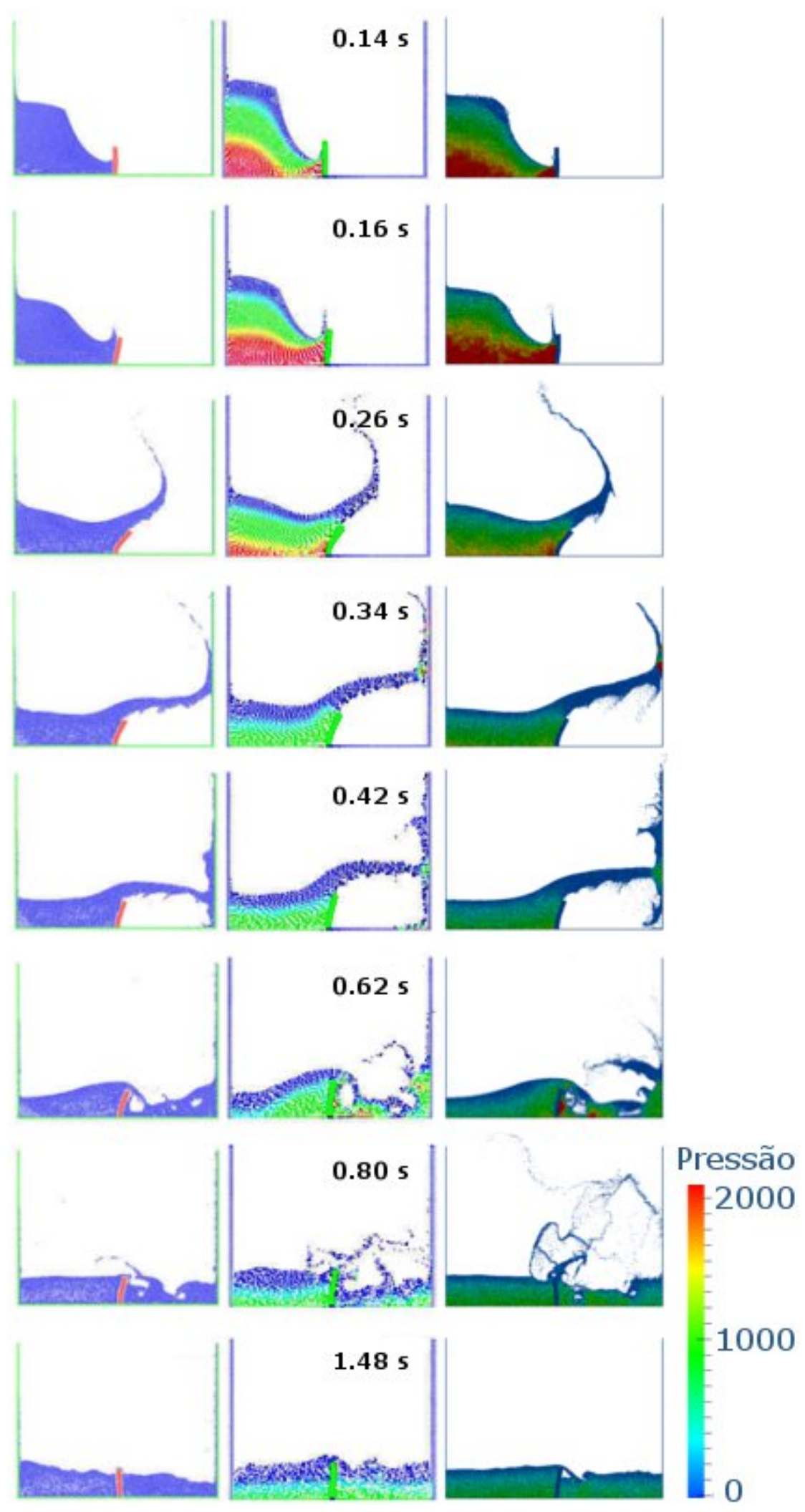

Figura 5.21: Comparação entre os métodos SPH (RAFIEE; THIAGARAJAN, 2009), PFEM (IDELSOHN et al., 2008b) e MPS com $d p=0.50 \mathrm{~mm}(0.14 \mathrm{~s}, 0.16 \mathrm{~s}, 0.26 \mathrm{~s}, 0.34 \mathrm{~s}$, $0.42 \mathrm{~s}, 0.62 \mathrm{~s}, 0.80 \mathrm{~s}, 1.48 \mathrm{~s})$. 


\subsubsection{Placa elástica submetida a pressão de uma coluna d'água}

Um experimento envolvendo a interação entre uma coluna d'água e uma placa elástica proposto por Antoci, Gallati e Sibilla (2007) foi simplificado para um caso 2D, devido sua simetria, e simulado com o MPS, possibilitando a análise e comparação entre os resultados obtidos pelo MPS, resultados experimentais e resultados numéricos de um modelo híbrido SPH-FEM (YANG; JONES; MCCUE, 2012), adotando uma relação tensão x deformação linear, que será discutida mais a frente. A geometria inicial do experimento é apresentada na Figura 5.22, sendo que a placa elástica engastada, destacada em laranja, possui as dimensões $0.5 \times 7.9 \mathrm{~cm}$. Os valores adotados para as propriedades da placa elástica foram: densidade $\rho=1100 \mathrm{~kg} / \mathrm{m}^{3}$, módulo de Young $E=10 \mathrm{MPa}$ e coeficiente de Poisson $\nu=0.4$; e para o fluído foram: densidade $\rho=1000 \mathrm{~kg} / \mathrm{m}^{3}$ e viscosidade $v=10^{-6} \mathrm{~m}^{2} / \mathrm{s}$. Como parâmetros de simulação, os valores mostrados na tabela 5.7 foram adotados.

Tabela 5.7: Parâmetros de simulação.

\begin{tabular}{ccccc}
\hline$d p(\mathrm{~mm})$ & $\Delta t_{\text {fluido }}(\mathrm{s})$ & $\Delta t_{\text {solido }}(\mathrm{s})$ & Partículas de fluido & Partículas de sólido \\
\hline \hline 1.00 & $10^{-5}$ & $10^{-6}$ & 14000 & 395 \\
0.50 & $10^{-5}$ & $10^{-7}$ & 56000 & 1580 \\
0.25 & $10^{-5}$ & $10^{-7}$ & 224000 & 6320 \\
\hline
\end{tabular}

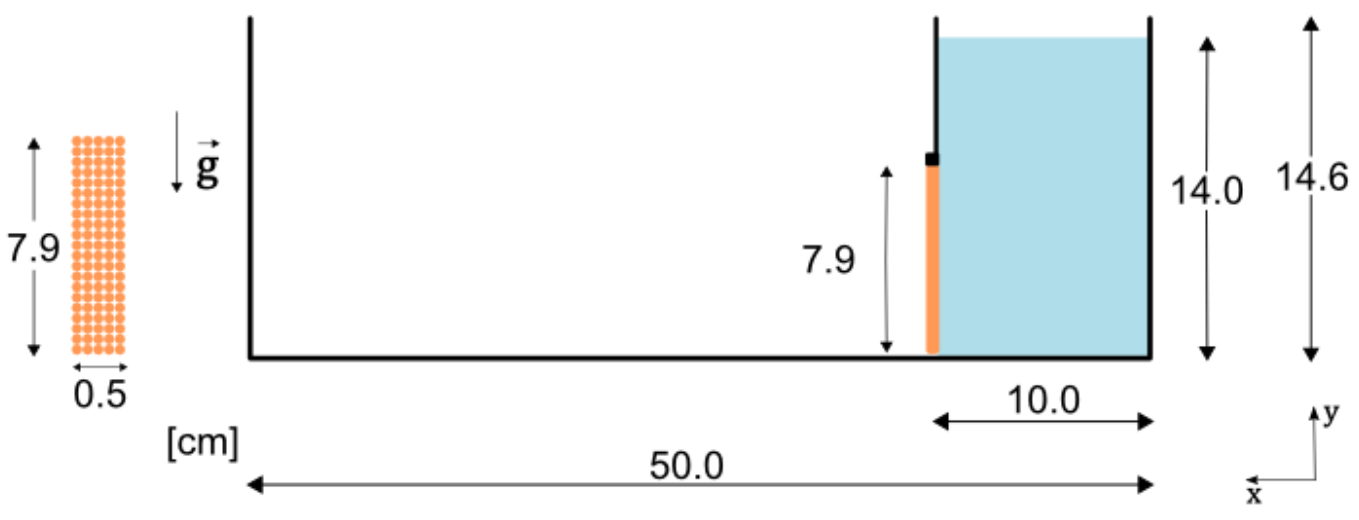

Figura 5.22: Condições iniciais da placa elástica submetida a pressão.

A Figura 5.23 apresenta o deslocamento horizontal da extremidade inferior da placa elástica obtido pela simulação com o MPS, SPH-FEM e pelo experimento. Inicialmente, as curvas obtidas pelo MPS seguem a mesma tendência apresentada pelos valores experimentais e SPH-FEM até o instante $0.10 \mathrm{~s}$. Um valor máximo de $3.9 \mathrm{~cm}$, no instante $0.11 \mathrm{~s}$, é obtido pelo SPH-FEM, um valor máximo de $4.2 \mathrm{~cm}$, no instante $0.12 \mathrm{~s}$, é obtido 
pela simulação com o MPS e um valor máximo de $4.6 \mathrm{~cm}$, no instante $0.16 \mathrm{~s}$, foi medido experimentalmente. A partir do instante $0.14 s$, as curvas pelo MPS e SPH-FEM decrescem até o valor de $2.8 \mathrm{~cm}$, no instante $0.28 \mathrm{~s}$, abaixo do valor experimental de $4.1 \mathrm{~cm}$. Após o instante $0.25 \mathrm{~s}$, as curvas do MPS e SPH-FEM permanecem, aproximadamente, constantes no valor de $2.8 \mathrm{~cm}$, enquanto que os valores experimentais decrescem até o valor de $3.7 \mathrm{~cm}$.

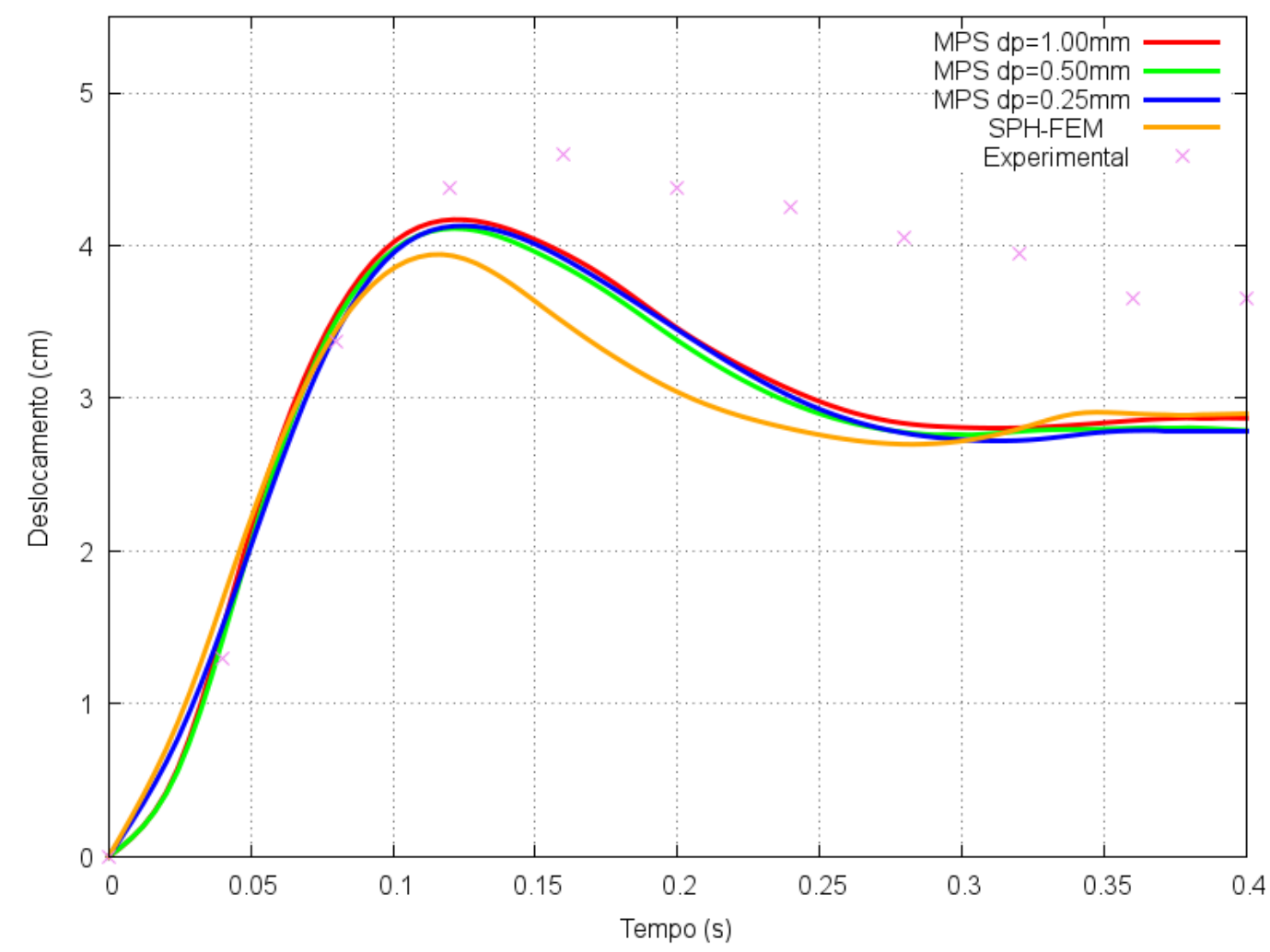

Figura 5.23: Deslocamento horizontal experimental da extremidade inferior da placa elástica, valores do método SPH-FEM (YANG; JONES; MCCUE, 2012) e valores obtidos pelo MPS para $d p=1.00 \mathrm{~mm}, d p=0.50 \mathrm{~mm}$ e $d p=0.25 \mathrm{~mm}$.

A Figura 5.24 apresenta o deslocamento vertical da extremidade inferior da placa elástica obtido experimentalmente, por meio da simulação com o MPS e SPH-FEM. Novamente as curvas obtidas pelo MPS seguem a mesma tendência que os valores experimentais e SPH-FEM até o instante $0.12 \mathrm{~s}$. Um valor máximo de $1.3 \mathrm{~cm}$, no instante $0.11 \mathrm{~s}$, é obtido pela simulação com o SPH-FEM, um valor máximo de $1.4 \mathrm{~cm}$, no instante $0.12 \mathrm{~s}$, é obtido pelo MPS e um valor máximo de $1.7 \mathrm{~cm}$, no instante $0.16 \mathrm{~s}$, foi medido experimentalmente. A partir do instante $0.14 s$, as curvas pelo MPS e SPH-FEM decrescem até o valor de $0.6 \mathrm{~cm}$, no instante $0.28 \mathrm{~s}$, abaixo do valor experimental de $1.3 \mathrm{~cm}$. Após o instante $0.25 \mathrm{~s}$, as curvas do MPS e SPH-FEM permanecem, aproximadamente, constantes no valor de $0.6 \mathrm{~cm}$, enquanto que os valores experimentais decrescem até o valor de $1.1 \mathrm{~cm}$. 


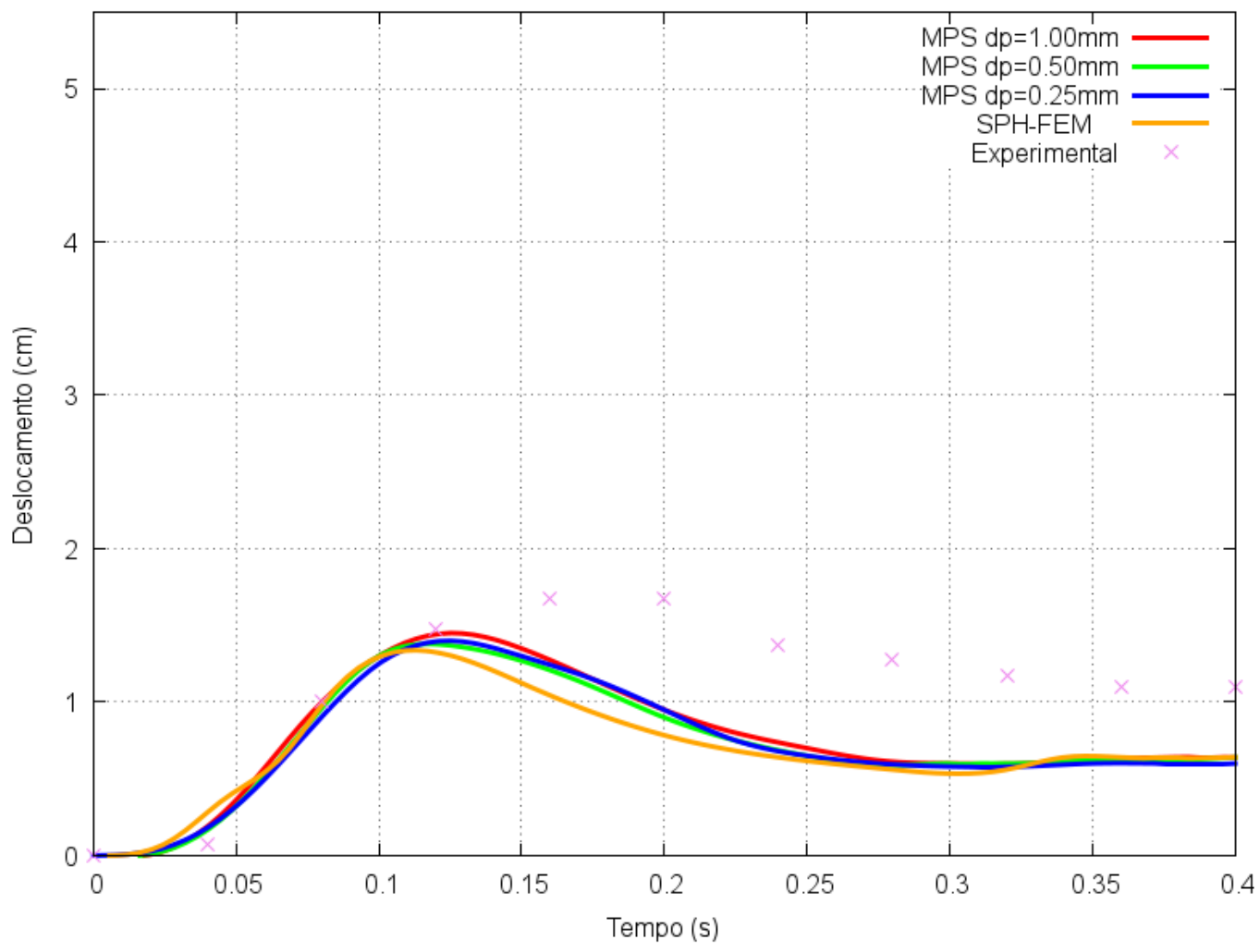

Figura 5.24: Deslocamento vertical experimental da extremidade inferior da placa elástica, valores do método SPH-FEM (YANG; JONES; MCCUE, 2012) e valores obtidos pelo MPS para $d p=1.00 \mathrm{~mm}, d p=0.50 \mathrm{~mm}$ e $d p=0.25 \mathrm{~mm}$.

Comparando os deslocamentos horizontal e vertical obtidos pelo MPS e as curvas formadas pelos valores experimentais, nota-se claramente uma discrepância relevante após o instante 0.14 s. Para o deslocamento horizontal, a maior discrepância ocorre no instante $0.28 s$ com um erro relativo de $30.89 \%$. Para o deslocamento vertical, a maior discrepância ocorre no instante $0.20 \mathrm{~s}$ com um erro relativo de $43.28 \%$. Essa diferença ocorre devido as equações constitutivas adotadas neste trabalho não serem apropriadas para o material utilizado no experimento. O material utilizado no experimento apresenta uma relação tensão x deformação não linear (YANG; JONES; MCCUE, 2012), diferentemente do modelo proposto neste trabalho que obedece uma relação linear. Semelhante a este trabalho, Yang, Jones e McCue (2012) também utilizaram um modelo com relação linear para o método híbrido SPH-FEM, obtendo resultados próximos ao modelo aqui adotado, mas diferentes do experimento. Yang, Jones e McCue (2012) sugerem um modelo hiper-elástico para o a simulação do caso, melhorando a precisão do cálculo na presença de grandes deslocamentos na placa elástica.

A Figura 5.25 apresenta o decaimento da altura da coluna d'água medido experimentalmente e obtido com o MPS. Os resultados obtidos pelo MPS apresentam uma boa 
concordância com os valores experimentais até o instante $0.20 \mathrm{~s}$. Após o instante $0.20 \mathrm{~s}$, os valores experimentais apresentam uma queda mais acentuada do que os resultados obtidos pelo MPS. Devido a utilização do modelo linear proposto neste trabalho, os deslocamentos da placa elástica obtidos com o MPS são menores do que os valores apresentados no experimento, o que acaba diminuindo a seção de saída de água ocasionando redução um pouco mais lenta de nível na coluna d'água.

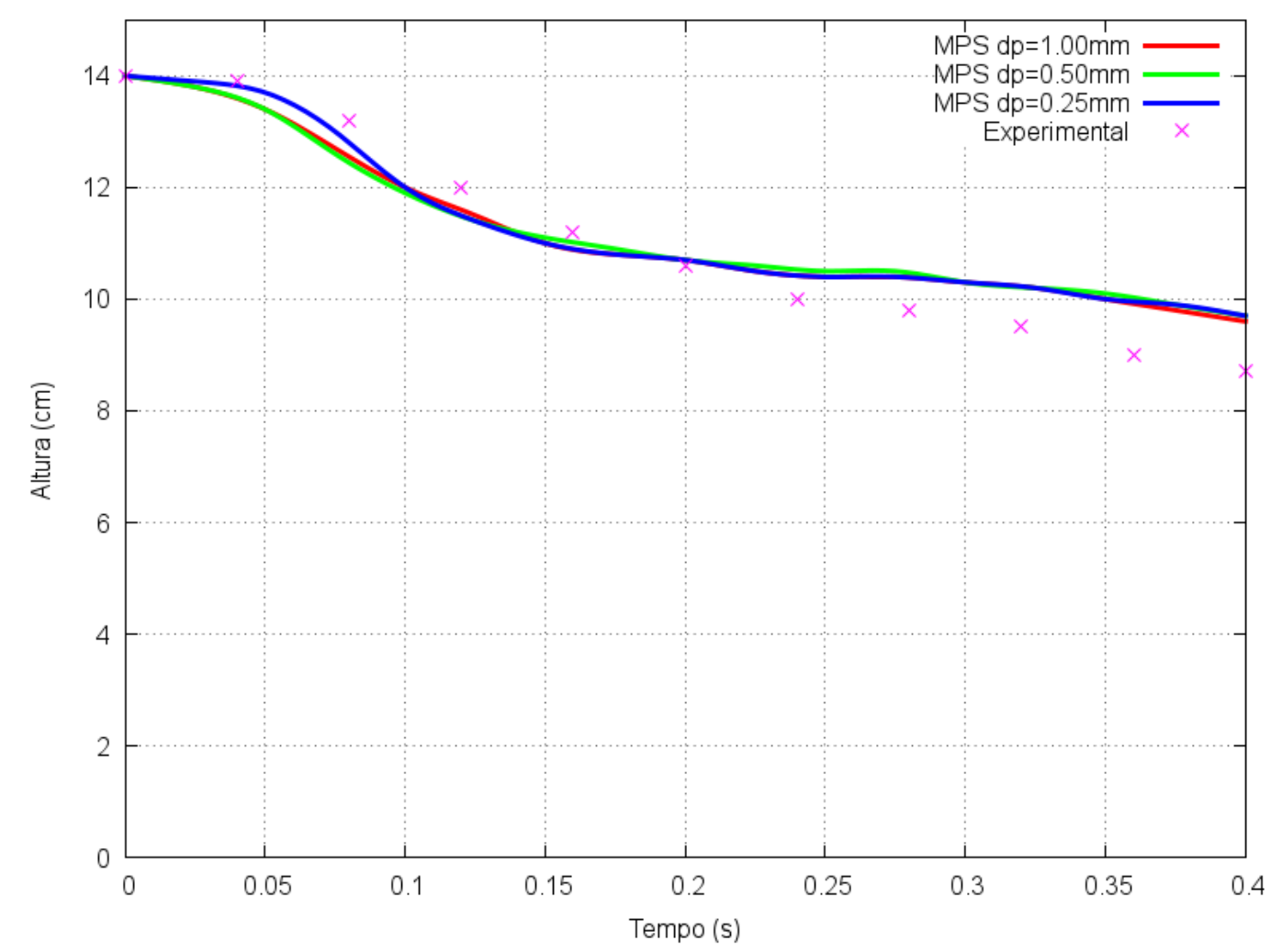

Figura 5.25: Valores experimentais da altura da coluna d'água e valores obtidos pelo MPS para $d p=1.00 \mathrm{~mm}, d p=0.50 \mathrm{~mm}$ e $d p=0.25 \mathrm{~mm}$.

As Figuras 5.26, 5.27 e 5.28 apresentam diferentes instantes de tempo do experimento e das simulações obtidas pelo MPS para distância de partículas $d p=1.00 \mathrm{~mm}, 0.50 \mathrm{~mm}$ e $0.25 \mathrm{~mm}$, respectivamente. Na simulação com o MPS, a placa elástica atinge o deslocamento máximo no instante $0.12 \mathrm{~s}$ enquanto que experimentalmente, a placa elástica atinge o deslocamento máximo no instante $0.16 s$ (ANTOCI; GALATTI; SIBILLA, 2007). No instante $0.20 \mathrm{~s}$, nota-se a maior flexão da barra elástica no experimento em relação a simulação numérica, independente da distância entre partículas. Conforme mencionado anteriormente, isso é devido as equações constitutivas adotadas neste trabalho não serem apropriadas para o material utilizado no experimento. No entanto, é interessante notar que em relação à superfície livre, a simulação com o MPS apresenta inclinação da coluna d'água similar ao experimento, mas uma queda mais lenta na altura da coluna d'água. 
De forma geral, os valores obtidos pelo MPS apresentaram erros significativos quando a deflexão da placa mostrou-se muito grande, devido à não linearidade do material utilizado no experimento, característica que não foi considerada no modelo numérico. No entanto, pode-se observar comportamento semelhante entre simulação numérica e experimento, independente da resolução espacial utilizada. 

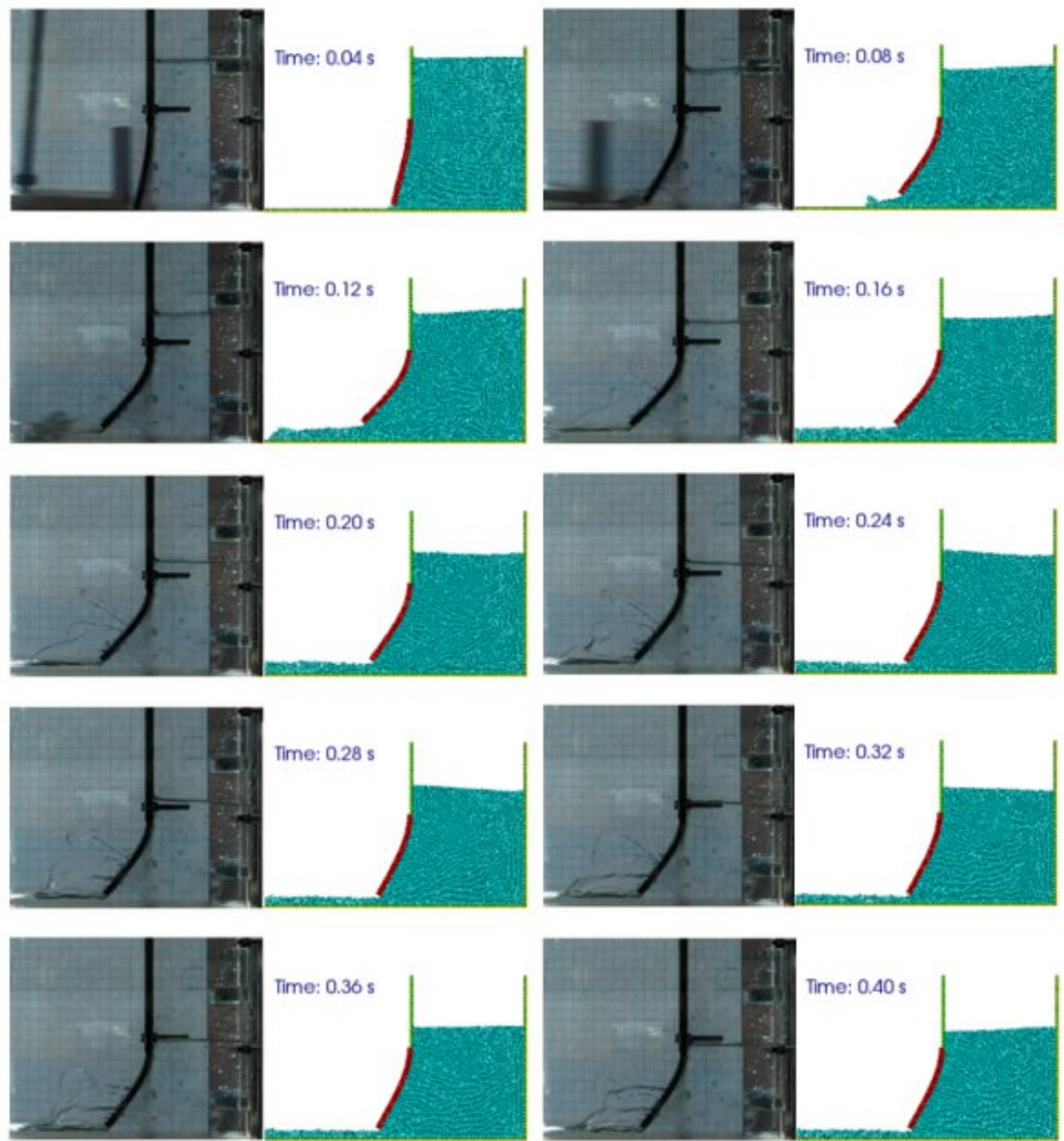

Time: $0.40 \mathrm{~s}$

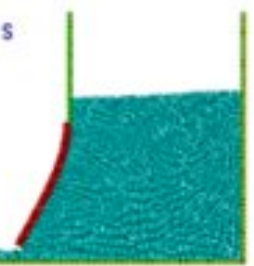

Experimental Numérico $(\mathrm{dp}=1.00 \mathrm{~mm})$

Experimental

Numérico $(\mathrm{dp}=1.00 \mathrm{~mm})$

Figura 5.26: Comparação entre o experimento e a simulação com o MPS para $d p=1.0 \mathrm{~mm}(0.04 \mathrm{~s}, 0.08 \mathrm{~s}, 0.12 \mathrm{~s}, 0.16 \mathrm{~s}, 0.20 \mathrm{~s}, 0.24 \mathrm{~s}, 0.28 \mathrm{~s}, 0.32 \mathrm{~s}, 0.36 \mathrm{~s}, 0.40 \mathrm{~s})$. 

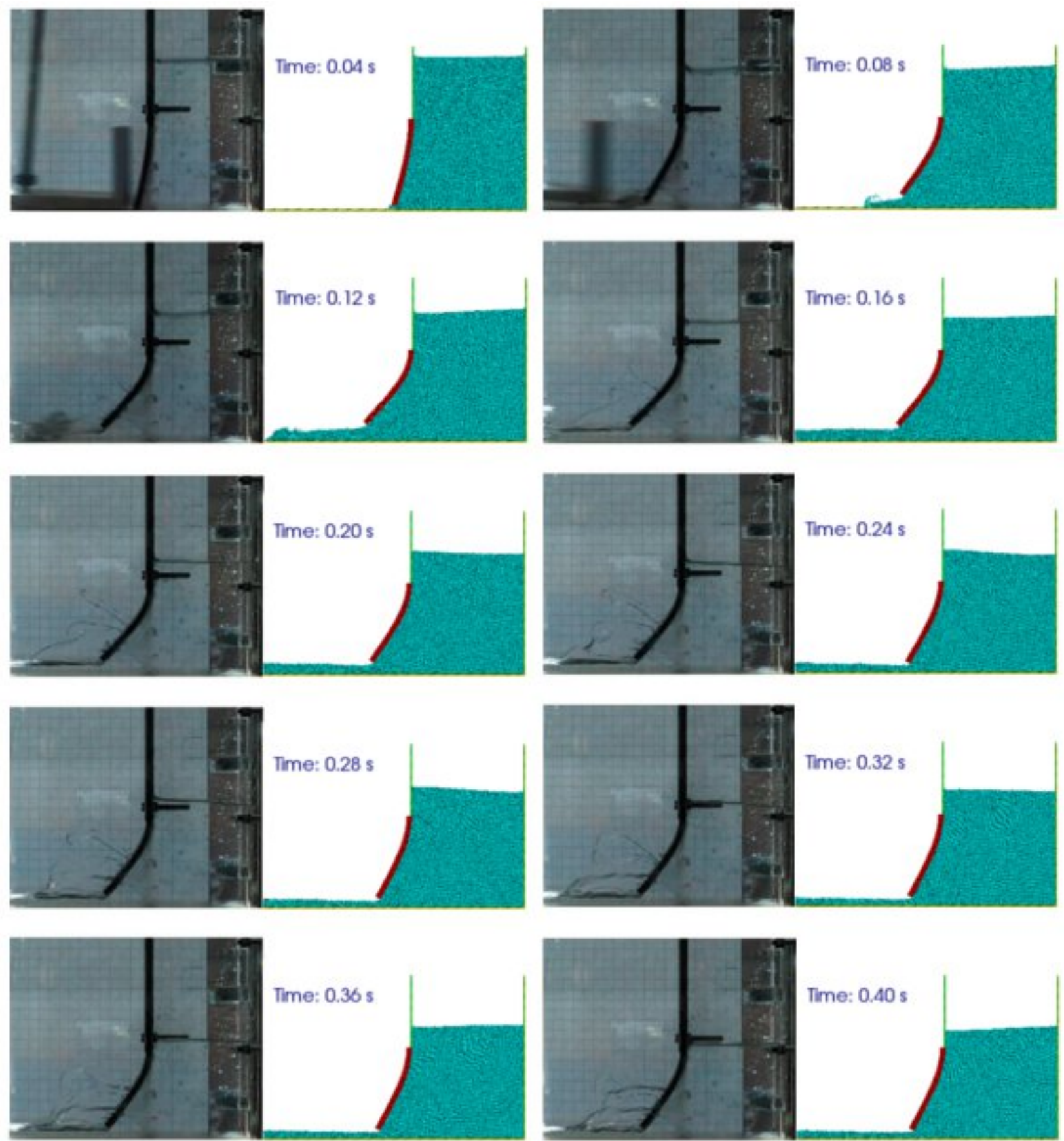

Experimental Numérico $(\mathrm{dp}=0.50 \mathrm{~mm})$

Experimental

Numérico $(\mathrm{dp}=0.50 \mathrm{~mm})$

Figura 5.27: Comparação entre o experimento e a simulação com o MPS para $d p=0.5 \mathrm{~mm}(0.04 \mathrm{~s}, 0.08 \mathrm{~s}, 0.12 \mathrm{~s}, 0.16 \mathrm{~s}, 0.20 \mathrm{~s}, 0.24 \mathrm{~s}, 0.28 \mathrm{~s}, 0.32 \mathrm{~s}, 0.36 \mathrm{~s}, 0.40 \mathrm{~s})$. 

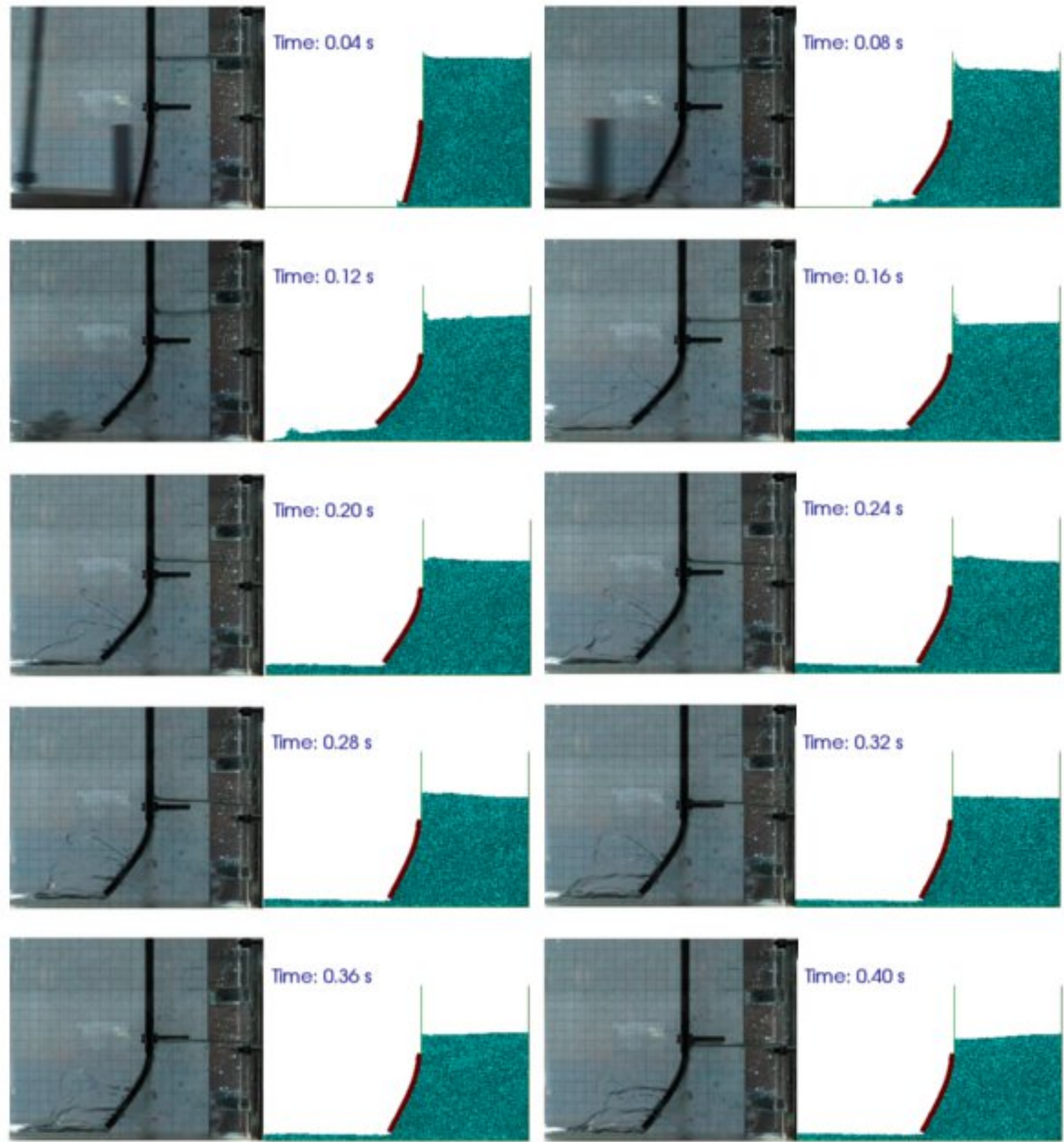

Time: 0.36 s
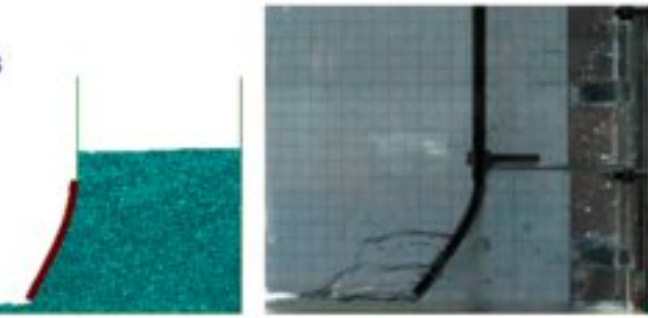

Time: 0.40 s

Experimental Numérico $(\mathrm{dp}=0.25 \mathrm{~mm})$

Experimental

Numérico $(\mathrm{dp}=0.25 \mathrm{~mm})$

Figura 5.28: Comparação entre o experimento e a simulação com o MPS para $d p=0.25 \mathrm{~mm}(0.04 \mathrm{~s}, 0.08 \mathrm{~s}, 0.12 \mathrm{~s}, 0.16 \mathrm{~s}, 0.20 \mathrm{~s}, 0.24 \mathrm{~s}, 0.28 \mathrm{~s}, 0.32 \mathrm{~s}, 0.36 \mathrm{~s}, 0.40 \mathrm{~s})$. 


\subsubsection{Placa elástica submetida a sloshing}

Este caso consiste em um tanque retangular preenchido parcialmente com óleo e uma placa elástica engastada no ponto médio do fundo do tanque, como realizado experimentalmente por Idelsohn et al. (2008a). O tanque gira em torno do ponto médio de sua parte inferior, com um movimento imposto de forma senoidal, e período obtido pela seguinte equação

$$
T=2 \pi\left(\sqrt{\frac{\pi g}{L} \tanh \left(\frac{\pi H}{L}\right)}\right)^{-1}
$$

onde $L$ é o comprimento do tanque e $H$ a altura de líquido.

O tanque foi submetido a um movimento de rotação de amplitude $\alpha=4^{0}$ e os deslocamentos $(x)$ da ponta da placa elástica em relação ao seu referencial local, Figura 5.29, foram analisados.

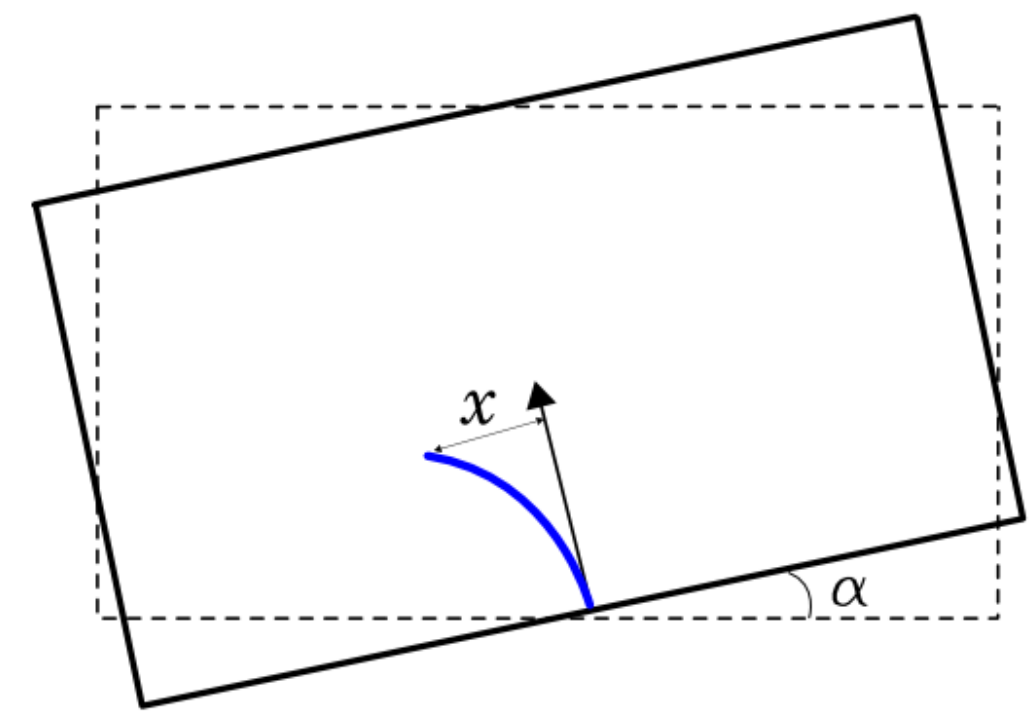

Figura 5.29: Referencial local.

Deve ser salientado as diferenças iniciais entre o experimento e simulação numérica, devido a inércia do tanque e seus efeitos no acionamento do motor. No experimento, a transição entre o estado de repouso e de movimento harmônico, ocorre gradativamente, enquanto que na simulação numérica, essa transição ocorre de forma instantânea. Dessa forma, fluido e estrutura apresentam respostas diferentes entre o experimento e simulação numérica, nos instantes iniciais. Para reparar essa diferença, os resultados obtidos com o MPS foram deslocados no tempo, coincidindo o primeiro pico de deslocamento dos resultados experimental e numérico. 


\subsubsection{Caso raso}

A geometria inicial do caso raso é apresentada na Figura 5.30, sendo que a placa elástica engastada, destacada em azul, possui as dimensões 0.40 x $5.74 \mathrm{~cm}$. Os valores adotados para as propriedades da placa elástica foram: densidade $\rho=1100 \mathrm{~kg} / \mathrm{m}^{3}$, módulo de Young $E=6 M P a$ e coeficiente de Poisson $\nu=0.49$; e para o fluído foram: densidade $\rho=917 \mathrm{~kg} / \mathrm{m}^{3}$ e viscosidade $v=5 \times 10^{-5} \mathrm{~m}^{2} / \mathrm{s}$. O tanque foi submetido a um movimento de rotação com um período $T=1.646 \mathrm{~s}$. Como parâmetros de simulação, os valores mostrados na Tabela 5.8 foram utilizados.

Tabela 5.8: Parâmetros de simulação.

\begin{tabular}{ccccc}
\hline$d p(\mathrm{~mm})$ & $\Delta t_{\text {fluido }}(\mathrm{s})$ & $\Delta t_{\text {solido }}(\mathrm{s})$ & Partículas de fluido & Partículas de sólido \\
\hline \hline 1.00 & $10^{-5}$ & $10^{-6}$ & 34485 & 228 \\
0.80 & $10^{-5}$ & $10^{-6}$ & 54432 & 360 \\
0.50 & $10^{-5}$ & $10^{-7}$ & 139150 & 920 \\
\hline
\end{tabular}

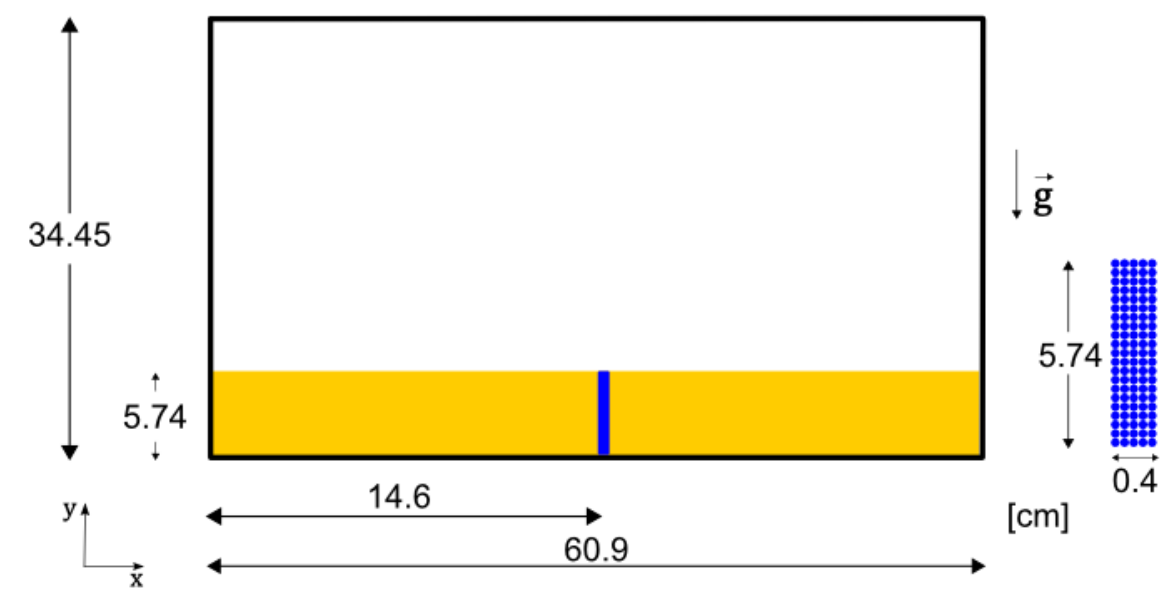

Figura 5.30: Condições iniciais do caso raso de sloshing.

A Figura 5.31 apresenta o deslocamento horizontal da ponta da placa elástica, em relação ao seu referencial local, obtidos experimentalmente e com o MPS. Devido as diferenças nas excitações nos instantes iniciais do modelo experimental e numérico, como mencionado anteriormente, os valores experimentais apresentam um deslocamento de $0.12 \mathrm{~cm}$ no instante $0.48 \mathrm{~s}$ e $-0.47 \mathrm{~cm}$ no instante $0.92 \mathrm{~s}$, enquanto que o resultado numérico, apresenta um deslocamento de $-0.8 \mathrm{~cm}$ no instante $1.00 \mathrm{~s}$. Após o instante $1.00 \mathrm{~s}$, podese observar a oscilação da placa elástica, com período de aproximadamente $1.70 \mathrm{~s}$, para a medição experimental e resultado numérico obtido com o MPS. Entre os instantes $1.00 \mathrm{~s}$ e $7.00 \mathrm{~s}$, as medições experimentais dos deslocamentos máximos representados no lado positivo e negativo não apresentam simetria em relação a condição indeformada da placa 
elástica (deslocamento nulo). Já para os valores obtidos com o MPS, essa simetria é observada. Após o instante $7.00 \mathrm{~s}$, as medições experimentais apresentam valores tendendo ao eixo positivo dos deslocamentos, prejudicando uma comparação quantitativa entre dados experimentais e numéricos.

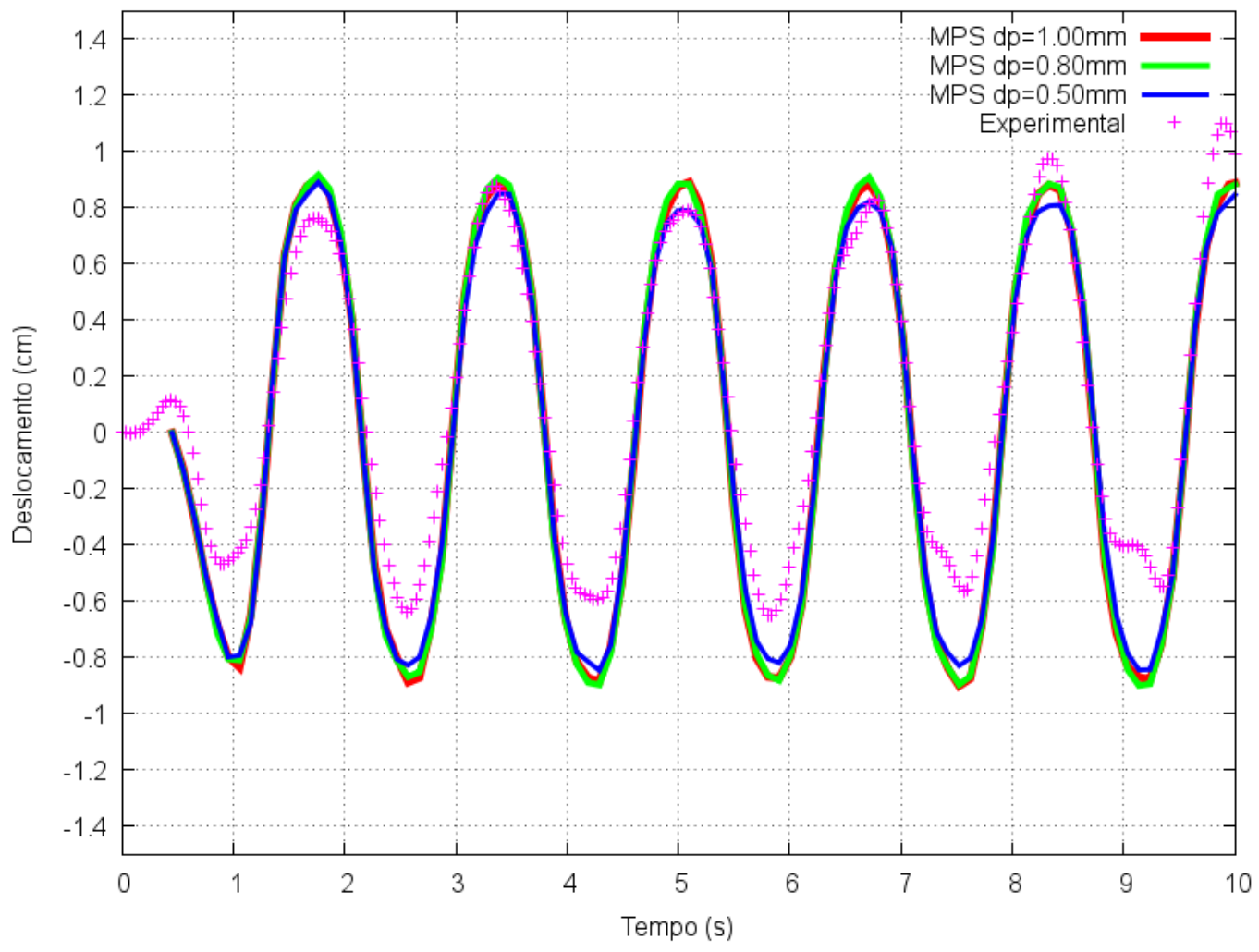

Figura 5.31: Deslocamento horizontal experimental da ponta da placa elástica e valores obtidos pelo MPS para $d p=1.00 \mathrm{~mm}, d p=0.80 \mathrm{~mm}$ e $d p=0.50 \mathrm{~mm}$.

Devido a melhor regularidade observada nos deslocamentos experimentais entre os instantes $1.72 s$ e $6.76 s$, apenas nesse intervalo de tempo foi comparado a altura média da oscilação medida experimentalmente e a altura média obtida pelo MPS. O erro foi calculado como a razão entre o módulo da diferença entre estas alturas pela altura experimental. A Tabela 5.9 apresenta os erros entre resultado experimental e resultados com o MPS para distâncias entre partículas $d p=1.00 \mathrm{~mm}, 0.80 \mathrm{~mm}$ e $0.50 \mathrm{~mm}$.

Tabela 5.9: Erro MPS x Experimental.

\begin{tabular}{cccc}
\hline$d p(\mathrm{~mm})$ & Experimental $(\mathrm{cm})$ & MPS $(\mathrm{cm})$ & Erro $(\%)$ \\
\hline \hline 1.00 & 1.44 & 1.83 & 27.08 \\
0.80 & 1.44 & 1.84 & 27.78 \\
0.50 & 1.44 & 1.71 & 18.75 \\
\hline
\end{tabular}

A Figura 5.32 apresenta diferentes instantes de tempo do experimento e das simulações obtidas pelo MPS para distâncias entre partículas $d p=1.00,0.80$ e $0.50 \mathrm{~mm}$. Pode ser 
observado um comportamento semelhante para a placa elástica e para o fluido, tanto no experimento quanto na simulação com o MPS, independente da distância entre partículas.

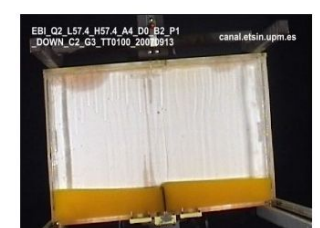

$0.90 \mathrm{~s}$
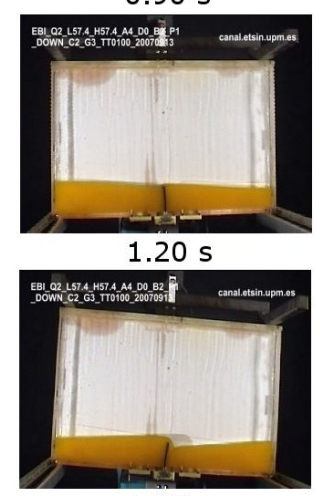

$1.67 \mathrm{~s}$

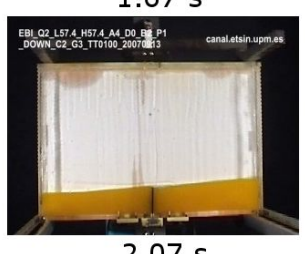

$2.07 \mathrm{~s}$

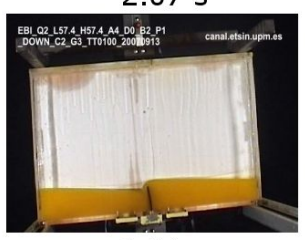

$2.47 \mathrm{~s}$

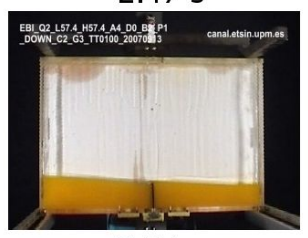

$2.87 \mathrm{~s}$

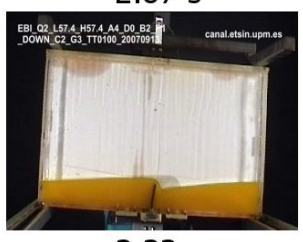

$3.33 \mathrm{~s}$

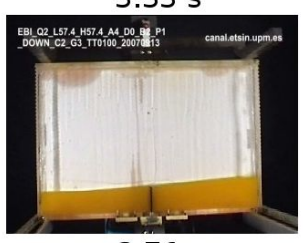

$3.76 \mathrm{~s}$
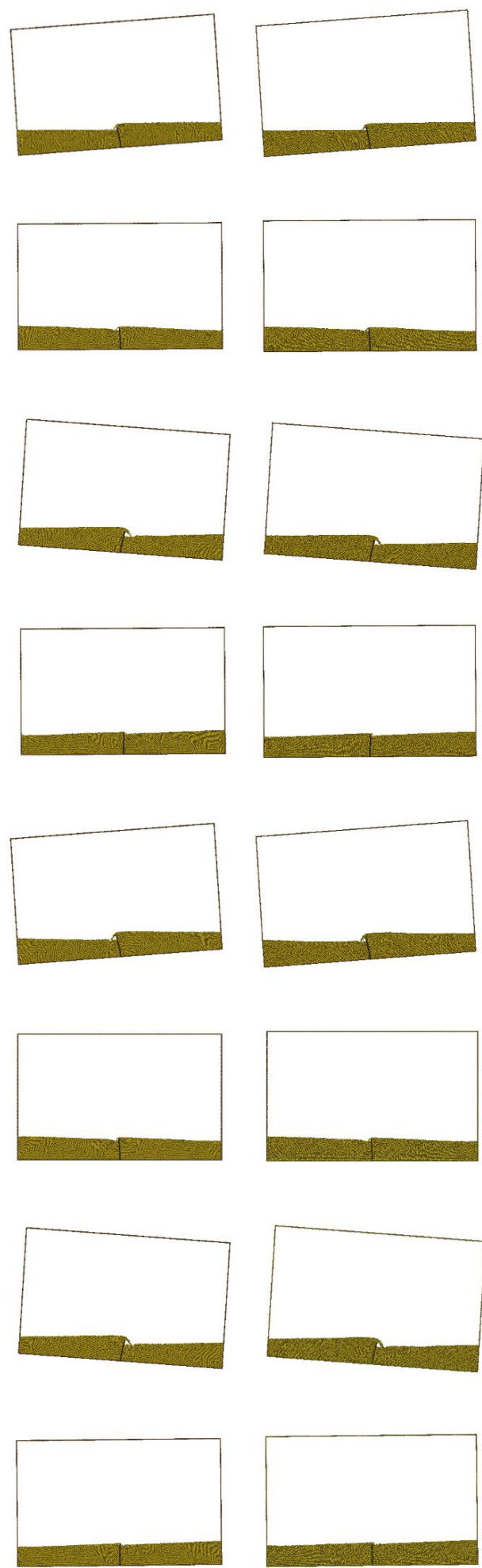

$\mathrm{dp}=1.0 \mathrm{~mm}$
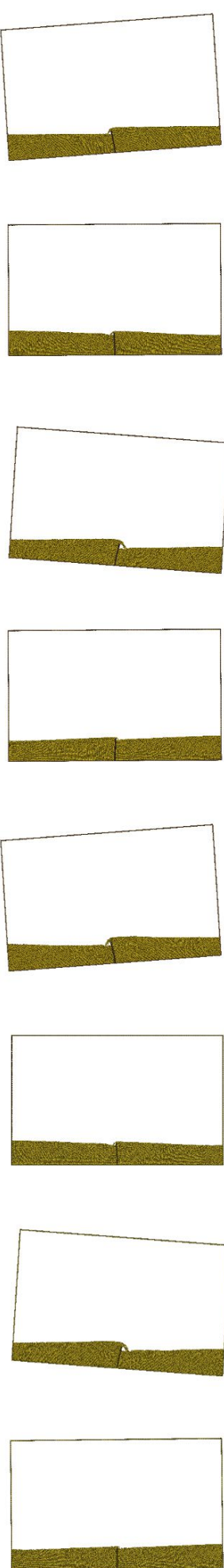

$\mathrm{dp}=0.8 \mathrm{~mm}$
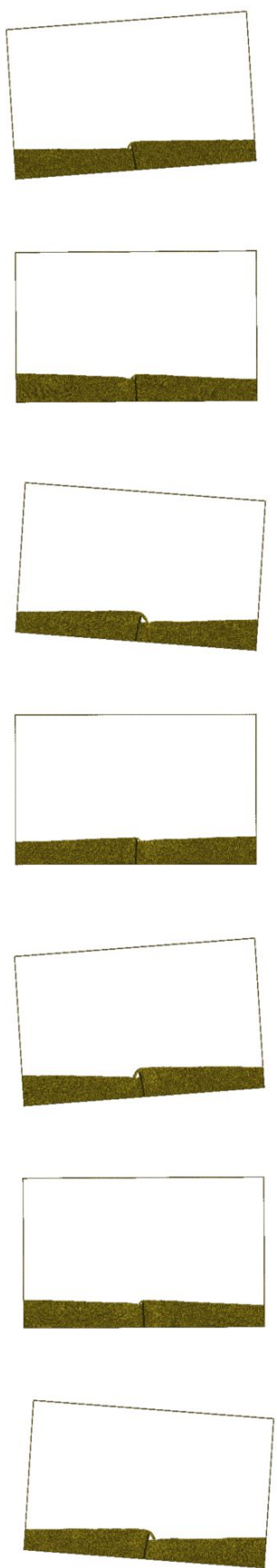

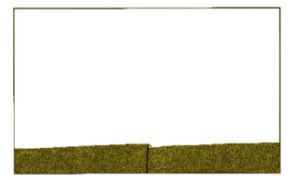

$\mathrm{dp}=0.5 \mathrm{~mm}$

Figura 5.32: Comparação entre o experimento e a simulação com o MPS para $d p=1.00,0.80$ e $0.50 \mathrm{~mm}(0.90 \mathrm{~s}, 1.20 \mathrm{~s}, 1.67 \mathrm{~s}, 2.07 \mathrm{~s}, 2.47 \mathrm{~s}, 2.87 \mathrm{~s}, 3.33 \mathrm{~s}, 3.76 \mathrm{~s})$. 


\subsubsection{Caso fundo}

A geometria inicial do caso fundo é apresentada na Figura 5.33, sendo que a placa elástica engastada, destacada em azul, possui as dimensões 0.40 x $11.48 \mathrm{~cm}$. Os valores adotados para as propriedades da placa elástica foram: densidade $\rho=1100 \mathrm{~kg} / \mathrm{m}^{3}$, módulo de Young $E=6 M P a$ e coeficiente de Poisson $\nu=0.49$; e para o fluído foram: densidade $\rho=917 \mathrm{~kg} / \mathrm{m}^{3}$ e viscosidade $v=5 \times 10^{-5} \mathrm{~m}^{2} / \mathrm{s}$. O tanque foi submetido a um movimento de rotação com um período $T=1.211 \mathrm{~s}$. Como parâmetros de simulação, os valores mostrados na Tabela 5.10 foram utilizados.

Tabela 5.10: Parâmetros de simulação.

\begin{tabular}{ccccc}
\hline$d p(\mathrm{~mm})$ & $\Delta t_{\text {fluido }}(\mathrm{s})$ & $\Delta t_{\text {solido }}(\mathrm{s})$ & Partículas de fluido & Partículas de sólido \\
\hline \hline 1.00 & $10^{-5}$ & $10^{-6}$ & 69920 & 460 \\
0.80 & $10^{-5}$ & $10^{-6}$ & 108864 & 720 \\
0.50 & $10^{-5}$ & $10^{-7}$ & 278300 & 1840 \\
\hline
\end{tabular}

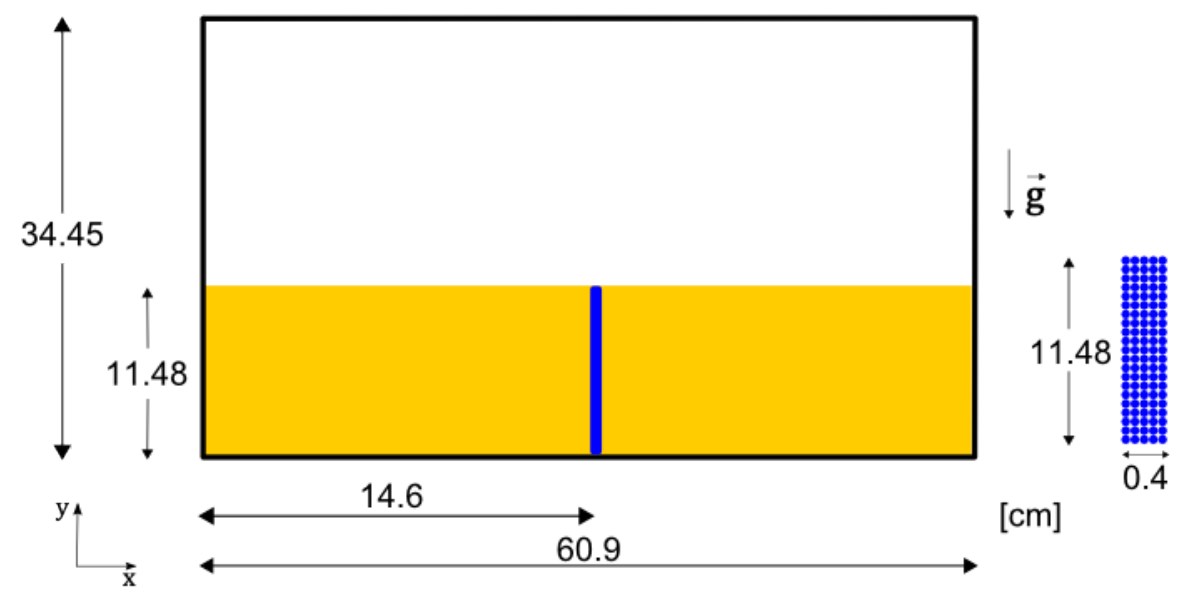

Figura 5.33: Condições iniciais do caso fundo de sloshing.

A Figura 5.34 apresenta o deslocamento horizontal da ponta da placa elástica, em relação ao seu referencial local, obtidos experimentalmente e numericamente. Da mesma forma que no caso raso, as diferenças nas excitações nos instantes iniciais impostas no modelo experimental e numérico, acarretam em discrepâncias relevantes, com os valores experimentais apresentando um deslocamento de $-3.94 \mathrm{~cm}$ no instante $0.68 \mathrm{~s}$, enquanto que a simulação com o MPS apresenta um deslocamento de $-5.22 \mathrm{~cm}$. Após o instante $1.00 s$, pode-se observar a oscilação da placa elástica, com período de aproximadamente $1.20 \mathrm{~s}$, para a medição experimental e obtido com o MPS. Após o instante $1.00 \mathrm{~s}$, a medição experimental apresenta valores extremos entre $-7.52 \mathrm{~cm}$ e $7.38 \mathrm{~cm}$, e o resultado do MPS apresenta valores extremos entre $-8.70 \mathrm{~cm}$ e $8.70 \mathrm{~cm}$ 


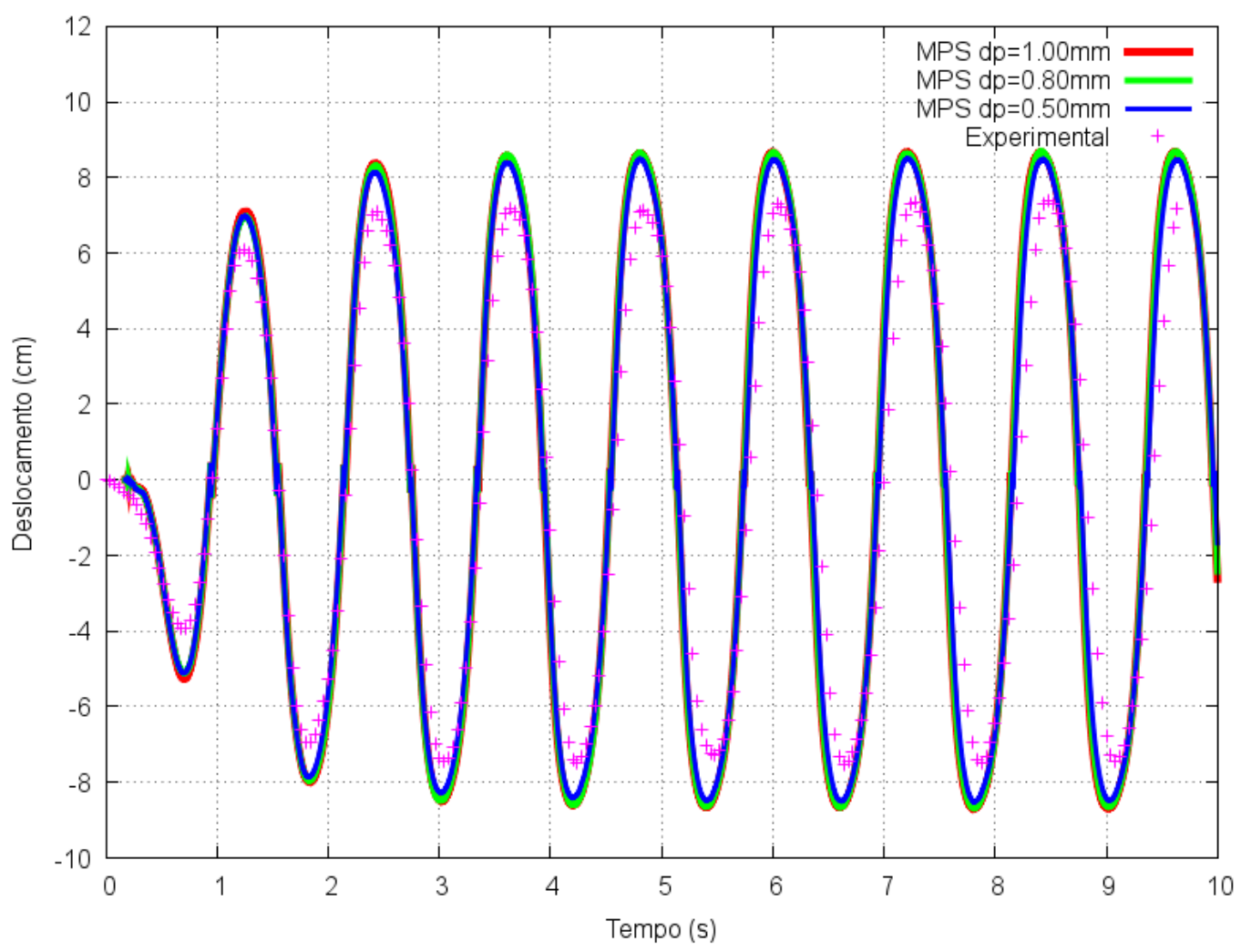

Figura 5.34: Deslocamento horizontal experimental da ponta da placa elástica e valores obtidos pelo MPS para $d p=1.00 \mathrm{~mm}, d p=0.80 \mathrm{~mm}$ e $d p=0.50 \mathrm{~mm}$.

Semelhante ao caso raso, a altura média da oscilação medida experimentalmente e a altura média obtida pelo MPS foram comparadas entre os instantes $2.44 \mathrm{~s}$ e 9.08. Novamente o erro foi calculado como a razão entre o módulo da diferença entre estas alturas pela altura experimental. A Tabela 5.11 apresenta os erros entre as medições experimentais e os resultados numéricos com o MPS para distâncias entre partículas $d p=1.00 \mathrm{~mm}, 0.80 \mathrm{~mm}$ e $0.50 \mathrm{~mm}$. Pode-se observar uma melhora entre os resultados experimentais e numérico em relação ao caso raso, e convergência entre os resultados obtidos pelo MPS.

Tabela 5.11: Erro MPS x Experimental.

\begin{tabular}{cccc}
\hline$d p(\mathrm{~mm})$ & Experimental $(\mathrm{cm})$ & MPS $(\mathrm{cm})$ & Erro $(\%)$ \\
\hline \hline 1.00 & 14.65 & 17.24 & 17.68 \\
0.80 & 14.65 & 17.22 & 17.54 \\
0.50 & 14.65 & 16.86 & 15.08 \\
\hline
\end{tabular}

A Figura 5.35 apresenta diferentes instantes de tempo do experimento e das simulações obtidas pelo MPS para distâncias entre partículas $d p=1.00,0.80$ e $0.50 \mathrm{~mm}$. Assim como no caso raso, pode ser observado um comportamento semelhante da placa elástica e fluido para o experimento e simulação com o MPS, independente da distância entre partículas. 

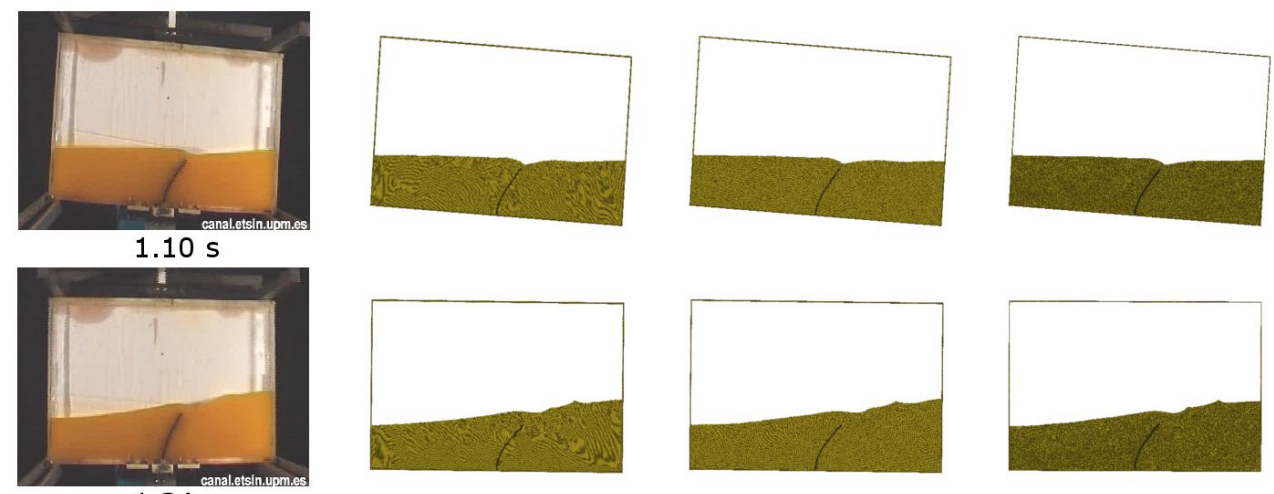

$1.34 \mathrm{~s}$
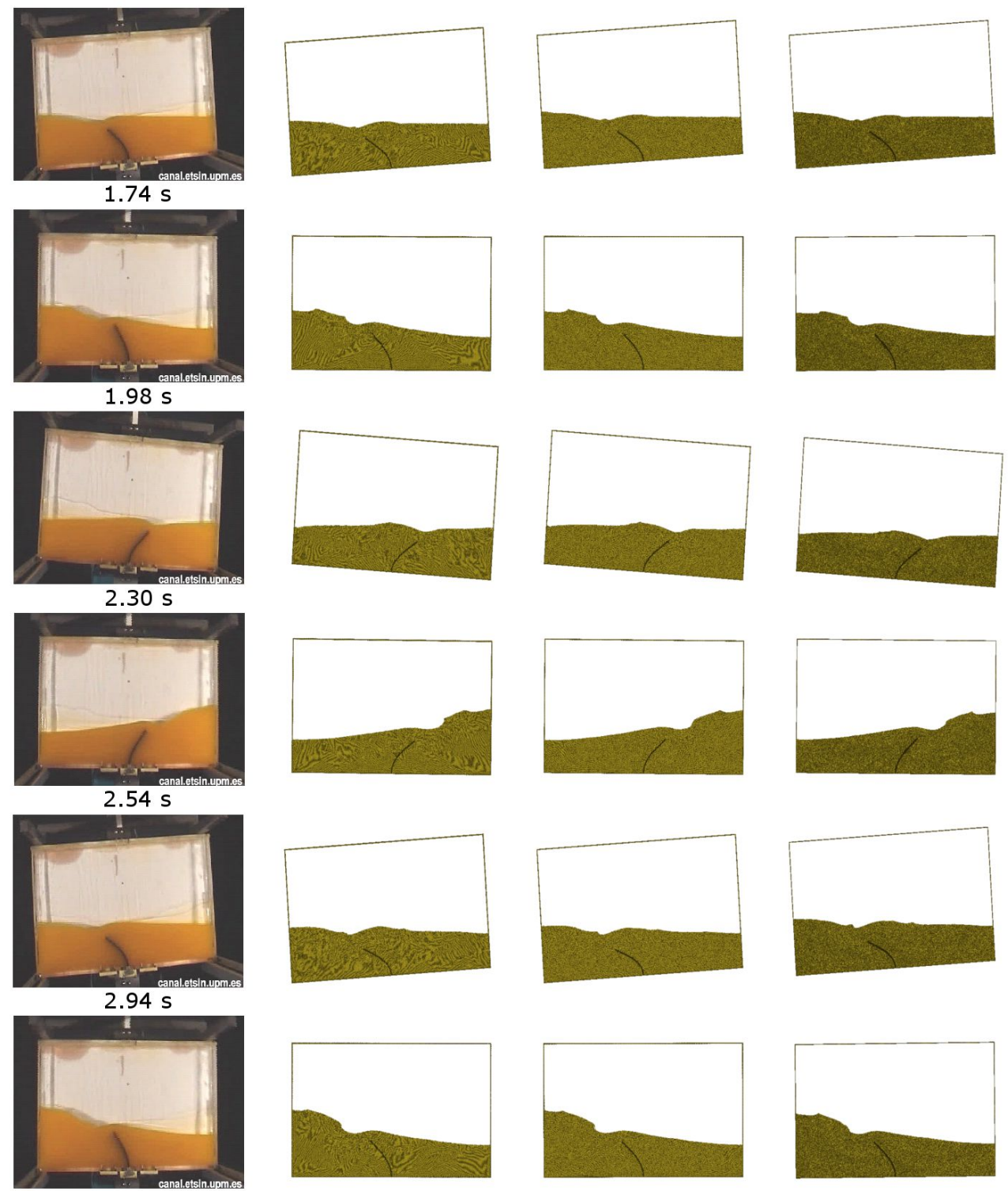

$\mathrm{dp}=1.0 \mathrm{~mm}$

$\mathrm{dp}=0.8 \mathrm{~mm}$

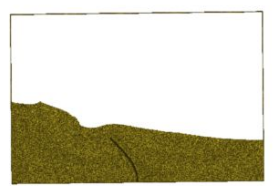

$\mathrm{dp}=0.5 \mathrm{~mm}$

Figura 5.35: Comparação entre o experimento e a simulação com o MPS para $d p=1.00,0.80$ e $0.50 \mathrm{~mm}(1.10 \mathrm{~s}, 1.34 \mathrm{~s}, 1.74 \mathrm{~s}, 1.98 \mathrm{~s}, 2.30 \mathrm{~s}, 2.54 \mathrm{~s}, 2.94 \mathrm{~s}, 3.18 \mathrm{~s})$. 


\section{Considerações Finais}

Este trabalho apresenta a implementação de um código computacional baseado no método MPS para simulação da dinâmica de sólidos elásticos e interação fluido-estrutura. Inicialmente, um caso estático de barra vertical presa na direção longitudinal em uma extremidade e livre na outra e um caso dinâmico de viga bi-engastada, submetidas ao peso próprio, foram simulados com o MPS e os resultados de deslocamento e frequência natural, no caso dinâmico, foram comparados com soluções analíticas auxiliando na validação do código. Feita estas validações, um algoritmo de fragmentação e detecção de contato foi proposto, permitindo a simulação de casos envolvendo fragmentação entre sólidos elásticos. Um caso de colisão entre 3 sólidos elásticos de propriedades e geometrias diferentes e um caso de 2 sólidos de propriedades e geometrias diferentes com possibilidade de fragmentação foram simulados, demonstrando a capacidade do método para simulação de diferentes fenômenos dinâmicos.

Na terceira parte do trabalho, o código computacional implementado foi acoplado com outro módulo do simulador MPS para fluido, permitindo a simulação de casos de interação fluido-estrutura. Três casos foram simulados e comparados com outros métodos computacionais ou resultados experimentais encontrados na literatura. No primeiro caso, uma coluna d'água colapsou com uma placa elástica e o deslocamento horizontal da placa obtido pelo MPS foi comparado com valores encontrados na literatura, obtidos por outros métodos, apresentando boa concordância. No segundo caso, uma coluna d'água foi confinada entre duas paredes verticais, com uma das parede modelada como uma placa elástica, possibilitando a saída de água. Inicialmente, as curvas obtidas pelo MPS seguiram a mesma tendência apresentada pelos valores experimentais, mas devido as equações constitutivas adotadas neste trabalho, que não levam em conta as não linearidades do material utilizado no experimento, notou-se uma discrepância relevante a partir de um certo valor de deformação da placa elástica. No terceiro caso, sloshing no interior de um tanque, interagindo com uma placa elástica engastada, foi simulado, considerando duas alturas de fluido, raso e fundo. Para o caso raso notou-se erros significativos nos des- 
locamentos, enquanto que no caso fundo pode-se observar melhora na comparação com o experimento e convergência entre os resultados do MPS. Nestas simulações, pode ser observado a capacidade do método para simular escoamentos com a presença de superfície livre interagindo com sólidos elásticos.

Como um primeiro trabalho de investigação do MPS para simulação dinâmica de sólidos elásticos, as simulações realizadas neste trabalho mostraram o potencial do MPS para estudar os casos envolvendo apenas sólidos elásticos ou sólidos elásticos em interação com escoamentos de superfície livre. Para um desenvolvimento futuro, algumas questões merecem destaque, seja pelas dificuldades encontradas neste trabalho ou pelo aprofundamento e ampliação da aplicabilidade do MPS:

- Por ser um método explícito, a influência do método de integração sobre a estabilidade e a conservação de energia, é muito importante para problemas envolvendo um longo período de tempo. Desta forma, outros métodos de integração temporal podem ser estudados;

- Não restrito a materiais com propriedades de elasticidade linear, a implementação de modelos não-linear e modelos de plasticidade;

- Para um melhor desempenho computacional, a implementação em GPU para um menor gasto computacional e a implementação em cluster (conjunto de computadores) para simulação de uma grande quantidade de partículas, são tarefas essenciais para aperfeiçoamento do simulador. 


\section{Referências}

AHMADIAN, M. T.; FIROOZBAKHSH, K; HASANIAN, M. Simulation of red blood cell motion in microvessels using modified moving particle semi-implicit method. Scientia Iranica, v. 19, n. 1, p. 113-118, 2012.

AMANIFARD, N.; HESSAN, M.; RAHBAR, B. An SPH approach for fluid-hypoelastic structure interactions with free surfaces. In Proceedings of the World Congress on Engineering, v. 3, p. 2256-2261, 2011.

ANTOCI, C.; GALLATI, M.; SIBILLA, S. Numerical simulation of fluid-structure interaction by SPH. Computers \& Structures, v. 85, n. 11-14, p. 879-890, 2007.

ARGYRIS, J. H.; KELSEY, S. Energy theorems and structural analysis: A generalized discourse with applications on energy principles of structural analysis including the effects of temperature and non-linear stress-strain relations part II. Applications to thermal stress problems and St. Venant torsion. Aircraft Engineering and Aerospace Technology, v. 26, n. 12, p. 410-422, 1954.

ATAIE-ASHTIANI, B.; FARHADI, L. A stable moving-particle semi-implicit method for free surface flows. Fluid Dynamics Research, v. 38, n. 4, p. 241-256, 2006.

BARAFF, D. An introduction to physically based modeling: rigid body simulation 1 unconstrained rigid body dynamics. Lecture Note of SIGGRAPH'9', 1997.

BECKER, A. A. The boundary element method in engineering: a complete course. McGraw-Hill, 1992.

BONET, J.; LOK, T.-S.L. Variational and momentum preservation aspects of smooth particle hydrodynamic formulations. Computer Methods in Applied Mechanics and Engineering, v. 180, n. 1-2, p. 97-115, 1999.

BRUMELEN, E. H.; HULSHOFF, S. J.; BORST, R. Energy conservation under incompatibility for fluid-structure interaction problems. Computer Methods in Applied Mechanics and Engineering, v. 192, n. 25, p. 2727-2748, 2003.

CHHATKULI, S.; KOSHIZUKA, S.; UESAKA, M. Dynamic tracking of lung deformation during breathing by using particle method. Modelling and Simulation in Engineering, v. 2009, p. 1-7, 2009.

CHHATKULI, S.; KOJIMA, H.; KOSHIZUKA, S.; UESAKA, M. Meshfree simulation of lung deformation during inspiration. In Proceedings of the World Congress on Engineering and Computer Science 2009 Vol II, San Francisco, USA, 2009.

CHENG, A. H.-D.; CHENG, D. T. Heritage and early history of the boundary element method. Engineering Analysis with Boundary Elements, v. 29, n. 3, p. 268-302, 2005. 
CHIKAZAWA, Y.; KOSHIZUKA, S.; OKA, Y. A particle method for elastic and visco-plastic structures and fluid-structures interactions. Computational Mechanics, v. 27, n. 2, p. 97-106, 2001.

COOK, R. D.; MALKUS, D. S.; PlESHA, M. E.; WITT, R. J. Concepts and Applications of Finite Element Analysis. John Wiley e Sons, Inc., 2002.

COURANT, R.; FRIEDRICHS, K.; LEWY, H. On the partial difference equations of mathematical physics. IBM Journal of Research and Development, v. 11, n. 2, p. 215-234, 1967.

CUNDALL, P. A.; STRACK, O. D. L. A discrete numerical model for granular assemblies. Geotechnique, v. 29, n. 1, p. 47-65, 1979.

DALY, B. J.; HARLOW, F. H.; WELCH, J. E.; WILSON, E. N.; SAMMANN, E. E. Numerical fluid dynamics using the particle-and-force method. LA3144.

DONEA, J.; GIULIANI, S.; HALLEUX, J. An arbitrary lagrangian-eulerian finite element method for transient dynamic fluid-structure interactions. Computer Methods in Applied Mechanics and Engineering, v. 33, n. 1-3, p. 689-723, 1982.

DUNNE, T.; RANNACHER, R. Adaptive finite element approximation of fluid-structure interaction based on an Eulerian variational formulation. Lecture Notes in Computational Science and Engineering, v. 53, p. 110-145, 2006.

EYMARD, R.; GALLOUËT, T.; HERBIN, R. Finite volume methods, Handbook of numerical analysis, v. 7, North-Holland, Amsterdam, 2000. p. 713-1020.

GHUGAL, Y. M.; SHARMA, R. A refined shear deformation theory for flexure of thick beams. Latin American Journal of Solids and Structures, v. 8, n. 2, p. 183-195, 2011.

Gingold, R. A.; MONAGHAN, J. J. Smoothed particle hydrodynamics: theory and application to non-spherical stars. Monthly Notices of the Royal Astronomical Society, vol. 181, p. 375-389, 1977.

GOTOH, H.; IKARI, H.; MEMITA, T.; SAKAI, T. Lagrangian particle method for simulation of wave overtopping on a vertical seawall. Coastal Engineering Journal, v. 47, n. 2-3, p. 157-181, 2005.

GOTOH, H.; SAKAI, T. Key issues in the particle method for computation of wave breaking. Coastal Engineering, v. 53, n. 2-3, p. 171-179, 2006.

HARLOW, F. H. The particle-in-cell computing method for fluid dynamics. Methods in Computational Physics, v. 3, p. 319-343, 1964.

HARLOW, F. H.; WELCH, J. E. Numerical calculation of time-dependent viscous incompressible flow of fluid with free surface. Physics of Fluids, v. 8, n. 12, p. 2182-2189, 1965.

HEO, S. Y.; KOSHIZUKA, S.; OKA, Y. Numerical analysis of boiling on high heat-flux and high subcooling condition using MPS-MAFL. International Journal of Heat and Mass Transfer, v. 45, n. 13, p. 2633-2642, 2002. 
HIRASAWA, S.; BADARINARAYAN, H.; OKAMOTO, K.; TOMIMURA, T.; KAWANAMI, T. Analysis of effect of tool geometry on plastic flow during friction stir spot welding using particle method. Journal of Materials Processing Technology, v. 210, n. 11, p. 1455-1463, 2010.

HORI, C.; GOTOH, H.; IKARI, K.; KHAYYER, A. GPU-acceleration for moving particle semi-implicit method. Computers \& Fluids, v. 51, n. 1, p. 174-183, 2011.

ICHIKAWA, H.; LABROSSE, S. Smooth particle approach for surface tension calculation in moving particle semi-implicit method. Fluyd Dynamics Research, v. 42, n. 3, p. 1-18, 2010.

IDELSOHN, S. R.; OÑATE, E.; DEL PIN, F. The particle finite element method: a powerful tool to solve incompressible flows with free-surfaces and breaking waves. International Journal for Numerical Methods in Engineering, v. 61 n. 7, p. 964-989, 2004.

IDELSOHN, S. R.; OÑTE, E. To mesh or not to mesh. That is the question... . Computer Methods in Applied Mechanics and Engineering, v. 195, n. 37-40, p. 4681-4696, 2006.

IDELSOHN, S. R.; MARTI, J.; SOUTO-IGLESIAS, A.; OÑATE, E. Interaction between an elastic structure and free-surface flows: experimental versus numerical comparisons using the PFEM. Computational Mechanics, v. 43 n. 1, p. 125-132, 2008a.

IDELSOHN, S. R.; MARTI, J.; LIMACHE, A.; OÑATE, E. Unified lagrangian formulation for elastic solids and incompressible fluids: application to fluid-structure interaction problems via the PFEM. Computer Methods in Applied Mechanics and Engineering, v. 197 n. 19-20, p. 1762-1776, 2008b.

IKEDA, H.; KOSHIZUKA, S.; OKA, Y.; PARK, H. S.; SUGIMOTO, J. Numerical analysis of jet injection behavior for fuel-coolant interaction using particle method. Journal of Nuclear Science and Technology, v. 38, n. 3, p. 174-182, 2001.

ISHIHARA, D.; YOSHIMURA, S. A monolithic approach for interaction of incompressible viscous fluid and an elastic body based on fluid pressure Poisson equation. International Journal for Numerical Methods in Engineering, v. 64, n. 2, p. 167-203, 2005.

ISSHIKI, H. Discrete differential operators on irregular nodes (DDIN). International Journal for Numerical Methods in Engineering, v. 88, n. 12, p. 1323-1343, 2011.

KAKUDA, K.; TOYOTANI, J.; MATSUDA, S.; TANAKA, H.; KATAGIRI, K. Flow simulations by a particle method using logarithmic weighting function. Structural Longevity, v. 4, n. 3, p. 154-161, 2010.

KAKUDA, K.; NAGASHIMA, T.; HAYASHI, Y.; OBARA, S.; TOYOTANI, J.; KATSURADA, N.; HIGUCHI, S.; MATSUDA, S. Particle-based fluid flow simulations on GPGPU using CUDA. Computer Modeling in Engineering $\&$ Sciences, v. 88, n. 1, p. 17-28, 2012a.

KAKUDA, K.; OBARA, S.; TOYOTANI, J.; MEGURO, M.; FURUICHI, M. Fluid flow simulation using particle method and its physics-based computer graphics. Computer Modeling in Engineering \& Sciences, v. 83, n. 1, p. 57-72, 2012b. 
KAMADA, H.; TSUBOTA, K.; NAKAMURA, M.; ISHIKAWA, T.; YAMAGUCHI, T. A three-dimensional particle simulation of the formation and collapse of a primary thrombus. International Journal for Numerical Methods in Biomedical Engineering, v. 26, n. 3-4, p. 488-500, 2010.

KHAYYER, A.; GOTOH, H. Development of CMPS method for accurate water-surface tracking in breaking waves. Coastal Engineering Journal, v. 50, n. 2, p. 179-207, 2008.

KHAYYER, A.; GOTOH, H. On particle-based simulation of a dam break over a wet bed. Journal of Hydraulic Research, v. 48, n. 2, p. 238-249, 2010.

KHAYYER, A.; GOTOH, H. Enhancement of stability and accuracy of the moving particle semi-implicit method. Journal of Computational Physics, v. 230, n. 8, p. 3093-3118, 2011.

KHAYYER, A.; GOTOH, H. A 3D higher order Laplacian model for enhancement and stabilization of pressure calculation in 3D MPS-based simulations. Applied Ocean Research, v. 37, p. 120-126, 2012.

KIM, K.-S.; LEE, B.-H.; KIM, M.-H.; PARK, J.-C. Simulation of sloshing effect on vessel motions by using MPS (Moving Particle Simulation). Computer Modeling in Engineering E Sciences, v. 79, n. 3, p. 201-221, 2011.

KONDO, M.; KOSHIZUKA, S. Improvement of stability in moving particle semi-implicit method. International Journal for Numerical Methods in Biomedical Engineering, v. 65, n. 6, p. 638-654, 2011.

KOSHIZUKA, S.; OKA, Y.; TAMAKO, H. A particle method for calculating splashing of incompressible viscous fluid. In Proceedings International Conference on Mathematics and Computations, Reactor Physics and Environmental Analyses , v. 2, p. 1514-1521, 1995.

KOSHIZUKA, S.; TAMAKO, H.; OKA, Y. A particle method for incompressible viscous flow with fluid fragmentation. Computational Fluid Dynamics Journal, v. 4, n. 1, p. 29-46, 1995.

KOSHIZUKA, S.; OKA, Y. Moving-particle semi-implicit method for fragmentation of incompressible fluid. Nuclear Science and Engineering, v. 123, n. 3, p. 421-434, 1996.

KOSHIZUKA, S.; NOBE, A.; OKA, Y. Numerical analysis of breaking waves using the moving particle semi-implicit method. International Journal for Numerical Methods in Fluids, v. 26, n. 7, p. 751-769, 1998.

KOSHIZUKA, S.; IKEDA, H.; OKA, Y. Numerical analysis of fragmentation mechanisms in vapor explosions. Nuclear Engineering and Design, v. 189, n. 1-3, p. 423-433, 1999.

KOSHIZUKA, S.; SONG, M.; OKA, Y. A particle method for three-dimensional elastic analysis. In Proceedings of the 6th WCCM in Conjunction with APCOM, Beijing, China, 2004 .

KOSHIZUKA, OKA, Y. Moving particle semi-implicit method: fully lagrangian analysis of incompressible flows. In European Congress on Computational Methods in Applied Sciences and Engineering. ECCOMAS 2000, Barcelona, 2000. 
KUHL, E.; HULSHOFF, S.; BORST, R. An arbitrary lagrangian eulerian finite-element approach for fluid-structure interaction phenomena. International Journal for Numerical Methods in Engineering, v. 57, n. 1, p. 117-142, 2003.

LEE, B.-H.; PARK, J.-C.; KIM, M.-H.; HWANG, S.-C. Moving particle simulation for mitigation of sloshing impact loads using surface floaters. Computer Modeling in Engineering 85 Sciences, v. 75, n. 2, p. 89-112, 2011a.

LEE, B.-H.; PARK, J.-C.; KIM, M.-H.; HWANG, S.-C. Step-by-step improvement of MPS method in simulating violent free-surface motions and impact-loads. Computer Methods in Applied Mechanics and Engineering, v. 200, n. 9-12, p. 1113-1125, 2011b.

LEE, C. J. K.; NOGUSHI, H.; KOSHIZUKA, S. Fluid-shell structure interaction analysis by coupled particle and finite element method. Computer and Structures, v. 85, n. 11-14, p. 688-697, 2007.

LEE, J.; SCHULTZ, W. W. Eigenvalue analysis of Timoshenko beams and axisymmetric Mindlin plates by the pseudospectral method. Journal of Sound and Vibration, v. 269, n. 3-5, p. 609-621, 2004.

LIU, C.; WALKINGTON, N. J. An Eulerian description of fluids containing viscoelastic particles. Rational Mechanics and Analysis, v. 159, p. 229-252, 2001.

LIU, G. R. Meshfree Methods: Moving Beyond the Finite Element Method. CRC Press, 2003.

LIU, G. R.; GU, Y. T. An Introduction to Meshfree Methods and Their Programming. Springer, 2005.

LO, D. C.; YOUNG, D. L. Arbitrary Lagrangian-Eulerian finite element analysis of free surface flow using a velocity-vorticity formulation Journal of Computational Physics, v. 195, n. 1, p. 175-201, 2004.

LUCY, L. A numerical approach to the testing of the fission hypothesis. Astronomical Journal, v. 82, p. 1013-1024, 1977.

MARTI, J.; IDELSOHN, S. R.; LIMACHE, A.; CALVO, N.; D'EllA, J. A fully coupled particle method for quasi-incompressible fluid-hypoelastic structure interactions. Asociación Argentina de Mecánica Computacional, v. 25, n. 9, p. 809-827, 2006.

MARTIN, J. C.; MOYCE, W. J. An experimental study of the collapse of liquid column on a rigid horizontal plane. Philosophical Transactions Royal Society London, v. A244, p. 312-324, 1952.

NAGAYAMA, K.; HONDA, K. 3D particle simulations of deformation of red blood cells in micro-capillary vessel. Fluid Dynamics, Computational Modeling and Applications, p. 463-474, 2012.

NAKAZA, E.; IRIBE, T.; ROUF, M. A. Numerical simulation of tsunami currents around moving structures. In Proceedings of the International Conference on Coastal Engineering, Shangai, China, 2010. 
NOMURA, K.; KOSHIZUKA, S.; OKA, Y.; OBATA, H. Numerical analysis of droplet breakup behavior using particle method. Journal of Nuclear Science and Technology, v. 38, n. 12, p. 1057-1064, 2001.

OGASAWARA, T.; KIKUCHI, S.; SAKAI, S. Dynamic analysis of fluid-elastic solid interaction using the moving particle semi-implicit method. In Coasts, marine structures and breakwaters, p. 414-423, 2010.

PAIK, K. J. Simulation of fluid-structure interaction for surface ships with linear/nonlinear deformations. Tese (Doutorado) - University og Iowa, 2010.

PARK, S.; JEUN, G. Coupling of rigid body dynamics and moving particle semi-implicit method for simulating isothermal multi-phase fluid interactions. Computer Methods in Applied Mechanics and Engineering, v. 200, n. 1-4, p. 130-140, 2011.

PIPERNO, S.; FARHAT, C.; LARROUTUROU, B. Partitioned procedures for the transient solution of coupled aeroelastic problems - Part I: Model problem, theory and two-dimensional applications. Computer Methods in Applied Mechanics and Engineering, v. 124, n. 1-2, p. 79-112, 1995.

PREMOZE, S.; TASDIZEN, T.; BIGLER, J.; LEFOHN, A.; WHITAKER, R. T. Particle-based simulation of fluids. In Eurographics 2003, v. 22, n. 3, p. 401-410, 2003.

RAFIEE, A.; THIAGARAJAN K. P.; An SPH projection method for simulating fluid-hypoelastic structure interaction. Computer Methods in Applied Mechanics and Engineering, v. 198, n. 33-36, p. 2785-2795, 2009.

ROBORTELLA, M. S.; CHENG, L.; NISHIMOTO, K. Dynamic analizes of elastic structures by using moving particle semi-implicit method (mps). In Proceedings of the 20th International Congress of Mechanical Engineering (COBEM 2009), 2009.

SANCHES, R. A. K.; CODA, H. B. Fluid-structure interaction using an arbitrary lagrangian-eulerian fluid solver coupled to a positional lagrangian shell solver. Mecânica Computacional, v. 24, p. 1627-1647, 2010.

SHAKIBAEINIA, A.; JIN, Y.C.; A weakly compressible MPS method for modeling of open-boundary free-surface flow. International Journal for Numerical Methods in Fluids, v. 63, n. 10, p. 1208-1232, 2010.

SHAKIBAEINIA, A.; JIN, Y.C.; A mesh-free particle model for simulation of mobile-bed dam break. Advances in Water Resources, v. 34, n. 6, p. 794-807, 2011.

SHAO, S.; GOTOH, H. Turbulence particle models for tracking free surfaces. Journal of Hydraulic Research, v. 43, n. 3, p. 276-289, 2005.

SHEU, T. W. H.; CHIAO, C.; HUANG, C. Development of a particle interaction kernel function in MPS method for simulating incompressible free surface flow. Journal Applied Mathematics, p. 1-16, 2011.

SHIBATA, K.; KOSHIZUKA, S. Numerical analysis of shipping water impact on a deck using a particle method. Ocean Engineering, v. 34, n. 3-4, p. 585-593, 2007a. 
SHIBATA, K.; TANIZAWA, K.; KOSHIZUKA, S. Numerical analysis of coupling between ship motion and green water on Ddeck using MPS method. In Proceedings of International Conference on Violent Flows, 2007b.

SHIBATA, K.; KOSHIZUKA, S.; ; TANIZAWA, K. Three-dimensional numerical analysis of shipping water onto a moving ship using a particle method. Journal of Marine Science and Technology, v. 14, n. 2, p. 214-227, 2009.

SHIBATA, K.; KOSHIZUKA, S.; SAKAI, M.; TANIZAWA, K. Lagrangian simulations of ship-wave interactions in rough seas. Ocean Engineering, v. 42, p. 13-25, 2012.

SONG, M.; KOSHIZUKA, S.; OKA, Y. Dynamic analysis of elastic solids by mps method. In International Conference on Global Environment and Advanced Nuclear Power Plants,(GENES4/ANP 2003), Kyoto, Japan, 2003.

SONG, M.; KOSHIZUKA, S.; OKA, Y. A particle method for dynamic simulation of elastic solids. In Proceedings of the 6th WCCM in Conjunction with APCOM, Beijing, China, 2004.

SORIANO, H. L. Método de Elementos Finitos em Análise de Estruturas. São Paulo: Editora da Universidade de São Paulo, 2003.

SOULI, M.; BENSON, D. J. Arbitrary Lagrangian Eulerian and Fluid-Structure Interaction: Numerical Simulation. Wiley, 2010.

SOUTO-IGLESIAS, A.; MACIÀ, F.; GONZÁLEZ, L. M.; CERCOS-PITA, J. L. On the consistency of MPS. Computer Physics Communications, v. 184, p. 732-745, 2013.

SUEYOSHI, M.; KIHARA, H.; KASHIWAGI, M. A hybrid technique using particle and boundary-element methods for wave-body interaction problems. In Proceedings of the 9th International Conference on Numerical Ship Hydrodynamics, Ann Arbor, Michigan, 2007.

SUEYOSHI, M.; KIHARA, H.; KASHIWAGI, M. Numerical simulation using particle and boundary element method for highly nonlinear interaction problems between waves and floating body. , p. 93-101, 2008.

SUEYOSHI, M. Numerical simulation of tank sloshing with thin plate structures by using a particle method. In Proceedings of the Nineteenth (2009) International Offshore and Polar Engineering Conference, p. 303-307, 2009.

SULSKY, D.; CHEN, Z.; SCHREYER, H. L. A Particle method for history-dependent materials. Computer Methods in Applied Mechanics and Engineering, v. 118, n. 1, p. 179-196, 1994.

SUN, Z.; XI, G.; CHEN, X. A numerical study of stir mixing of liquids with particle method. Chemical Engineering Science, v. 64, n. 2, p. 341-350, 2009a.

SUN, Z.; XI, G.; CHEN, X. Mechanism study of deformation and mass transfer for binary droplet collisions with particle method. Physics of Fluids, v. 21, n. 3, 2009b.

TANAKA, M.; MASUNAGA, T. Stabilization and smoothing of pressure in MPS method by quasi-compressibility. Journal of Computational Physics, v. 229, n. 11, p. 4279-4290, 2010. 
TANIGUCHI, D.; SATO, L. M.; CHENG, L. Y. Explicit moving particle simulation method on GPU clusters. In 10th World Congress on Computational Mechanics, 2012.

THOM, A.; APELT, C. J. Field Computations in Engineering and Physics. London: Van Nostrand, 1961.

TIAN, W.; ISHIWATARI, Y.; IKEJIRI, S.; YAMAKAWA, M.; OKA, Y. Numerical computation of thermally controlled steam bubble condensation using Moving Particle Semi-implicit (MPS) method. Annals of Nuclear Energy, v. 37, n. 1, p. 5-15, 2010.

TIMOSHENKO, S. P. On the correction for shear of the differential equation for transverse vibrations of prismatic bars. Philosophical Magazine Series, v. 41, p. 742-746, 1921.

TSUBOTA, K.i.; WADA, S.; KAMADA, H.; KITAGAWA, Y.; LIMA, R.; YAMAGUCHI, T. A particle method for blood flow simulation, - Application to flowing red blood cells and platelets -. Journal of the Earth Simulator, v. 5, p. 2-7, 2006.

TSUBOTA, K.i.; WADA, S.; YAMAGUCHI, T. Particle method for computer simulation of red blood cell motion in blood flow. Computer Methods and Programs in Biomedicine, v. 83, n. 2, p. 139-146, 2006.

TSUKAMOTO, M. M. Desenvolvimento do método de partículas na representação de corpos flutuantes em ondas altamente não-lineares. Dissertação (Mestrado) — Escola Politécnica da USP , 2006.

TSUKAMOTO, M. M.; CHENG, L.; NISHIMOTO, K. Analytical and numerical study of the effects of an elastically-linked body on sloshing. Computers $\mathscr{E}$ Fluids, v. 49, n. 1, p. 1-21, 2011.

TURNER, M. J.; CLOUGH, R. W.; MARTIN, H. C.; TOPP, L. J. Stiffness and deflection analysis of complex structures. Journal of Aeronautical Science, v. 23, n. 9, p. 805-823, 1956.

WALHORN, E.; KOLKE, B.; HUBNER, B.; DINKLER, D. Fluid-structure coupling within a monolithic model involving free surface flows. Computers 85 Structures, v. 83, n. 25-26, p. 2100-2111, 2005.

YAMAMOTO, K. Real time two-way coupling of fluids to deformable bodies using particle method on GPU. ACM SIGGRAPH ASIA 2009 posters, 2009.

YANG, Q.; JONES, V.; MCCUE, L. Free-surface flow interactions with deformable structures using an SPH-FEM model. Ocean Engineering, v. 55, n. 0, p. 136-147, 2012.

YOON, H. Y.; KOSHIZUKA, S.; OKA, Y. A particle-gridless hybrid method for incompressible flows. International Journal of Numerical Methods in Fluids, v. 30, n. 4, p. 407-424, 1999.

XIE, H. Y.; KOSHIZUKA, S.; OKA, Y. Simulation of drop deposition process in annular mist flow using three-dimensional particle method. Nuclear Engineering and Design, v. 235, n. 16 , p. 1687-1697, 2005. 
ZHANG, S.; MORITA, K.; SHIRAKAWA, N.; FUKUDA, K. Simulation of the RayleighTaylor Instability with the MPS method. Memoirs of the Faculty of Engineering, Kyusku University, v. 64, n. 4, p. 215-228, 2004.

ZHANG, S.; MORITA, K.; FUKUDA, K.; SHIRAKAWA, N. An improved MPS method for numerical simulations of convective heat transfer problems. International Journal of Numerical Methods in Fluids, v. 51, n. 1, p. 31-47, 2006a.

ZHANG, S.; MORITA, K.; FUKUDA, K.; SHIRAKAWA, N. Simulation of threedimensional convection patterns in a Rayleigh-Benard system using the MPS method. Memoirs of the Faculty of Engineering, Kyusku University, v. 66, n. 1, p. 29-37, 2006b.

ZHANG, Y.; WAN, D. Apply MPS method to simulate liquid sloshing in LNG tank. In Proceedings of the Twenty-second (2012) International Offshore and Polar Engineering Conference, v. 4, p. 381-391, 2012.

ZHU, X.; CHENG, L.; LU, L.; TENG, B. Implementation of the moving particle semi-implicit method on GPU. Science China Physics, Mechanics and Astronomy, v. 54, n. 3, p. 523-532, 2011.

ZIENKIEWICZ, O. C.; TAYLOR, R. L. The Finite Element Method. Vol I: The Basis. Oxford: Butterworth-Heinemann, 2000. 


\section{Anexo A - Método MPS para fluido}

\section{A.1 Equações governantes de fluidos}

As equações governantes para escoamentos incompressíveis são representadas pela lei da conservação de massa e do momento

$$
\begin{gathered}
\frac{D \rho}{D t}+\rho(\nabla \cdot \boldsymbol{v})=0 \\
\frac{D \boldsymbol{v}}{D t}=-\frac{1}{\rho} \nabla P+\nu \nabla^{2} \boldsymbol{v}+\boldsymbol{f}
\end{gathered}
$$

onde $\rho$ é a massa específica, $\boldsymbol{v}$ o vetor velocidade, $P$ a pressão, $\nu$ a viscosidade cinemática e $\boldsymbol{f}$ o vetor força externa.

\section{A.2 Algoritmo para o escoamento incompressível}

Para simulação de escoamento incompressível, um algoritmo semi-implícito é utilizado no método MPS. Inicialmente, velocidade $\boldsymbol{v}_{i}{ }^{*}$ e posição $\boldsymbol{r}_{i}{ }^{*}$ são calculadas explicitamente para cada partícula $i$, considerando os termos de viscosidade $\nu \nabla^{2} \boldsymbol{v}$ e força externa $\boldsymbol{f}$ da equação de conservação do momento, Eq. (A.2), (IKEDA, 2001)

$$
\begin{gathered}
\boldsymbol{v}_{i}^{*}=\boldsymbol{v}_{i}^{n}+\Delta t\left(\nu \nabla^{2} \boldsymbol{v}_{i}^{n}+\boldsymbol{f}_{i}\right) \\
\boldsymbol{r}_{i}^{*}=\boldsymbol{r}_{i}^{n}+\Delta t \boldsymbol{v}_{i}^{*}
\end{gathered}
$$

Sendo a massa específica do fluido $\rho$ proporcional ao número de densidade de partículas $n_{i}$, aplicando-se a lei da conservação de massa, Eq. (A.1), têm-se que o divergente da velocidade $\boldsymbol{v}_{i}^{\prime}$ é dado por 


$$
\nabla \cdot \boldsymbol{v}_{i}^{\prime}=-\frac{1}{\Delta t} \frac{\rho_{i}^{n+1}-\rho_{i}^{*}}{\rho^{0}}=-\frac{1}{\Delta t} \frac{n_{i}^{n+1}-n_{i}^{*}}{n^{0}}
$$

onde $n_{i}^{*}$ é o número de densidade de partículas calculado após os cálculos da parte explícita, e a velocidade $\boldsymbol{v}_{i}^{\prime}$ é obtida pelos termos de pressão calculados implicitamente na equação de conservação do momento

$$
\boldsymbol{v}_{i}^{\prime}=-\frac{\Delta t}{\rho} \nabla P_{i}^{n+1}
$$

Substituindo a Eq. (A.5) na Eq. (A.6), e considerando escoamento incompressível, i.e. $n_{i}^{n+1}=n_{0}$, a equação de Poisson para a pressão fica

$$
\nabla^{2} P_{i}^{n+1}=\frac{\rho}{\Delta t^{2}} \frac{n_{i}^{0}-n_{i}^{*}}{n^{0}}
$$

Admitindo um modelo com baixa compressibilidade, a resolução numérica do sistema de equações é obtida de forma mais rápida em comparação ao modelo incompressível, considerado na Eq. (A.7), melhorando a eficiência computacional. Comparado com resultados do modelo incompressível, o modelo de baixa compressibilidade apresenta efeitos desprezíveis quanto a acurácia dos resultados (SHAKIBAEINIA; JIN, 2010). Além disto, um coeficiente de relaxação $\kappa$ é utilizado, melhorando a estabilidade do método computacional. Assim, a Eq. (A.7) é reescrita como

$$
\nabla^{2} P_{i}^{n+1}-\alpha P_{i}^{n+1}=\kappa \frac{\rho}{\Delta t^{2}} \frac{n_{i}^{0}-n_{i}^{*}}{n^{0}}
$$

onde $\alpha=1 /\left(\rho c^{2}\right)$ e $c$ a velocidade do som. É importante salientar que valores muito baixos de $\kappa$ aumentam a compressibilidade do fluído.

Por fim, através da Eq. (A.6), a velocidade $\boldsymbol{v}_{i}{ }^{n+1}$ da partícula $i$ é atualizada e a nova posição $\boldsymbol{r}_{i}^{n+1}$ é obtida por

$$
\boldsymbol{r}_{i}^{n+1}=\boldsymbol{r}_{i}^{n}+\Delta t \boldsymbol{v}_{i}^{n+1}
$$

O fluxograma do algoritmo semi-implícito baseado no método MPS para simular a dinâmica de fluidos é apresentado na Fig. (A.1). 


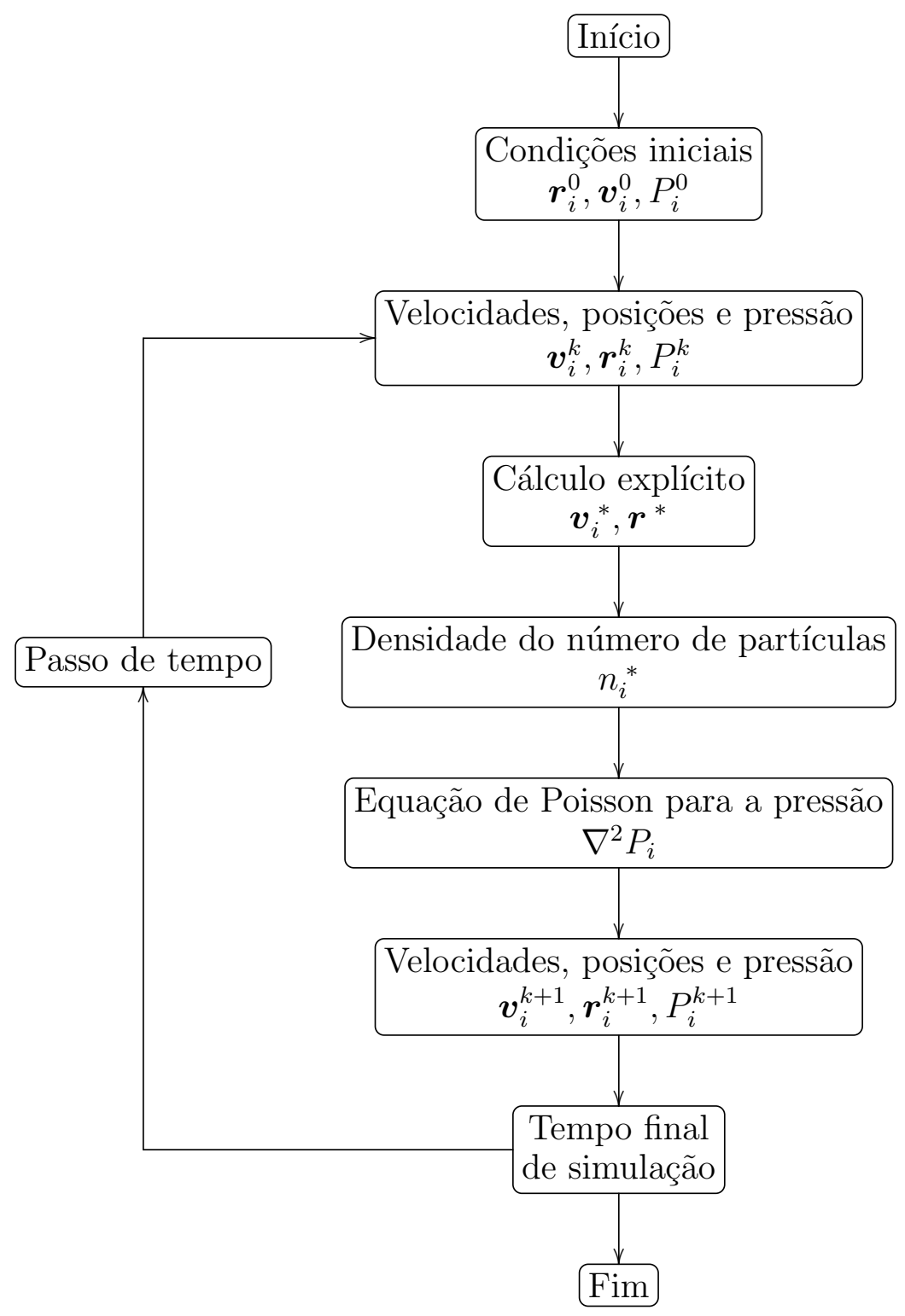

Figura A.1: Fluxograma do algoritmo MPS para fluido. 